University of Louisville

ThinkIR: The University of Louisville's Institutional Repository

Electronic Theses and Dissertations

$5-2012$

\title{
Tuning the bandgap of an amorphous sputtered germanium photovoltaic cell.
}

Bryon Staebler 1979-

University of Louisville

Follow this and additional works at: https://ir.library.louisville.edu/etd

\section{Recommended Citation}

Staebler, Bryon 1979-, "Tuning the bandgap of an amorphous sputtered germanium photovoltaic cell." (2012). Electronic Theses and Dissertations. Paper 1368.

https://doi.org/10.18297/etd/1368

This Master's Thesis is brought to you for free and open access by ThinkIR: The University of Louisville's Institutional Repository. It has been accepted for inclusion in Electronic Theses and Dissertations by an authorized administrator of ThinkIR: The University of Louisville's Institutional Repository. This title appears here courtesy of the author, who has retained all other copyrights. For more information, please contact thinkir@louisville.edu. 
TUNING THE BANDGAP OF AN AMORPHOUS SPUTTERED GERMANIUM PHOTOVOLTAIC CELL

By

Bryon Staebler

B.S. Ch.E., University of Louisville, May 2011

B.S. Biology University of Kentucky, 2001

\author{
A Thesis \\ Submitted to the Faculty of the \\ University of Louisville \\ J. B. Speed School of Engineering \\ as Partial Fulfillment of the Requirements \\ for the Professional Degree
}

MASTER OF ENGINEERING

Department of Chemical Engineering

May 2012 
TUNING THE BANDGAP OF A SPUTTERED AMORPHOUS GERMANIUM PHOTOVOLTAIC CELL

Submitted by:

A Thesis Approved On

by the Following Reading and Examination Committee:

Dr. Xiao-An Fu, Thesis Advisor

Dr Kevin Walsh

Dr James Watters 


\section{ACKNOWLEDGEMENTS}

I would like to thank my wife, Deborah, for her unconditional support and encouragement over the last four years as I left a stable career to return to school to

pursue further education to enable a more satisfying career. I would also like to thank my daughter Etta for coping so well with her father spending so much time away from home during her first year.

Many thanks to Dr. Xiao-An Fu, my advisor, for giving me the opportunity to work in an area of research of great interest to me, microfab training, and for facilitating my access to the cleanroom.

I would like to thank Kane Miller for his extensive advice and help in pursuing this project. None of this would have been possible without his help.

I would also like to thank Dr. Shamus McNamara for providing his insights and suggestions for design and processing improvements.

I thank Mr. Michael Martin for his help, training, and for being an invaluable source of insight and advice; Dr. Julia Aebersold for training and assistance throughout the project. Don Yeager, Curt McKenna, and the rest of the cleanroom staff for all of their help in making this project possible.

I extend special thanks to Dr. James Watters and Dr. Kevin Walsh for sitting on my defense committee and for their suggestions for improvements. 


\begin{abstract}
Microfabricated planar solar cells with an active solar collection area of $0.04 \mathrm{~cm}^{2}$ were fabricated on n-type silicon wafers to test the viability of sputtered amorphous thin film photovoltaics for potential use in amorphous multijunction cells or inexpensive laser detectors. Several variants based on the same photovoltaic cell design were produced using amorphous silicon, amorphous germanium, and amorphous germanium-tin to explore band gap depression phenomenon in amorphous thin films that had been previously described in crystalline germanium-tin and germanium-silicon-tin alloys.

UV/VIS spectroscopy and Tauc Plot band gap analysis indicated that tin inclusion led to band gap depression of $0.046 \mathrm{eV}$ for every percentage increase in tin content in cosputtered germanium-tin films. In sputtered amorphous germanium-tin films, increases in average incident photon conversion efficiency of $1.93 \%$ for $\mathrm{Sn}_{.05} \mathrm{Ge}_{.95}$ and $2.95 \%$ for $\mathrm{Sn}_{.10} \mathrm{Ge}_{.90}$ as compared to germanium only films were observed. Overall cell efficiency increases were also observed with the inclusion of tin by $0.68 \%$ for $\mathrm{Sn}_{.05} \mathrm{Ge}_{.95}$ and $0.78 \%$ for $\mathrm{Sn}_{.10} \mathrm{Ge}_{.90}$ when compared to germanium films.

Comparing sputtered germanium films to PECVD deposited amorphous silicon films, the sputtered germanium films displayed significantly lower overall conversion efficiencies and incident photon conversion efficiencies. When comparing to amorphous silicon thin films, improved absorption of longer wavelength radiation in the IR and NIR range was expected with germanium and tin thin films exhibiting band gap depression phenomenon.
\end{abstract}




\section{TABLE OF CONTENTS}

APPROVAL PAGE $\quad$ ii

ACKNOWLEDGEMENTS

ABSTRACT

TABLE OF CONTENTS Vi

NOMENCLATURE viii

LIST OF TABLES $\quad$ xi

LIST OF FIGURES — xii

I. INTRODUCTION

II. BACKGROUND

2.1 Basics of Photovoltaic Operation 3

2.2 Types of Photovoltaic Cells and Typical Method of Manufacture 5

2.3 Limits of Photovoltaic Technology $\quad 8$

2.4 Current Research into IR Absorption and Multijunction Cells 11

III. EXPERIMENTATION

3.1 Plan of Experimentation $\quad 13$

$\begin{array}{ll}\text { 3.2 Materials } & 13\end{array}$

3.3 Device Fabrication Procedure 16

3.4 Equipment 34

IV. RESULTS AND DISCUSSION

4.1 Thermal Coefficient of Expansion Incompatibility and High 41

Temperature Processing

4.2 Band Gap Measurement 46

4.3 AM 1.5 Solar Performance

4.3.1 Amorphous Silicon Based Devices $\quad 50$

4.3.2 Germanium Based Devices $\quad 60$

4.3.3 5\% SnGe Based Devices 66

4.3.4 10\%SnGe Based Devices $\quad 68$

$\begin{array}{ll}\text { V. CONCLUSIONS } & 72\end{array}$

VI. RECOMMENDATIONS 


\section{NOMENCLATURE}

$\eta$

a.Si Amorphous Silicon
Air testing solar cells

\section{AM 1.5}

$\mathrm{Ar}$

BOE Buffered Oxide Etch

CVD Chemical Vapor Deposition

DC Direct current powe

DI Deionized water

eV Electron Volts

FF Fill Factor

Ge Germanium

$\mathrm{HCl} \quad$ Hydrochloric acid

HF Hydrofluoric Acid

$\mathrm{H}_{2} \quad$ Hydrogen gas

$\mathrm{H}_{2} \mathrm{O} \quad$ Water

$\mathrm{H}_{2} \mathrm{O}_{2} \quad$ Hydrogen peroxide

IC Integrated circuit

InGaAs Indium Gallium Arsenide

InGaP Indium Gallium Phosphide

IPCE Incident photon conversion efficiency

IR Infrared

ITO Indium tin oxide

IV Voltammetric testing

$\mathbf{J}_{\mathrm{sc}} \quad$ Short circuit current density
$\%$

$\mathrm{W} / \mathrm{m}^{2}$

W

$\mathrm{eV}$ unitless

$\%$

$\mathrm{A} / \mathrm{cm}^{2}$

KJL PVD-75 Kurt J Lesker Physical Vapor Deposition sputtering apparatus

MCP-Primer Primer used for adhesion layer with photoresist 
MF-319 Solution used to develop photoresist

MVHF PECVD Modified very high frequency plasma enhanced chemical vapor deposition

$\mathrm{n}+\quad$ Region of semiconductor doped heavily with n-type dopants that provide electrons conduction

n-type Semiconductor with impurities introduced that act as electron donors

Nd:Yag Neodymium-doped yttrium aluminum garnet laser system - a common IR laser system

$\mathrm{NH}_{3} \quad$ Ammonia

$\mathrm{NH}_{4} \mathrm{~F} \quad$ Ammonium fluoride

NIDOS Nitrogen doped silicon

NIR Near infrared

PECVD Plasma enhanced chemical vapor deposition

P-I-N Semiconductor structure with p-type doped regions, un-doped intrinsic regions, and n-type doped regions

P-N Semiconductor with n-type doped regions and p-type doped regions

p-type Semiconductor material doped with impurities that act as electron acceptors

PV Photovoltaic

PVD Physical vapor deposition

QDR Quick dump rinser

RF Radio frequency (microwave induced plasma)

RTP Rapid thermal processor

SCCM Standard cubic centimeters per minute

$\mathrm{SCM} / \mathrm{min}$

Si Silicon

SiGe Silicon germanium

$\mathrm{SiH}_{4} \quad$ Silane

$\mathrm{SiN}_{3} \quad$ Silicon nitride

Sn Tin

SnGe Tin germanium

TCE Thermal coefficient of expansion

$(\Delta \mathrm{L} / \mathrm{L} \Delta \mathrm{T}) /{ }^{\circ} \mathrm{C}$ 
TW

$\mathrm{V}_{\mathrm{oc}} \quad$ Open circuit voltage

W

Watt

Terrawatt

TW

V

W 


\section{LIST OF TABLES}

TABLE 1: CURRENT IR DETECTION MATERIALS.............................................. 11

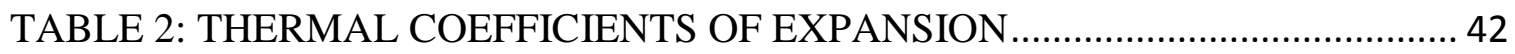

TABLE 3: BAND GAPS MEASURED FOR AMORPHOUS MATERIALS ............... 49

TABLE 4: PERFORMANCE NON-ANNEALED A.SI, 5 MIN DIFFUSION ............... 52

TABLE 5: PERFORMANCE AMORPHOUS SILICON, NON-ANNEALED .............. 55

TABLE 6: SOLAR PERFORMANCE 5 MIN ANNEALED ...................................... 58

TABLE 7: PERFORMANCE ANNEALED A.SI 20 MIN DIFFUSION ...................... 61

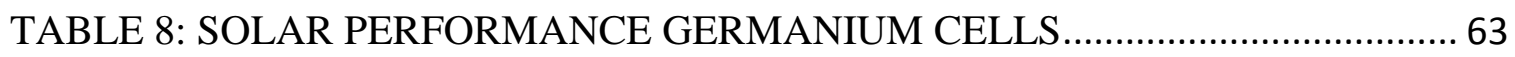

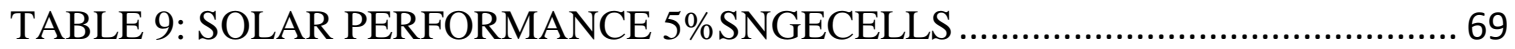

TABLE 10: 10\% SNGE SOLAR PERFORMANCE ............................................... 72 


\section{LIST OF FIGURES}

Figure 1: typical amorphous silicon material structure............................................. 5

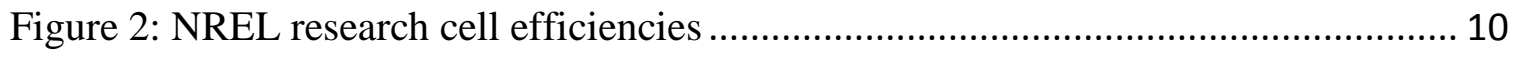

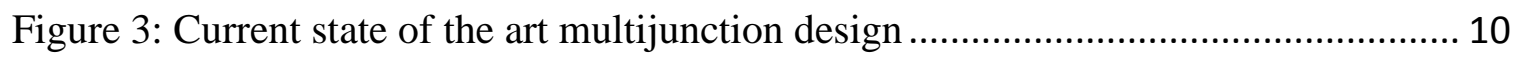

Figure 4: General device fabrication procedure.......................................................... 16

Figure 5: KJL PVD 75 Germanium deposition as a function of RF power.................... 21

Figure 6: Tin deposition rate with 3" target as a function of DC power at..................... 22

Figure 7: Tin deposition rate with 4" target as a function of DC power......................... 22

Figure 8: Layers of amorphous silicon based devices .............................................. 25

Figure 9: Amorphous germanium and amorphous silicon cell layers .......................... 29

Figure 10: Germanium and tin device layers ...................................................... 30

Figure 11: Typical finished patterned cells before dicing .......................................... 32

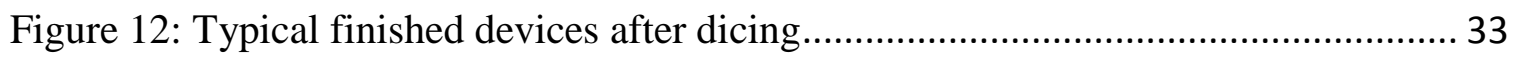

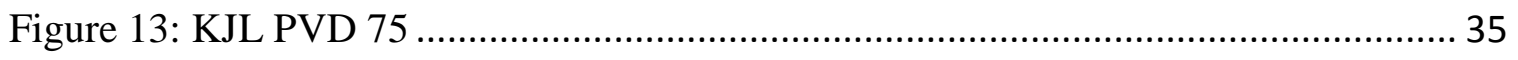

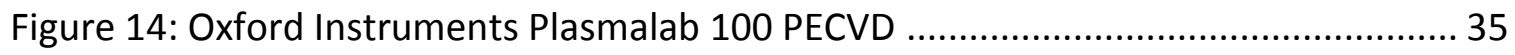

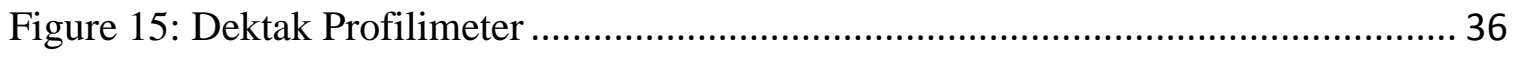

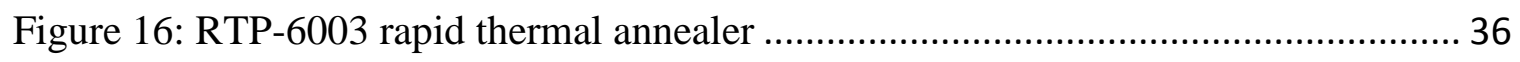

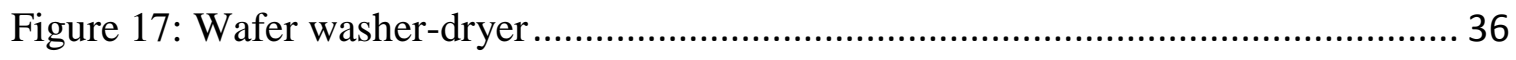

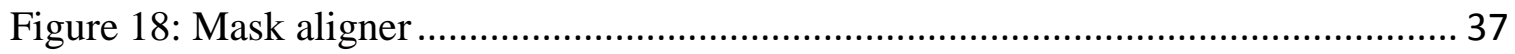

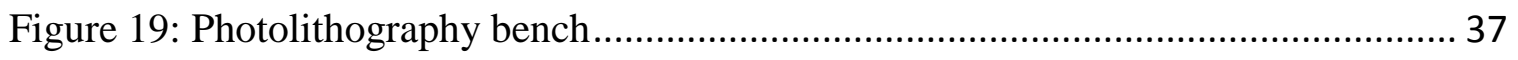




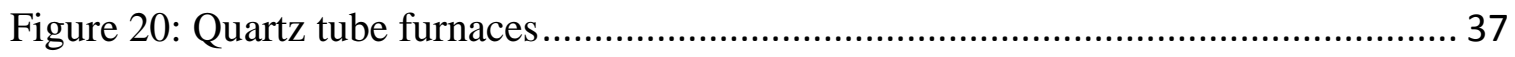

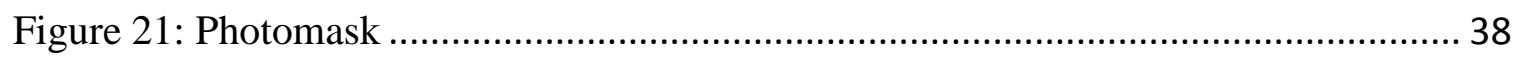

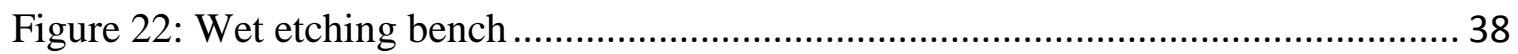

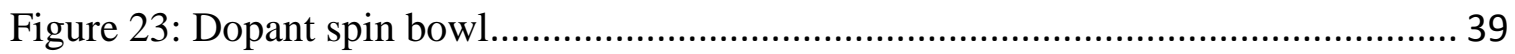

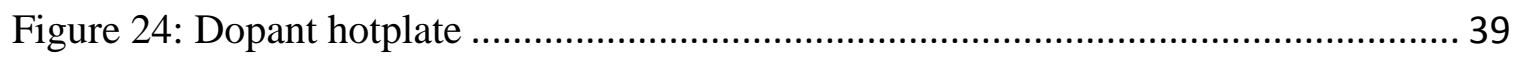

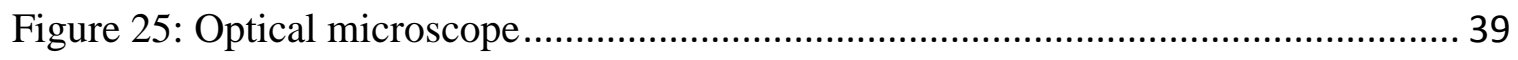

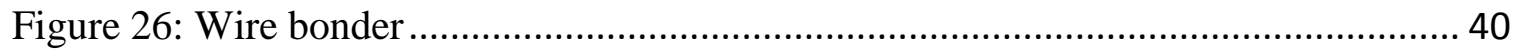

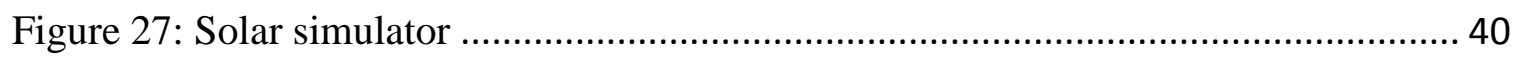

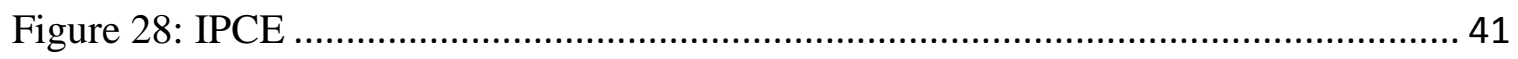

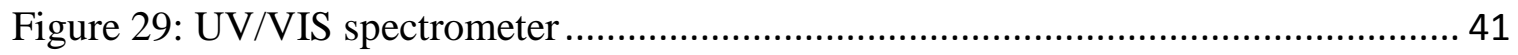

Figure 30: Ge device wafer after polyboron diffusion, oxidation, and etching ............... 43

Figure 31: Ge device wafer following polyboron diffusion, oxidation, and etching........ 43

Figure 32: Optical micrograph of Ge on Si after diffusion........................................ 43

Figure 33: Optical micrograph of Ge device following RTP diffusion ......................... 43

Figure 34: 5\%SnGe after polyboron diffusion, oxidation, and etching ........................ 44

Figure 35: Optical micrograph of 5\%SnGe after doping processes ........................... 44

Figure 36: 7\%GeSn after polyboron diffusion, oxidation, and etching ........................ 44

Figure 37: Optical micrograph of film defects in 7\% SnGe after doping ...................... 44

Figure $38: 10 \%$ SnGe after polyboron diffusion, oxidation, and etching ........................ 45

Figure 39: Optical micrograph of $10 \%$ SnGe after doping processes ............................ 45

Figure 40: Tauc plot for amorphous germanium ................................................ 48

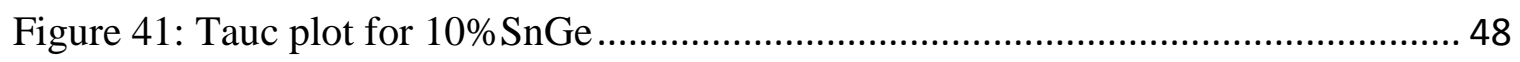


Figure 42: UV/VIS and Tauc plot band gap of GeSn as a function of $\mathrm{Sn} \%$.................... 50

Figure 43: Amorphous silicon no anneal, 5 minute diffusion, IV and IPCE.................. 51

Figure 44: IV Curve displaying Isc and Voc for a.Si Cell 1 ..................................... 52

Figure 45: Amorphous silicon, non-annealed 20 minute diffusion IV and IPCE............ 55

Figure 46: Amorphous silicon annealed 5 minute diffusion IV and IPCE .................... 57

Figure 47: Amorphous silicon, 5min anneal in RTP IV and IPCE ............................ 57

Figure 48: Annealed a.Si 20 minute diffusion 900C Cells 1\&2 IV and IPCE ................ 60

Figure 49: Annealed a.Si 20 minute diffusion 900C Cells 3\&4 IV and IPCE ................ 60

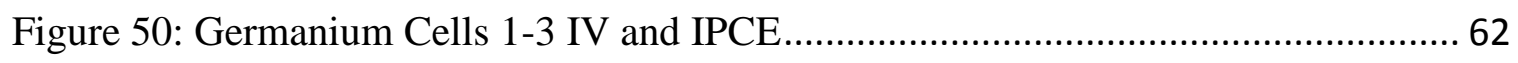

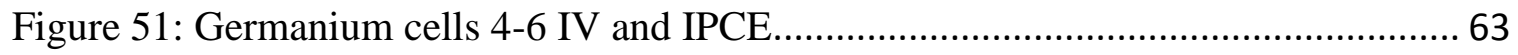

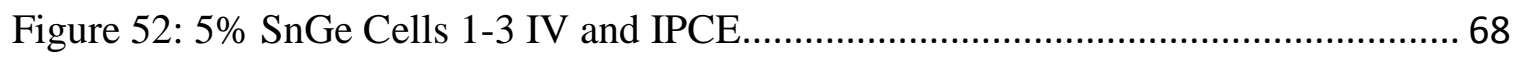

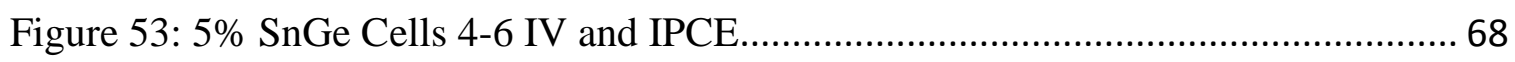

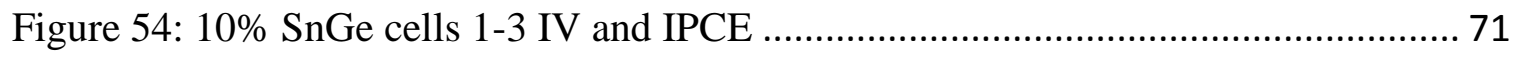

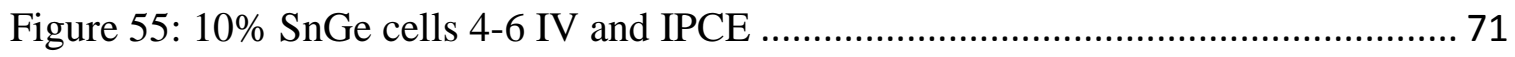

Figure 56: IV Curve displaying open circuit voltage and short circuit current density.... 72

Figure 57: Average IPCE of best 2 function devices made with each material .............. 73

Figure 58: Tauc Plot absorbance coefficient vs photon energy ….............................. 78

Figure 59: Tauc Plot square root of absorbance coefficient vs photon energy .............. 79

Figure 60: Final Tauc plot graph used for band gap determination ............................. 79 


\section{INTRODUCTION}

Photovoltaic devices directly convert incoming light into electrical power and are an integral technology for replacing current non-renewable energy resources with renewable resources. The interest in photovoltaics has increased over the last several decades due to increases in global population, rising affluence and service consumption per individual coupled with simultaneously decreasing reserves of the fossil fuels needed to run a modern society.

Global population in 2010 was 6.84 billion and is predicted to rise to more than 10.1 billion by the end of the century ${ }^{[1]}$. Global energy demand in 2005 was $14 \mathrm{TW}$ and it is predicted to rise to $28 \mathrm{TW}$ by 2050 . In 2006 , the global energy demand was met by a mix of $33.5 \%$ Crude oil, $27.4 \%$ Coal, $22.8 \%$ natural gas, $6.6 \%$ hydroelectric, $5.9 \%$ nuclear, and 3.8\% geothermal and other renewables. Increasing energy demand, prices, and concerns over the continued use of fossil fuels as the primary energy source are driving a resurgence of interest in the area of alternative energy research. There is also concern about the long term viability of global oil reserves. In 1900, the ratio of energy invested to energy extracted from US oil fields in 1930 was 100:1; in the 1970's, 30:1, in 2010 this ratio had fallen to roughly 11:1 $1^{[2]}$.

Energy resources are needed to replace this reducing capacity and meet increasing demand. Hydroelectric currently produces 0.3 TW globally with a total feasible potential of approximately $1.5 \mathrm{TW}$ if all potential hydroelectric resources are utilized in the future. Geothermal potential is $11.5 \mathrm{TW}$. Oceanic and tidal power potential is $2.7 \mathrm{TW}$. Wind potential is $2 \mathrm{TW}$. Biomass and biofuel potential is $20 \mathrm{TW}$ if $1.3 \mathrm{X} 10^{2} \mathrm{~m}^{2}$, or $31 \%$ of the total global land area is devoted to biofuel production. Nuclear electricity generation in 
2010 was $0.06 \mathrm{TW}$; the build times and facility lifespan of nuclear plants would require breaking ground on the equivalent of current total production capacity every year to meet projected needs and abate the closing of current facilities that are reaching the end of their usable lifespan. The potential of solar energy is $1.2 \times 10^{5} \mathrm{TW}$; the practical harvestable potential is $600 \mathrm{TW}$. The build time on solar is fast relative to other technologies ${ }^{[2]}$. Photovoltaic solar technology will be one of the major technologies adopted in the transition from a fossil fuel based economy.

In order for photovoltaics to achieve a high degree of market penetration and begin to offset more traditional technologies, the cost per unit of energy produced must meet the cost of more conventional technologies. In order for this to happen, manufacturing costs must decrease and efficiencies must increase. The US Department of Energy introduced the SunShot Initiative with goals of using solar energy to generate $14 \%$ of US energy by 2030 and $27 \%$ by $2050^{[3]}$.

The cost goal for this initiative is to reduce the cost of generation to below one dollar per watt; this target has shifted emphasis from purely increasing efficiency to finding the best compromise between efficiency and total cost of installed technology ${ }^{[3]}$. One area of research is in making amorphous cells more efficient and less expensive through reel to reel manufacturing of amorphous multijunction cells ${ }^{[4]}$. This work investigates germanium based amorphous thin films with tunable band gaps for potential use in multijunction flexible thin film photovoltaics or for use in manufacturing inexpensive laser detectors. 


\section{BACKGROUND}

\subsection{BASICS OF PHOTOVOLTAIC OPERATION}

Photovoltaic solar cells convert photons of light into electrical energy by absorbing the energy in the photon and transitioning to an excited state. Typically this is performed by a semiconductor material absorbing energy greater than its band gap, forming charge carriers of opposite charge magnitudes known as electron-hole pairs.

Electrons have energies associated with them that lie within certain ranges between the ground state and free electron energy. The ground state is the energy state of electron bound tightly to the nucleus; free energy state is the energy of an electron free from the material. The energy levels are divided into discrete quantum states; quantum states are a mathematical description of a set of variables fully describing a quantum system. The lower energy quantum states are closer to the nucleus and are generally fuller than the higher energy quantum states. Electrons fill these bands up to the valence band, which is defined as the highest electron occupied band at absolute zero. In conductors, the valence band and conduction bad overlap, allowing for conduction of electrons. In semiconductors and insulators, a forbidden band that no electrons can occupy exists in energy levels between the valence band and the conduction band. The difference in energy between the valence band and the conduction band is the band gap. The difference between a semiconductor and an insulator is somewhat arbitrary and determined by the magnitude of this band gap. Semiconductors are materials with narrow band gaps below about $4 \mathrm{eV}$; insulators have band gaps above $4 \mathrm{eV}$. 
Charge carrier pairs must be separated in order to harness the absorbed energy. In semiconductor materials, this is accomplished by impurity doping forming a doped junction which then imparts a net electric field over the material causing the charges to separate by diffusion and drift through the solid material. The junction imparts an intrinsic voltage on carriers, the open circuit voltage, which plays a major role in the amount of charge potential that can be stored in the material, harnessed, and ultimately sets overall efficiency limits for the device.

Finally the separated charges must be extracted from the semiconductor material for use in an external circuit. This is usually accomplished via ohmic metal or ITO contacts with the doped semiconductor. 


\subsection{TYPES OF CELLS AND TYPICAL METHOD OF MANUFACTURE}

\subsubsection{AMORPHOUS}

This project focused on developing an amorphous germanium based photovoltaic cell. Amorphous photovoltaic cells were first fabricated by RCA in 1976 with early efficiencies around 4\%; current efficiencies are typically $12-13 \%{ }^{[5]}$. Amorphous cells are generally one of the least expensive photovoltaic technologies. Amorphous solar cells are non-crystalline materials prepared by CVD or PVD processes. In amorphous cells, there are small disordered variations in bond angles; there is no clearly established uniform lattice for the whole material.

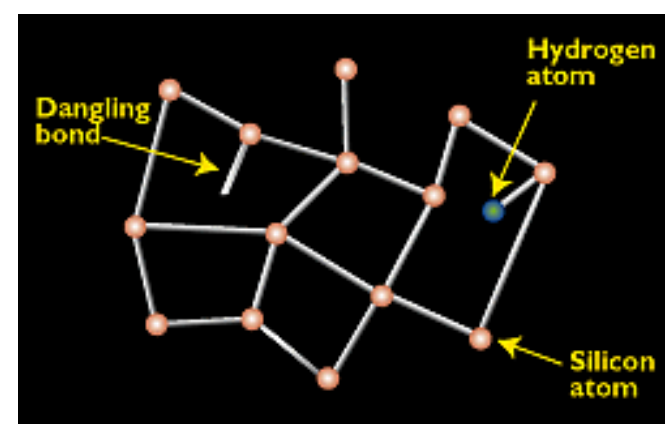

Figure 1: typical amorphous silicon material structure ${ }^{[5]}$

Amorphous materials absorb light more efficiently than their crystalline counterparts, allowing for use of less material in thinner layers ${ }^{[5]}$. While other photovoltaic approaches require traditional batch manufacturing, amorphous materials can be prepared by step and repeat batch process like reel to reel manufacturing, greatly increasing yield per batch ${ }^{[6]}$. Amorphous materials with different band gaps can be 
deposited continuously on top of each other, simplifying multijunction cell manufacture and increasing the total efficiency when compared to single junction cells.

Amorphous cells are the lowest cost photovolatics and one of the least efficient photovoltaic technologies. Amorphous photovoltaics typically show efficiencies of 5$15 \%$.

\subsubsection{MONOCRYSTALLINE}

Monocrystalline cells are prepared from single crystal semiconductor. The manufacture of monocrystalline cells is similar to wafer manufacture for the IC industry. Silicon rich materials are melted in an electric arc furnace; the impurities are removed; the purified molten silicon in placed in a Czochralski apparatus with a seed of single crystal silicon which is rotated as it is withdrawn, pulling an ingot of purified single crystal from the apparatus. Typically dopants are introduced during this process to dope the material either n-type or p-type. The ingot is then sliced, the top is doped through gaseous thermal diffusion processes or ion implantation, contacts are applied, and finally an antireflective layer is applied.

Some of the advantages of monocrystalline cells over other variants are higher conductivity, higher efficiency, and greater longevity than many other types of cells. The major disadvantages are high cost and the cells are typically fragile and prone to cracking. 


\subsubsection{POLYCRYSTALLINE}

Bulk polysilicon production is usually achieved by a casting process. In the casting process, molten silicon is poured into a graphite vessel, then it is seeded with a crystal of known and desired structure, then allowed to cool. As the molten silicon cools, it forms a polycrystalline material.

Other methods for polycrystalline production include relatively high temperature CVD processes. While not as efficient as monocrystalline cells, polycrystalline silicon solar cells are generally much cheaper to manufacture.

\subsubsection{DYE SENSITIZED}

Dye sensitized Cells are sealed electrochemical cells containing a light absorbing dye, and electrolyte filling the cell, and a metal oxide anode and cathode. In dye sensitized cells, the dye absorbs incident light liberating electrons. Charge carriers are separated via an electrochemical potential across the cell and transported through the electrolyte to the metal oxide cathode and anode.

Dye sensitized cells are generally low efficiency, but are relatively inexpensive to manufacture. Dye sensitized cells do employ advanced materials, but assembly and manufacture is relatively simple and low tech. The major obstacles to widespread adoption of dye sensitized cells are low cell efficiencies and durability issues. 


\subsection{LIMITS OF PHOTOVOLTAIC TECHNOLOGY}

The Shockley-Quessier limit is used to calculate the maximum amount of energy that can be extracted from every incident photon and thus the theoretical maximum efficiency achievable from any traditional P-N photovoltaic technology.

The primary sources for losses are blackbody radiation, charge pair recombination, spectrum losses, and losses due to interstitial defects. Blackbody losses are caused by PV material emitting radiation; recombination losses are caused by poor or slow charge separation; spectrum losses stem from the ability of a material to only absorb photons above the band gap of the material.

For single junction silicon based solar technology, this theoretical limit is $33.7 \%$; current commercial monocrystalline silicon cells are approaching the theoretical limit, at about $22 \%$ efficient. The high cost of single crystal materials has prevented widespread adoption of the technology by average consumers thus far. Silicon based technologies with a band gap of $\sim 1.1 \mathrm{eV}$ cannot convert infrared radiation to electricity as the energy in this range is below the band gap; half of the insolative solar power is in the infrared wavelength range or longer. This lack of absorption in the infrared range for higher band gap materials is the drive behind the use of lower band gap materials like germanium in order to capture some of the longer wavelength insolative power and increase overall conversion efficiencies.

Multijunction or tandem cells can have theoretical limits approaching $68 \%{ }^{[7]}$. Multijunction cells address the spectral limitations of single materials by combining multiple materials together that absorb over different spectral ranges. Generally, 
multijunction cells are manufactured with the highest band gap materials on the top surface and lower band gap materials deeper in the cell. Matching compatible materials in multijunction cells is a major challenge. The materials must be lattice matched, have similar thermal coefficients of expansion, and must be current matched as well. At present, state of the art multijunction cells show about $42 \%$ efficiency but complex manufacturing materials and techniques make them prohibitively expensive for general use. As a result, multijunction cells have been primarily used by the space industry where power to weight ratios make the cells practical.

Some groups are working on cheaper multijunction cells using reel to reel processes to make multijunction amorphous cells. While amorphous cells are less efficient, they are less expensive to manufacture than other cell types. Multijunction amorphous cells show potential for reaching the dollar per watt goal; the research in this thesis pertains to making amorphous materials for absorption in the IR range that could potentially be used in multijunction amorphous cells. Figure 2 shows research cell efficiencies over time. 


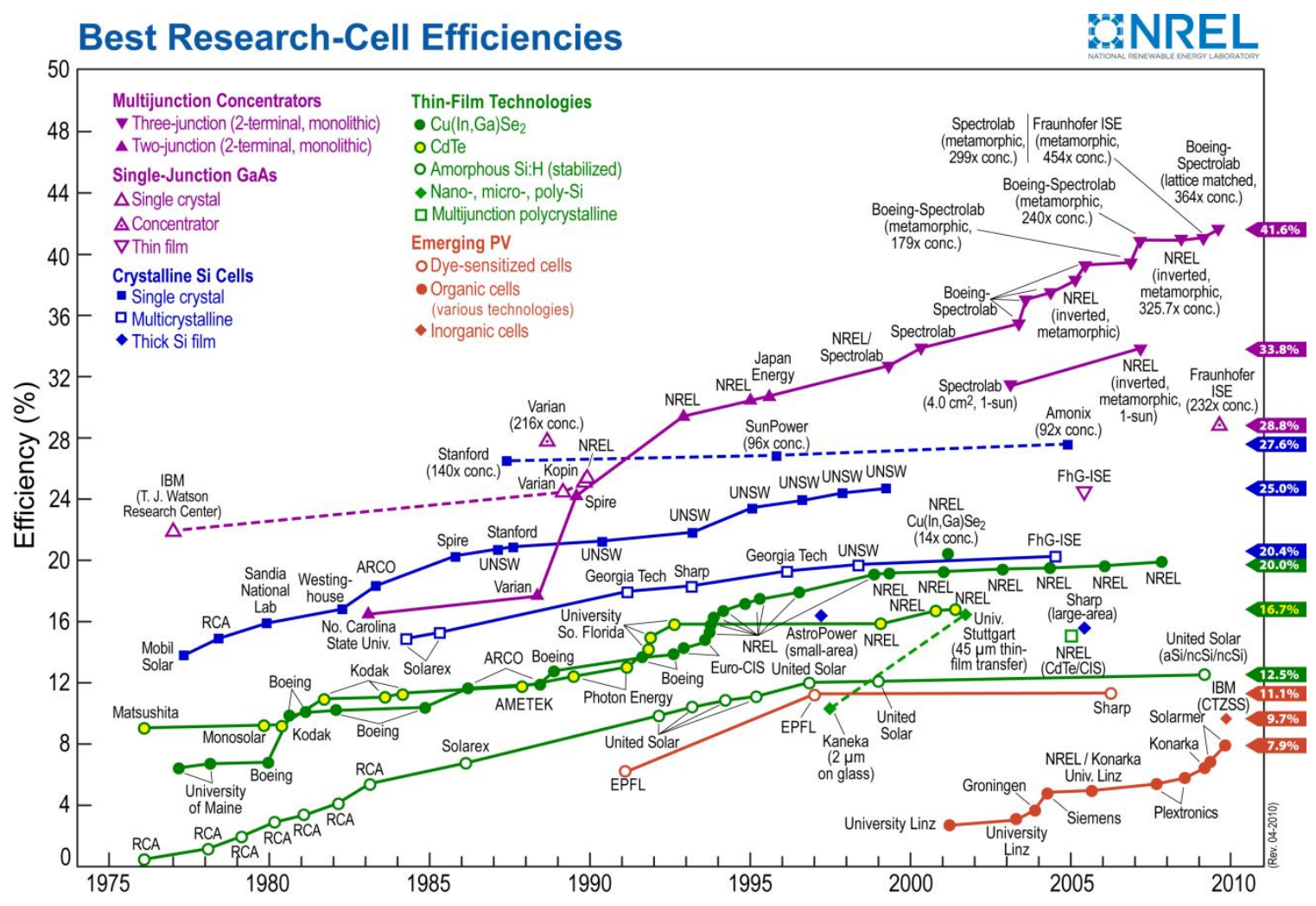

Figure 2: NREL research cell efficiencies

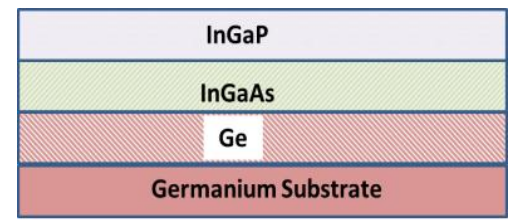

Figure 3: Current state of the art multijunction design ${ }^{[8]}$
Current State of the art multijunction designs are generally constructed on germanium wafers. From lowest to the uppermost, the layers are arranged in increasing band gap starting with epitaxial germanium, followed by indium gallium arsenide, followed by indium gallium phosphide on the top ${ }^{[8]}$ as displayed in Figure 3. 


\subsection{CURRENT RESEARCH INTO IR ABSORPTION AND MULTIJUNCTION CELLS}

Table 1: CURRENT IR DETECTION MATERIALS

\begin{tabular}{|l|c|}
\hline Material & Wavelength $(\boldsymbol{\mu m})$ \\
\hline Indium Gallium & $0.7-2.6$ \\
\hline Germanium & $0.8-1.7$ \\
\hline Lead Sulfide & $1.0-3.2$ \\
\hline Lead Selenide & $1.5-5.2$ \\
\hline $\begin{array}{l}\text { Indium } \\
\text { Antimonide }\end{array}$ & $1.0-6.7$ \\
\hline Indium Arsenide & $1.0-3.8$ \\
\hline Platinum Silicide & $1.0-5.0$ \\
\hline $\begin{array}{l}\text { Mercury Cadmium } \\
\text { Telluride }\end{array}$ & $0.8-25$ \\
\hline
\end{tabular}

The research in this work is investigating amorphous materials for absorption of longer wavelength radiation using germanium. There are already materials used for this purpose as shown in TABLE 1.

Due to the relatively low band gap of germanium $(0.67 \mathrm{eV})$, most of the incident energy in solar insolation is above the band gap and can theoretically be absorbed. This has led to germanium being a material of interest for solar technology for several decades. Germanium also adopts a diamond structure like silicon and has a similar lattice parameter. There is a $4.2 \%$ difference in lattice parameters, which does results in mild strain when combining these materials in thin film applications. Germanium very readily alloys with silicon to form silicon-germanium $\left(\mathrm{Si}_{\mathrm{x}} \mathrm{Ge}_{\mathrm{y}}\right)$. The material properties and lattice parameter vary with changing relative concentrations.

Fang et al described ternary semiconductor alloys of Silicon, Germanium and Tin in specific ratios making tuning of the band gap possible while lattice matching to silicon $^{[8]}$. Current multijunction cells are constructed on a germanium base. Germanium has a smaller lattice parameter than silicon; tin has a larger lattice parameter than either 
silicon or germanium. The proposed germanium alloy material would offer many advantages for the construction of advanced, highly efficient multijunction cells on a silicon substrate - low strain epitaxial films and the ability to tune the band gap between silicon $(1.1 \mathrm{eV})$, germanium $(0.67 \mathrm{eV})$, and silicon germanium. The ability to use silicon as the substrate by lattice matching and eliminating strain greatly reduces $\operatorname{cost}^{[8]}$.

Sputtered germanium films have been investigated for photodetection in the IR range by several groups with some exhibiting the ability to deposit epitaxial films by sputtering techniques ${ }^{[9]}$.

Fere' et al explored the viability of sputtered epitaxial germanium films on silicon for photodetection purposes ${ }^{[9 a]}$. The viability of using MVHF PECVD processes for amorphous thin film reel to reel multijunction solar cell manufacture with silicon, silicon germanium and silicon on stainless steel was investigated by United Solar Ovionic Corporation in 2005 . They reported achieving $14.5 \%$ efficiency from a triple junction cell $^{[6]}$; SE Powerfoil has reported efficiencies of above $12 \%$ from similar structures ${ }^{[4]}$. Fang et al suggested that adding an additional tin-germanium alloy could boost efficiency of a similar structure ${ }^{[8]}$. The purpose of this work is to explore the viability of using sputtering techniques to deposit amorphous materials for solar applications and to investigate band gap depression with tin content in sputtered amorphous germanium alloys. 


\section{EXPERIMENTATION}

\subsection{Plan of Experimentation}

Several photovoltaic devices were proposed for fabrication and performance comparisons. All devices were fabricated on 4" n-type silicon wafers. The devices structures were amorphous silicon; amorphous germanium and amorphous silicon; amorphous then alloyed germanium-tin on 4" silicon wafer; amorphous silicon, then alloyed germanium-tin covered in amorphous silicon. Several processes had to be characterized in order to fabricate these devices.

\subsection{Materials}

Wafers:

4" n-type <100> Wafers

CZ Method; Dopant Ph; $100 \Omega \mathrm{cm}$

Wafer Works

Taoyuan 32542, Taiwan R.O.C.

High Optical Transmittance Glass Slides 25x50x.5mm Corning Aluminosilicate Glass Cut Edges

Part No. c137-1105

Delta Technologies, Mn 55082

Sputtering Targets:

Germanium (Ge) 99.999\% Pure 3" diameter 0.125 " thick Lot\# PLA00946734

Plasmaterials Inc, Livermore Ca 94550

Tin (Sn) $99.999 \%$ Pure

3" diameter 0.125 " thick

Lot\# PLA200914567

Plasmaterials Inc, Livermore Ca 94550 
Tin (Sn) $99.95 \%$ Pure

3.99" diameter 0.250" thick

Lot\# 69747514CS

Angstrom Sciences

Duquesne, $\mathrm{Pa} 15110$

Aluminum (Al) 99.999\% Pure

3" diameter 0.125 " thick

Plasmaterials Inc,

Livermore Ca 94550

Dopants:

Phosphorus Spin-on Diffusant

P508 spin on dopant glass

Lot \# 092611

Filmtronics Advanced Semiconductor Process Materials

Butler, Pa 16003

Polyboron Film

PBKF6MK-37W Spin-on polyboron film

Lot\# 1020908

Filmtronics Advanced Semiconductor Process Materials

Butler, Pa 16003

\section{Photoresists}

Microposit S1805 Photoresist

Shipley Company - Rohm and Haas Electronic Materials LLC

Marlborogh, Ma 01752

Microposit SC1827 Photoresist

Shipley Company - Rohm and Haas Electronic Materials LLC

Marlborogh, Ma 01752

\section{Developer}

Microposit MF-319 Developer

Shipley Company - Rohm and Haas Electronic Materials LLC

Marlborogh, Ma 01752

Oxide Etch

BOE (6:1 Buffered Oxide Etch)

Mallinckrodt Baker Inc

Phillipsburg NJ 08865. 


\section{$\underline{\text { RCA Clean }}$}

Ammonium Hydroxide (10-35\% $\mathrm{NH}_{3}$ )

Mallinckrodt Baker Inc

Phillipsburg NJ 08865.

Hydrochloric Acid (33-40\%)

Mallinckrodt Baker Inc

Phillipsburg NJ 08865.

Hydrogen Peroxide (30\% by volume)

Mallinckrodt Baker Inc

Phillipsburg NJ 08865.

\section{General Cleaning}

Deionized water

$\mathrm{N}_{2}$

Matheson Tri-Gas, Inc

Parsippany, NJ 07054-0624

Acetone (99-100\%)

Mallinckrodt Baker Inc

Phillipsburg NJ 08865.

Methanol (100\%)

Mallinckrodt Baker Inc

Phillipsburg NJ 08865.

\section{Chip DIP Packages}

Spectrum Semiconductor

P/N CSB 01652

Mfg dwg: IDK16F1-494CAL

016 side braze

Cav: $.221 \times .400$

D/A Plating AU 


\subsection{Device Fabrication Procedure}

The general fabrication and testing plan is detailed in Figure 4.

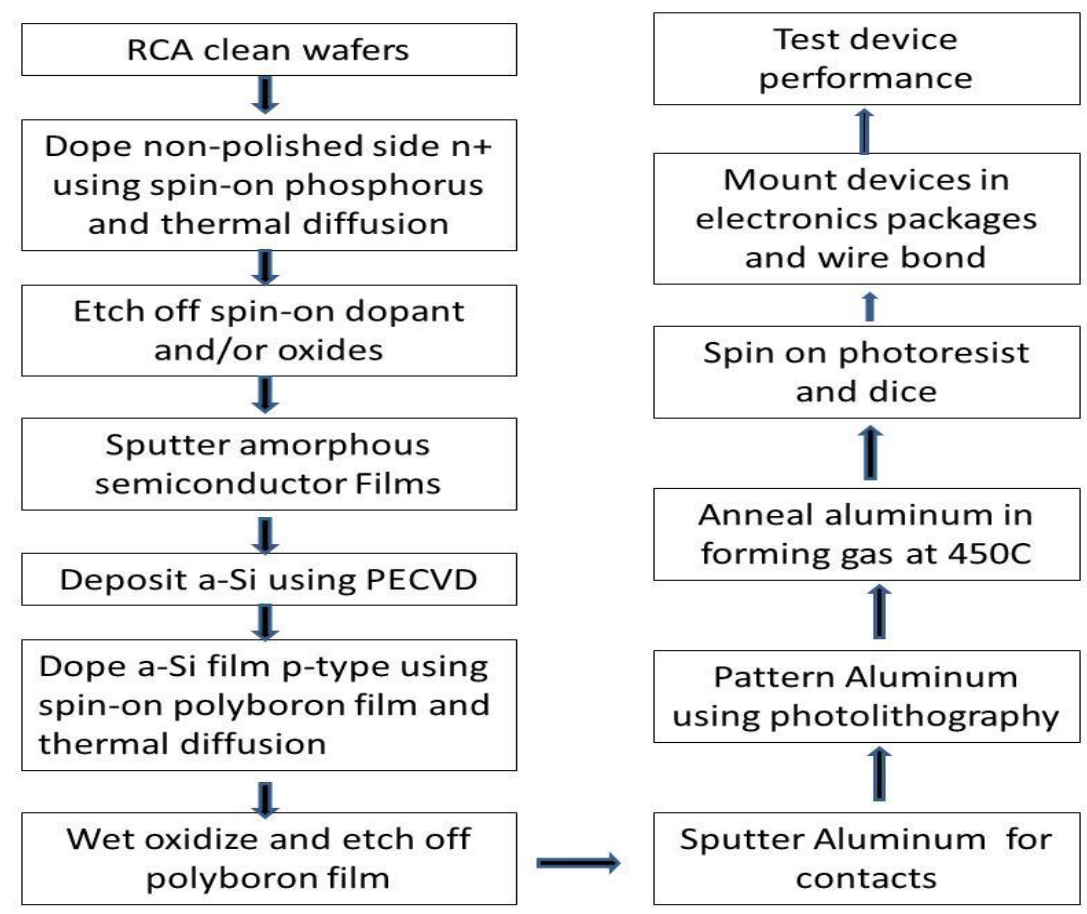

Figure 4: General device fabrication procedure

\subsubsection{RCA Cleaning}

All wafers were first subjected to a bath RCA clean process to remove all potential unintended impurities before any further processing. The RCA method used included several steps

Step 1.) Solvent cleaning with acetone, methanol, and finally water.

Step 2.) The wafers were placed into a wafer boat then into a prepared and preheated RCA 1 bath at $75^{\circ} \mathrm{C}$ and held for 15 minutes. The bath was prepared by combining $\mathrm{H}_{2} \mathrm{O} / \mathrm{H}_{2} \mathrm{O}_{2} / \mathrm{NH}_{4} \mathrm{OH}$ in a 6:1:1 volume ratio. The RCA 1 bath is used to remove all organics; organic contaminants would burn in high temperature processing. This step leads to the formation of a thin oxide layer and generally some trace ionic contamination 
that is removed in subsequent steps. The RCA 1 bath was prepared fresh for every cleaning; due to peroxide degradation at elevated temperature the RCA baths are generally only acceptable to use for about one hour after preparation.

Step 3.) The wafers were transferred to the QDR and taken through a traditional three water change rinse. The QDR rinse bath uses DI water to rinse all water soluble materials and acid/base residues off of the wafer surfaces.

Step 4) The wafers were placed in a 50:1 HF/water solution and held for 1 minute to remove all oxides formed during the RCA 1 clean and to remove some of the other trace ionic contamination

Step 5.) The wafers were then placed into a prepared RCA 2 bath at $75^{\circ} \mathrm{C}$ and held for 15 minutes. The RCA 2 bath consisted of $\mathrm{H}_{2} \mathrm{O} / \mathrm{H}_{2} \mathrm{O}_{2} / \mathrm{HCl}$ in a $6: 1: 1$ volume ratio and was prepared fresh for every cleaning cycle due to degradation of peroxide at elevated temperatures. The RCA 2 bath removes all ionic/metallic contamination; this prevents metal diffusion into the wafer during any later high temperature processing; this step is necessary to prevent metal diffusion into semiconductors which can produce trap states in the band gap, degrading semiconductor performance.

RCA cleaning is incompatible with germanium layers because peroxide etches germanium $^{[10]}$. This was seen when attempting to take germanium layers through an RCA clean in initial fabrications, then confirmed through a literature search. All RCA cleaning steps were used prior to germanium depositions. 


\subsubsection{Backside Doping}

In preparation for use of aluminum contacts on both the polished (front) side and non-polished (back) side, the non-polished sides were doped $n+$. All wafers used for this project are background doped n-type by the manufacturer. Following the RCA Clean process, all wafers were doped $n+$ on the back/non-polished side to ensure formation of ohmic contacts with aluminum and to reduce the formation of Schottky diodes at the contacts. Aluminum, while an excellent material for making contacts due to low resistivity, is a p-type dopant and prone to spiking within the semiconductor during contact annealing at $450^{\circ} \mathrm{C}^{[11]}$. Depositing aluminum and annealing can lead to the formation of a P-N Schottky diode structure that would be in opposition to intended current flows. To combat this, the backsides of all wafers were doped $n+$ using a spin on glass phosphorous dopant. By doping $\mathrm{n}+$ and creating a shallow junction through a short diffusion at relatively low temperatures for silicon solid-solid diffusion processes, the ptype doping effects of aluminum are abated.

In a hood dedicated to spin on doping processes, the phosphorus doping glass is spun on to the wafers. The wafers are then placed on a hot plate held at $200^{\circ} \mathrm{C}$ to set the dopant glass by driving off the volatile organic carriers before high temperature diffusion processes. The wafers were then loaded into a preheated quartz tube furnace for diffusion. The tube furnace was preheated to approximately $400^{\circ} \mathrm{C}$ under a constant flux of nitrogen. The furnace was allowed to heat up to an initial temperature of about $400^{\circ} \mathrm{C}$ and held there until loading of the wafers was complete. After the phosphorus dopant glass had been allowed to set at $200^{\circ} \mathrm{C}$ on the hotplate for 30 minutes, the wafers were then loaded into a quartz boat which was then loaded into the oven. 
The oven ramp rate was set at $20^{\circ} \mathrm{C} / \mathrm{min}$ up to a holding temperature of $900^{\circ} \mathrm{C}$; the wafers were held at $900^{\circ} \mathrm{C}$ for $1 \mathrm{hr}$ to allow for solid-solid diffusion of the phosphorus dopant into the silicon crystal, doping the backside, $n+$. The oven then ramped down to $450^{\circ} \mathrm{C}$ at $20^{\circ} \mathrm{C} / \mathrm{min}$; the wafers were removed when the oven reached approximately $500^{\circ} \mathrm{C}$ and were then allowed to cool in ambient air in the quartz boat until cool to the touch.

The remaining dopant glass on the surface was removed by multiple extended soaks in BOE (buffered oxide etch - a mixture of $6: \mathrm{HF} \mathrm{NH}_{4} \mathrm{~F}$ ) in a plastic beaker and washing with DI in the QDR with a standard 3 cycle wash. The wafers were then loaded into a spin dryer for final washing with water and drying with heat under nitrogen in a Semtech Gold Series Rhetech wafer spin washer-dryer.

\subsubsection{Germanium Deposition}

Germanium deposition was performed by sputtering with a 3" germanium target in a Kurt J Lesker PVD 75 multiple source magnetron sputterer. Sputtering processes use a plasma of an inert gas, in this case Argon. Argon is generally used because it is both non-reactive and has a high molecular weight. The high molecular weight aids in physically knocking material off of the source target. Germanium is a semiconductor material which can be deposited using either an RF-plasma or a pulsed DC plasma ${ }^{[9 a]}$. Due to the resistivity of the germanium target, a standard DC plasma was not used. RF plasmas are generated using microwaves to excite argon; magnetic fields are then used to direct the argon plasma such that it knocks material off of the source target. 
Germanium depositions were characterized over several powers and gas pressures. Early deposition experiments utilized 200W RF and an Argon pressure of 15mTorr Capman. These sputtering conditions led to excessive heat buildup in the germanium target and started to damage the target with cracks showing up around the edges and a broad crack across the center.

In order to address target damage problems, low deposition rates, and match the lower gas flow rates that are compatible with metal sputtering under DC conditions, the process characterization was repeated at lower gas flow rates and lower powers. The lower gas flow rates allow for more typical sputtering condition for metals; this was necessary when co-sputtering germanium and tin. Multiple deposition experiments were used to determine deposition rates as a function of RF power at a constant argon pressure of 5mTorr Capman. The deposition rate was measured through deposition of films on glass slides masked by polyamide tape in three locations. After the deposition was run, the polyamide tape was removed and the film thickness measured in three locations on the glass slide using a Dektak Profilometer. These data are plotted in Figure 5; each data point represents an average of all three measured thicknesses on each slide; three deposition runs were performed at each power setting. 


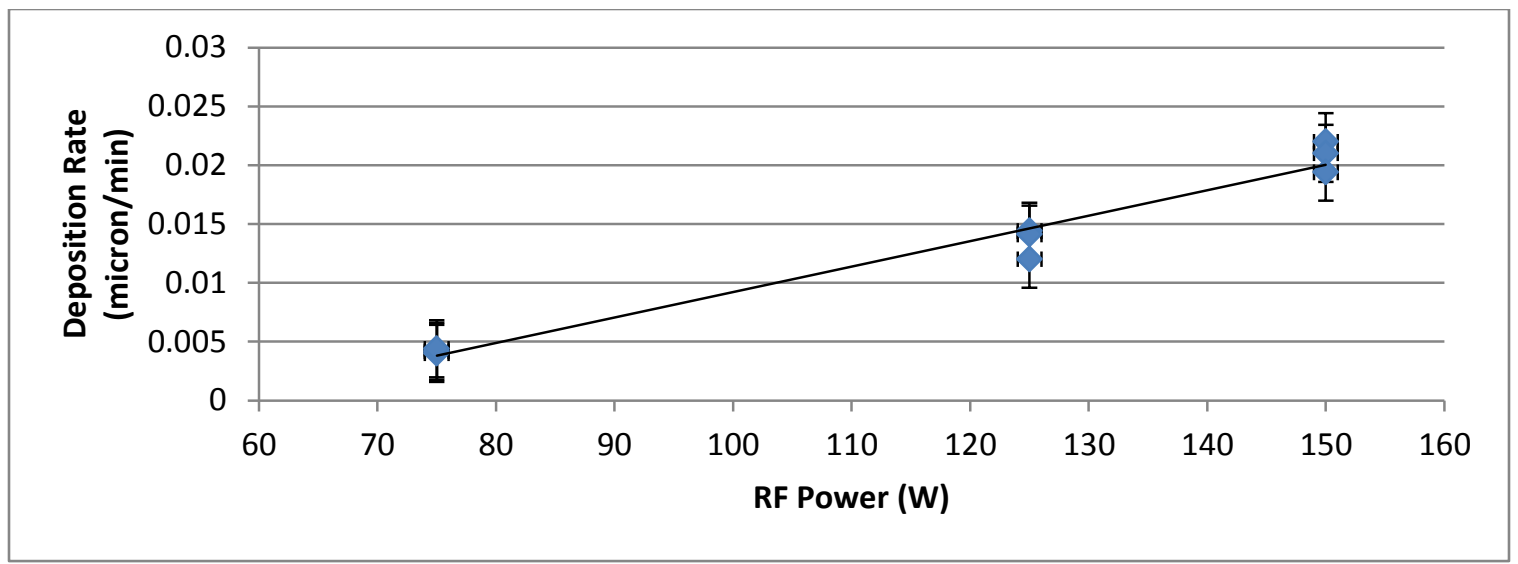

Figure 5: KJL PVD 75 Germanium deposition as a function of RF power at 5 mTorr Ar

This deposition data were converted to a molar deposition rate based on published data showing that amorphous film density is $98 \%+/-1.8 \%$ that of crystalline films ${ }^{[12]}$.

\subsubsection{Tin Deposition}

Tin deposition as a function of power was investigated for both 3 " and 4" targets using DC sputtering at 5 mTorr capman with the Kurt J Lesker PVD75. Deposition rate was measured by depositing tin on glass slides masked with polyamide tape in three locations, then measuring film thickness with the Dektak Profilometer. Each data point in Figures 6 and 7 represents an average of all three thicknesses on each slide; each deposition test was run three times at each power setting. 


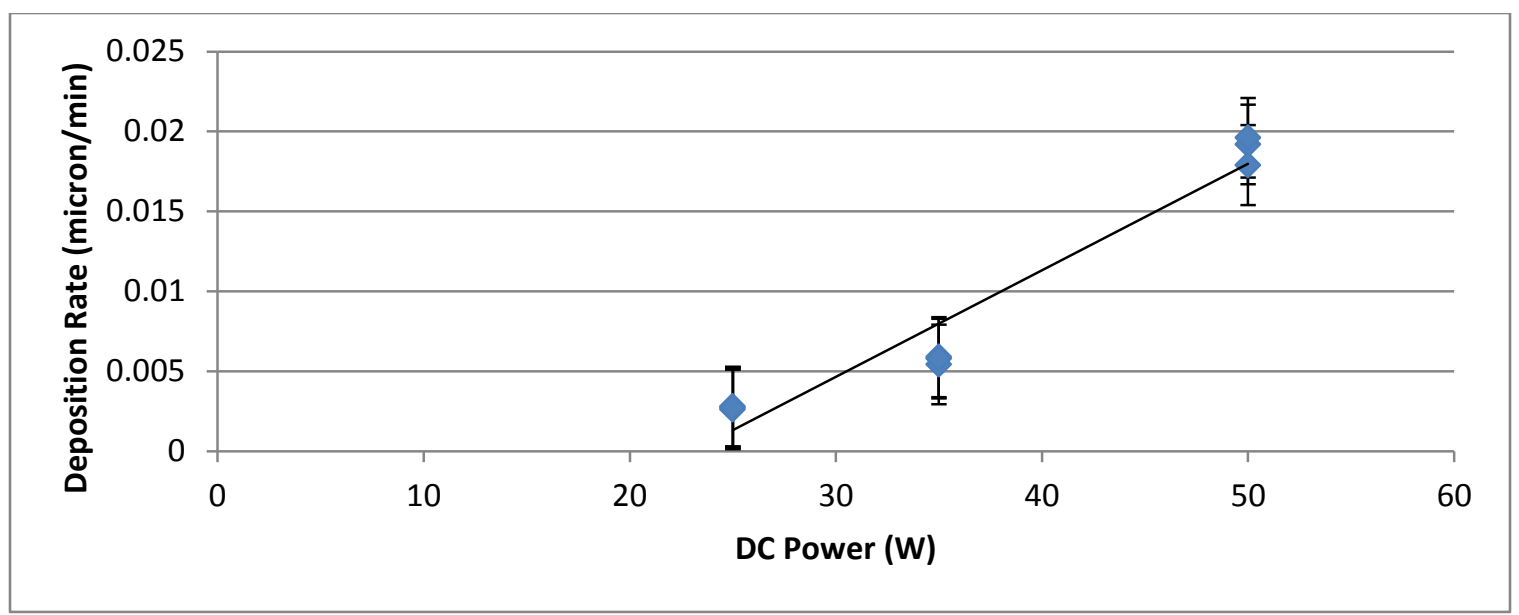

Figure 6: Tin deposition rate with 3" target as a function of DC power at 5 mTorr Ar

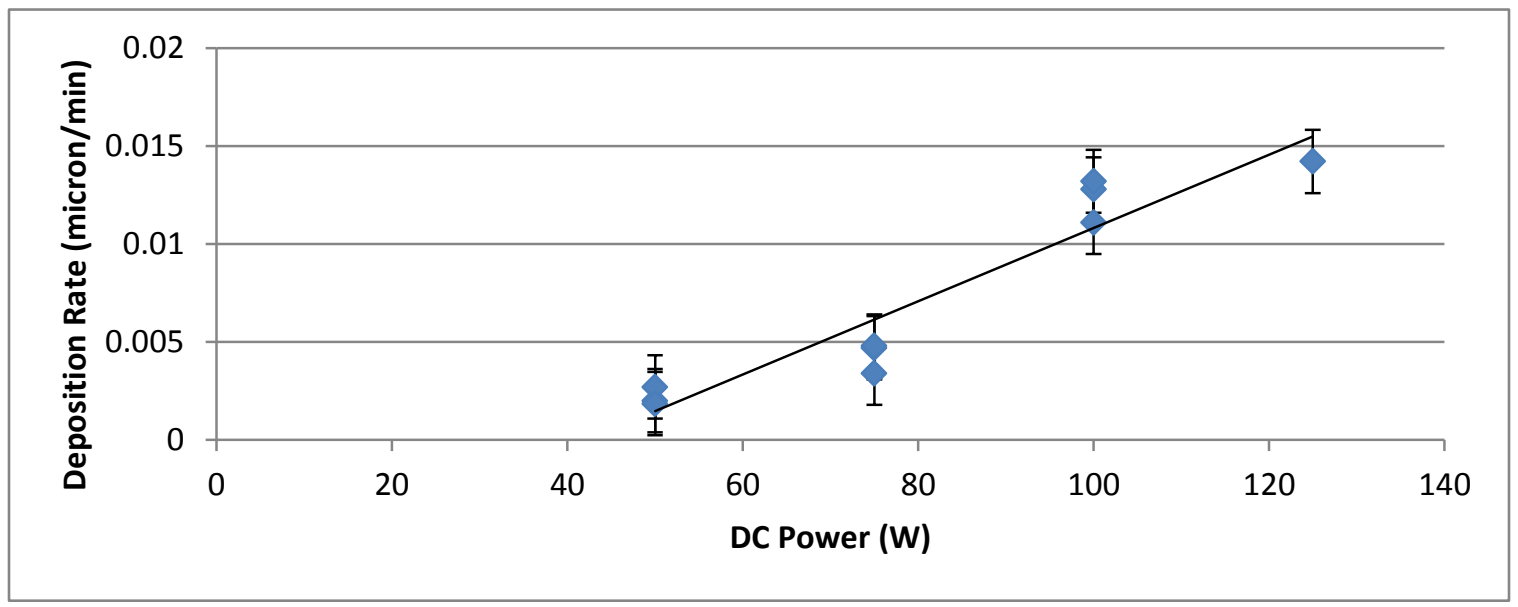

Figure 7: Tin deposition rate with 4" target as a function of power at 5mTorr Ar

Germanium tin alloy concentrations were controlled by adjusting sputtering power independently for each target during co-sputtering processes. Germanium was sputtered with 150 Watts RF for all depositions. For $5 \% \mathrm{SnGe}$, tin was sputtered at 42 watts DC with the 4" target. For $10 \% \mathrm{SnGe}$, tin was sputtered using 65 Watts DC.

\subsubsection{Amorphous Silicon Deposition}


An Oxford Instruments Plasmalab 100 PECVD, located in the University of Louisville Cleanroom was used to lay down amorphous silicon layers through the following chemical reaction:

$$
\mathrm{SiH}_{4} \stackrel{\text { plasma }}{\longrightarrow} \mathrm{Si}+2 \mathrm{H}_{2}
$$

The a-Si recipe used for the deposition on the devices was developed by starting with the stock a-Si recipe which specifies a deposition temp of $350^{\circ} \mathrm{C}$ and a silane flow rate of 300 SCCM.

Through several runs and visual inspections of film quality under a Zeiss optical microscope at magnifications from 5-100X, the stock recipe was modified to improve film quality. The temperature and silane flow rate were reduced to $250^{\circ} \mathrm{C}$ and $100 \mathrm{SCCM}$ respectively, creating a recipe called Si KM250. This recipe reduced pinhole defects in the film also exhibited a reduction in deposition rate. With this recipe, the deposition rate was 62.5 angstroms/min. Research into practices at other facilities showed the developed recipe is very similar to the recipe used by the cleanroom clients at UC Berkley for a-Si depositions.

\subsubsection{Doping Amorphous Films}

Doping of amorphous films proved to be difficult with the processes available in the cleanroom and this proved to be the most challenging aspect of this project for several reasons. High temperature solid-solid diffusion process, while well characterized and used for many decades for crystalline semiconductors, are not very well characterized or well suited for doping amorphous films. With crystalline films, the diffusivity is 
predictable and exhibits an Arrhenius relationship. Base diffusivities are well documented and diffusion schedules can be accurately modeled before undertaking high temperature processes. With amorphous films however, diffusion processes are less predictable and depend on the characteristics of the film. Film characteristics and quality can vary greatly depending on deposition methods and conditions. For this reason, standard diffusivities of dopants in amorphous films are not available for modeling and the standard diffusion modeling methods do not apply. Solid-solid diffusion processes also require high temperatures. At high temperatures, amorphous films tend to anneal to polycrystalline films ${ }^{[13]}$. When amorphous films anneal to polycrystalline, dopants tend to diffuse through the grain boundaries rather than through the crystals themselves. Dopant diffusivities at the grain boundaries are several orders of magnitude higher than diffusivities through the solid crystals ${ }^{[14]}$. When the dopants diffuse at grain boundaries, doping profiles and junction depths created from these processes become unpredictable $e^{[14]}$.

For these reasons, doping of amorphous films is generally accomplished by in-situ doping processes. In the case of a p-type doped amorphous film for example, during CVD processes, a dopant gas is run simultaneously with silane to deposit a doped film. This process eliminates the need for high temperature diffusion processes. The Oxford PECVD in the cleanroom is intended to have this capability and much of the equipment is installed to enable these processes in the future; at the current time this is beyond the processing capabilities available to users.

Another doping route would be to use ion implantation followed by a short high temperature anneal to activate the dopants. Ion implantation would present some similar 
problems to diffusion processes in that the implantation energy determines the depth of ion implantation; this is slightly unpredictable for amorphous films for the same reasons that diffusivities are unpredictable in amorphous films. Ion implantation also requires a high temperature anneal to incorporate dopants into the lattice and activate them. High temperature annealing is not compatible with heterogeneous amorphous structures as is discussed later. Ion implantation is not typically used for doping amorphous films; in-situ doping is typically preferred. Ion implantation is not currently a process available to cleanroom users, but wafers can be sent out for implantation processing by outside vendors.

\subsubsection{Amorphous Silicon Devices}

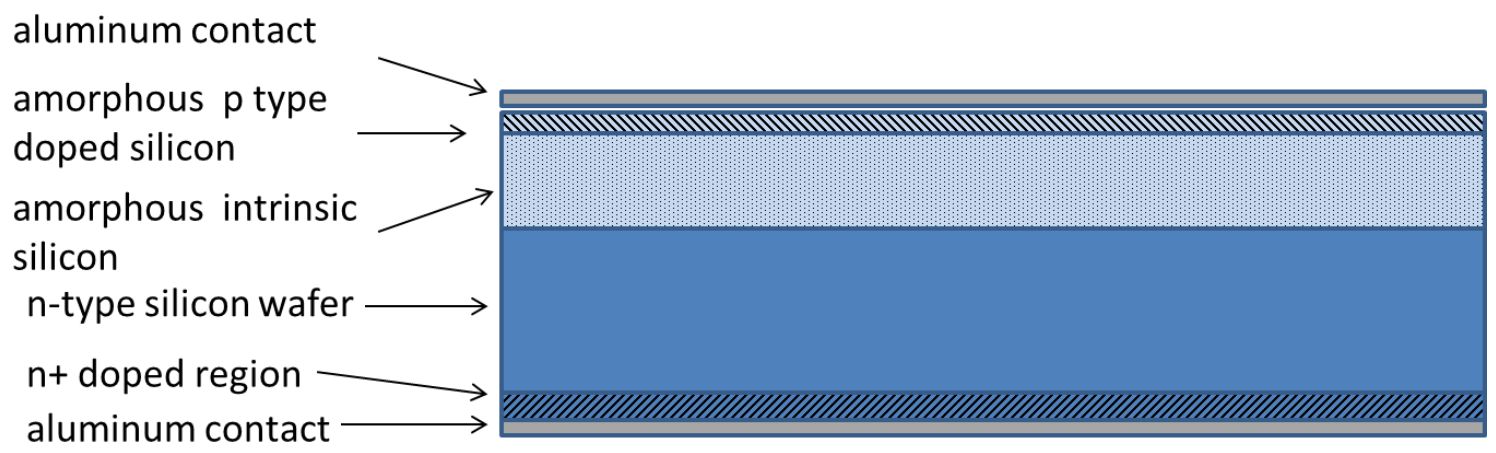

Figure 8: Layers of amorphous silicon based devices

Four amorphous silicon only devices were fabricated by using an Oxford PECVD to lay down amorphous silicon on wafers using the $\mathrm{KM} 250 \mathrm{Si}$ recipe described previously. The deposition rate was measured to be approximately 62 angstroms per minute; the desired film thickness was 1 micron; the deposition was allowed to run for 2 hours and 40 minutes per wafer in order to achieve the desired thickness. 
After silicon depositions were completed, the wafers were then immersed in BOE for 5 minutes to remove any native oxides that formed in storage following the depositions. The wafers were then washed in the QDR and spun dry.

Once native oxides were removed, two of the wafers were annealed before diffusion processes at $900^{\circ} \mathrm{C}$ under forming gas $\left(\mathrm{N}_{2}\right.$ and $\mathrm{H}_{2}$ in a quartz furnace. The purpose of this experiment was to see if annealing before doping had any effects on the establishment of a P-N or P-I-N structure and effects on overall cell efficiency. The furnace was preheated to $400^{\circ} \mathrm{C}$; the wafers were loaded in a quartz boat and inserted slowly into the furnace. The furnace was ramped at $20^{\circ} \mathrm{C} / \mathrm{min}$ up to $900^{\circ} \mathrm{C}$ and held for 1 hour under constant flux of forming gas. The oven was cooled at $20^{\circ} \mathrm{C} / \mathrm{min}$ and the wafers were slowly removed once the oven reached $450^{\circ} \mathrm{C}$; the wafers were allowed to cool at ambient temperature $\left(68^{\circ} \mathrm{F}\right)$.

Following the annealing and removal of native oxides, spin on polyboron film was applied to each wafer and all four were allowed to cure on a hot plate at $200^{\circ} \mathrm{C}$ for 30 minutes.

The diffusivity of boron in amorphous films is not well documented; experiments were needed to verify that a P-N junction could be established using thermal diffusion of spin on dopants into amorphous films. Diffusion through amorphous films can be several orders of magnitude higher than single crystal materials as explained previously. In solar cells, it is desired to have a portion of the semiconductor not doped, leaving the majority of the active layer intrinsic and creating a P-I-N structure. With high diffusivities and a need for a very shallow junction only for carrier extraction reasons, a rapid thermal annealer (RTP) was used for thermal diffusion for more accurate control of thermal 
diffusion times. Two diffusion times at $900^{\circ} \mathrm{C}$ were investigated, 5 minutes and 20 minutes. One wafer of non-annealed was run 5 minutes; the other 20 minutes. The diffusion schedules for the annealed wafers were identical to that of the non-annealed wafers.

Following diffusion, the wafers were soaked in a beaker of BOE for 15 minutes in preparation for wet oxidation. The purpose of the wet oxidation step is to oxidize the remaining polyboron film and top layers of silicon forming borosilicate glass which can then be etched using BOE or HF, exposing the doped silicon underneath. A quartz tube furnace with wet oxidation capabilities was preheated to $450{ }^{\circ} \mathrm{C}$; the water bubbler feeding the wet oxygen gas stream was preheated to $90^{\circ} \mathrm{C}$. After removing the wafers from BOE, they were loaded in a quartz boat and loaded slowly into the furnace. The furnace was heated to $800^{\circ} \mathrm{C}$ with a $20^{\circ} \mathrm{C} / \mathrm{min}$ ramp under a constant flux of wet oxygen. The furnace was held for 30 minutes at $800^{\circ} \mathrm{C}$, then ramped back down to $400^{\circ} \mathrm{C}$ at $20^{\circ} \mathrm{C} / \mathrm{min}$. The wafers were removed when the oven reached $450^{\circ} \mathrm{C}$ and allowed to cool in ambient air.

Following the oxidation process, the polyboron film and borosilicate glass layers were etched off by soaking the wafers in BOE for 15 minutes. The wafers were then removed from the BOE and washed in the QDR. Removal of the polyboron film was confirmed by a water break test showing that the surface of the wafer was again hydrophilic.

After polyboron removal, the wafers were then sputtered with aluminum on each side using the PVD 75. Aluminum was sputtered using 500W DC and 5 mTorr capmann for 15 minutes. 
After sputtering aluminum on both sides of the wafer, MCP photoresist primer and Shipley photoresist 1827 was spun onto the back of all wafers and allowed to hard bake at $115^{\circ} \mathrm{C}$ for 10 minutes to remove all volatile carriers and ensure good adhesion. After the hard bake step, MCP primer and Shipley 1827 was spun onto the front of the wafers and allowed to soft bake at $115^{\circ} \mathrm{C}$ for 2 minutes.

The wafers were then removed from heat and allowed to cool back to ambient temp. The photoresist on the front side was patterned using a Suss Mask Aligner with an exposure time of 35 seconds. The wafers were then transferred to MF-319 developer and agitated by hand. MF-319 first develops the photoresist then etches the exposed aluminum with an extended soak. Once the aluminum was patterned and etched, the wafers were removed from the MF-319 solution and washed with DI. The wafers were then rinsed with acetone, followed by methanol, followed by water until all of the photoresist was removed.

The annealing furnace was heated to $450^{\circ} \mathrm{C}$; the wafers with patterned aluminum were annealed at $450^{\circ} \mathrm{C}$ for 30 minutes to anneal the aluminum and ensure formation of good ohmic contacts.

After annealing, MCP Primer and Shipley 1805 were spun onto the polished and patterned wafer surface and allowed to hard bake for 10 minutes at $115^{\circ} \mathrm{C}$. The photoresist helps to protect the devices when dicing.

The wafers were then taken to the dicing lab, placed on dicing tape, and diced using an automated dicing saw.

Once diced, the devices were mounted in chip packages using a two part silver epoxy and cured at $100^{\circ} \mathrm{C}$ for 1 hour. After the epoxy was cured, the devices were taken 
to the wire bonding lab and aluminum wire was bonded using a wedge bonder which uses ultrasonic vibration to sink the fine wire into the contacts. After bonding was finished, the devices were set in a foam holder awaiting testing with the parameter analyzer, solar simulator, and IPCE.

\subsubsection{Amorphous Germanium and Silicon Devices}
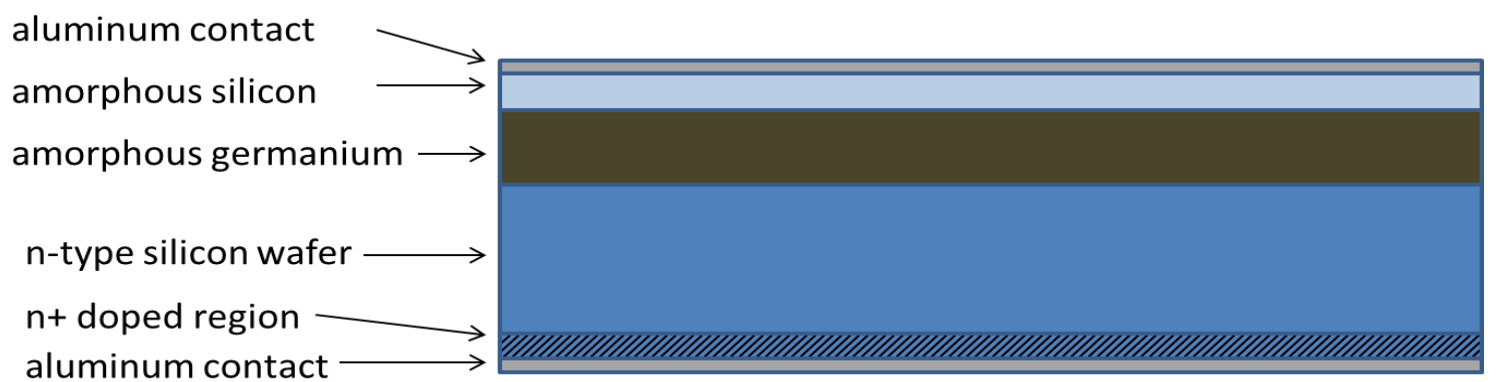

Figure 9: Amorphous germanium and amorphous silicon cell layers

Germanium was sputtered onto 4" wafers using the KJL PVD 75, 150W RF, 5 mTorr Capman, wafer spinning at 50rpm for even deposition, for a total of 60 minutes. With the substrate shutter closed, RF power was ramped up at $0.5 \mathrm{~W} / \mathrm{min}$ to 50 watts, then bumped off of a DC plasma on source number two. Once a stable RF plasma was going on source one, source two was shut off. The power continued to be ramped up to 150 watts DC at $0.5 \mathrm{~W} / \mathrm{min}$. Once $150 \mathrm{~W}$ was achieved, the substrate shutter was opened, allowing deposition in the wafer. The 60 minute run was split up into three 20 minute runs with RF power on and two 20 minute breaks with RF power off and Ar gas flow on in order to let the germanium target cool. This procedure was developed to alleviate problems discovered with heat buildup in the germanium target causing damage in earlier runs. 
After sputtering germanium to the desired film thickness, the wafers were immediately transferred to the Oxford PECVD and an amorphous silicon deposition was run for 40 minutes using the KM $250 \mathrm{Si}$ recipe to lay down 0.25 microns of silicon on top of the germanium. Polyboron film was then spun onto the amorphous film and baked at $200^{\circ} \mathrm{C}$ on a hot plate to drive off volatiles and set the dopant glass.

The wafers were then transferred to the RTP and 5 minute diffusions at $900^{\circ} \mathrm{C}$ were run to drive the polyboron into the silicon layer doping it p-type and completing the P-I-N structure. Following diffusion, wafers were immersed in BOE for 15 minutes then the wafers were oxidized in a quartz furnace at $800^{\circ} \mathrm{C}$ under wet oxygen as described in the amorphous silicon process. The polyboron film and borosilicate glass layers were etched in BOE for 15 minutes or until water break was observed. Aluminum was then sputtered and patterned, the wafers were prepped, and diced, and mounted in chip packages for testing as described in the amorphous process.

\subsubsection{Amorphous Germanium and Tin Devices}

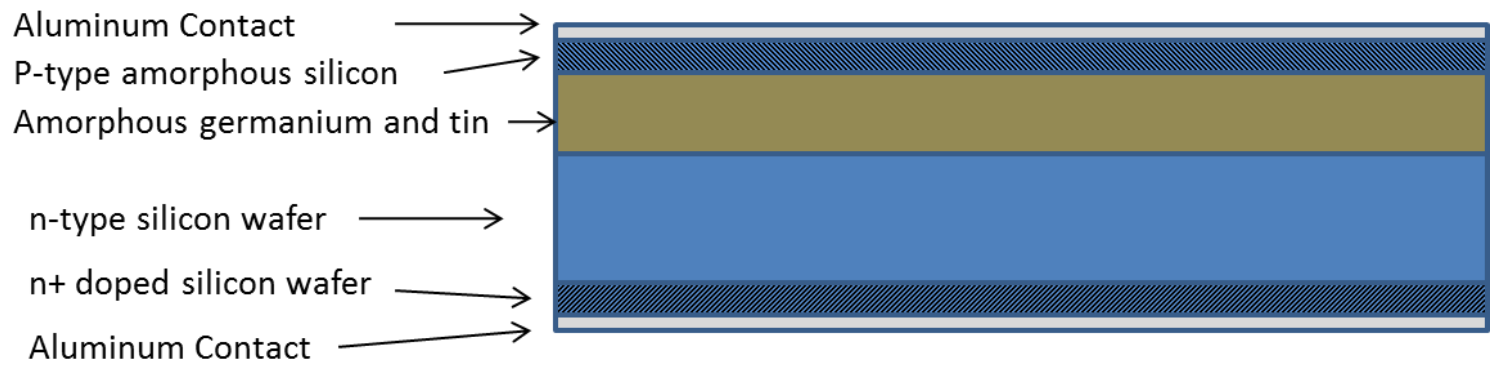

Figure 10: Germanium and tin device layers 
Amorphous germanium and tin films were deposited on n-type wafers via cosputtering using the KJL PVD 75. Germanium and tin were co sputtered using power on each source to control relative concentrations.

\subsubsection{Finished Device Mounting in Chip Packages}

All finished devices were diced using an automatic dicing saw. The exposed active photo area on each cell was $2 \mathrm{~mm}$ X $2 \mathrm{~mm}$. The diced cells were then mounted in gold plated chip packages provided by Spectrum Semiconductor. The devices were mounted with a two part silver epoxy then cured in a vacuum oven at atmospheric pressure and $100^{\circ} \mathrm{C}$ for $1 \mathrm{hr}$. The mounted devices were then removed from the oven, allowed to cool to room temperature and wire bonded using a wedge bonder with aluminum wire. Figure 11 shows typical finished patterned cells before dicing and Figure 12 shows typical finished devices after dicing. 


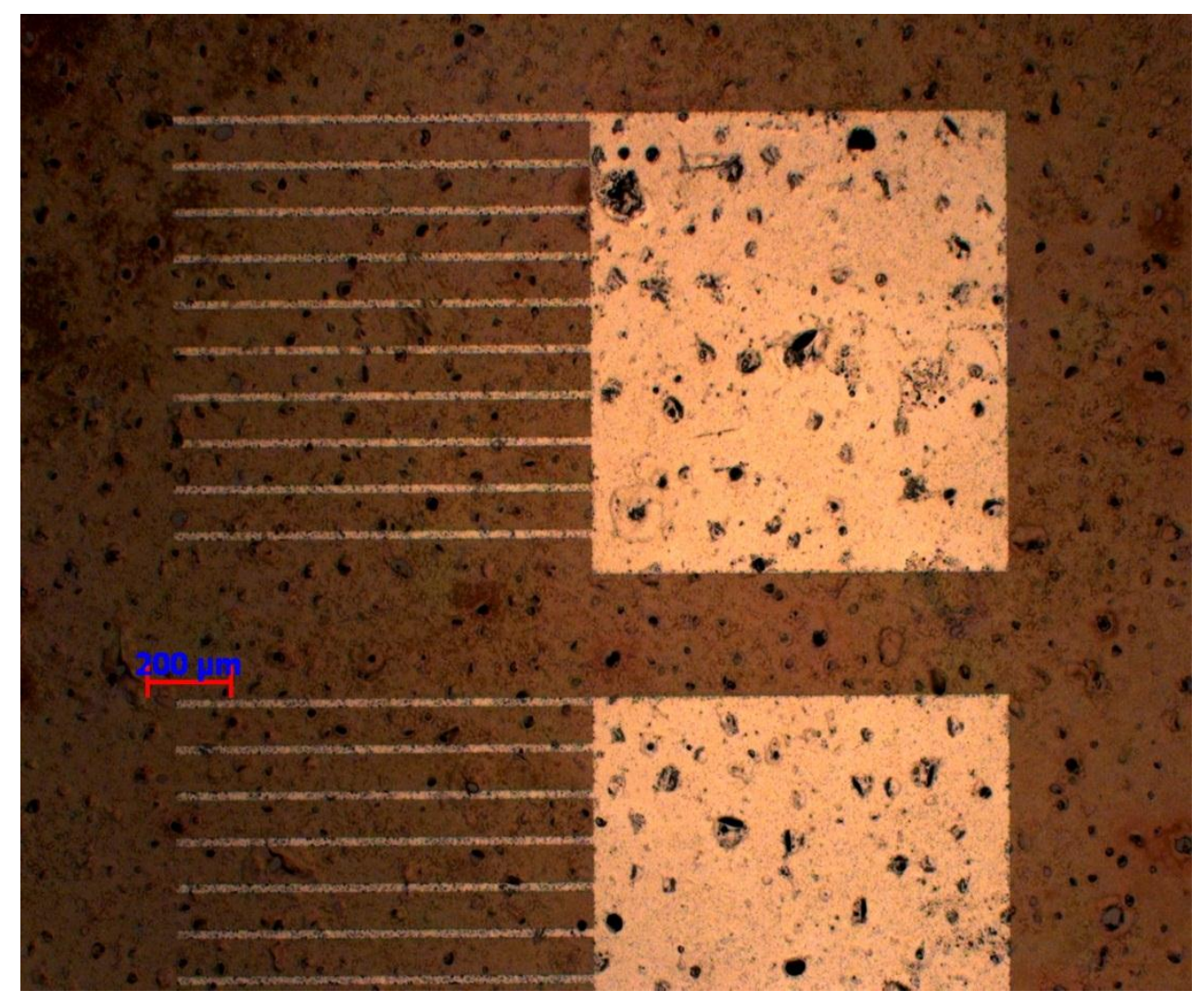

Figure 11: Typical finished patterned cells before dicing 


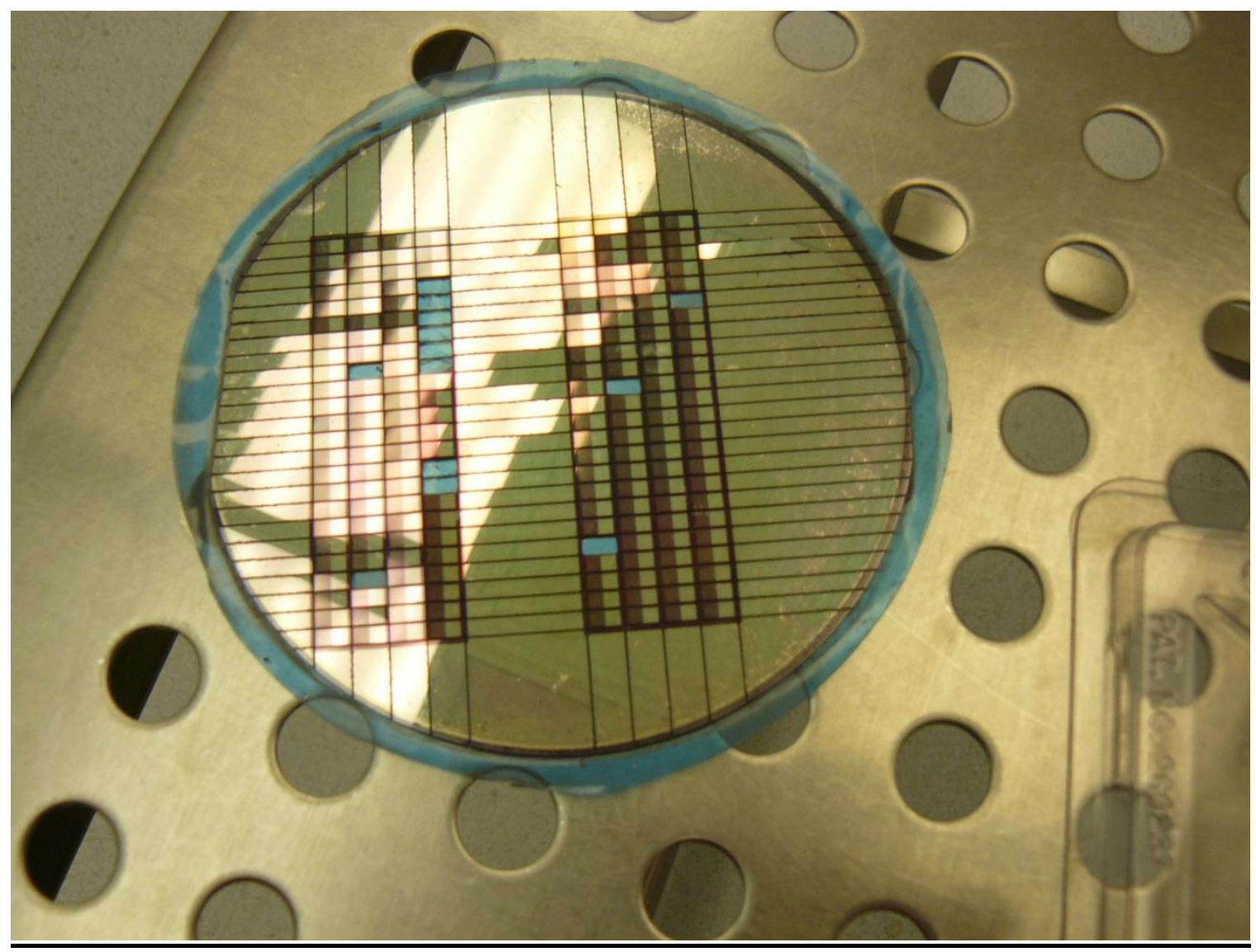

Figure 12: Typical finished devices after dicing

\subsubsection{Performance Testing}

After mounting in IC chip packages, all cells were subjected to performance testing. The chip packages with cells were mounted in a chip holder that was then mounted onto a small breadboard and copper wires were used for leads. The cells were first subjected to an I-V test under dark conditions to verify diode performance using a parameter analyzer and amplifier used with an Oriel solar simulator. The devices were then subjected to I-V testing under AM 1.5 simulated solar conditions provided by the Oriel solar simulator. Data from the illumination test can be used to determine the short circuit current density, open circuit voltage, fill factor, and overall cell efficiency. Short 
circuit current density $\left(\mathrm{J}_{\mathrm{sc}}\right)$ is the measured current in an I-V sweep when the potential equals zero divided by the area of the cell. The open circuit voltage $\left(\mathrm{V}_{\mathrm{oc}}\right)$ is the voltage in the I-V sweep at which the current output of the cell equals zero. Overall efficiency $(\eta)$ is calculated as the ratio of peak power output of the cell during the I-V sweep to the incoming power per unit area of the cell. The fill factor is the ratio of the maximum power to the open circuit voltage and short current calculated from the following equation:

$$
F F=\frac{P_{\max }}{J_{s c} V_{o c}}
$$




\section{$3.4 \quad$ Equipment}

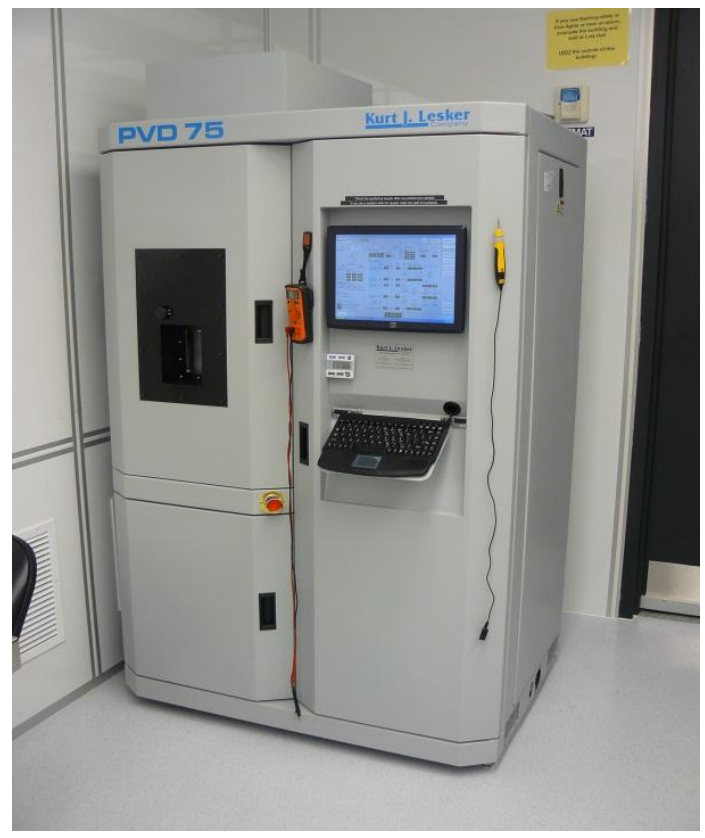

Kurt J Lesker PVD 75

Manufactured 12/10

Serial Number: PRD056852

Figure 13: KJL PVD 75

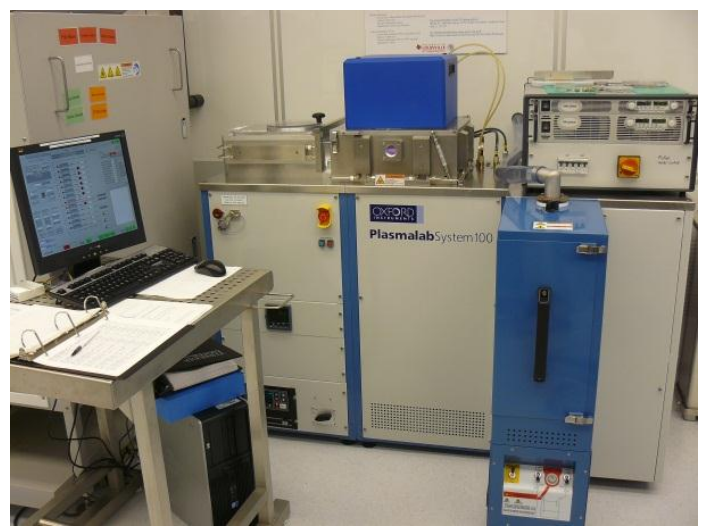

Oxford Instruments PECVD

Plasmalab 100

Figure 14: Oxford Instruments

Plasmalab 100 PECVD 


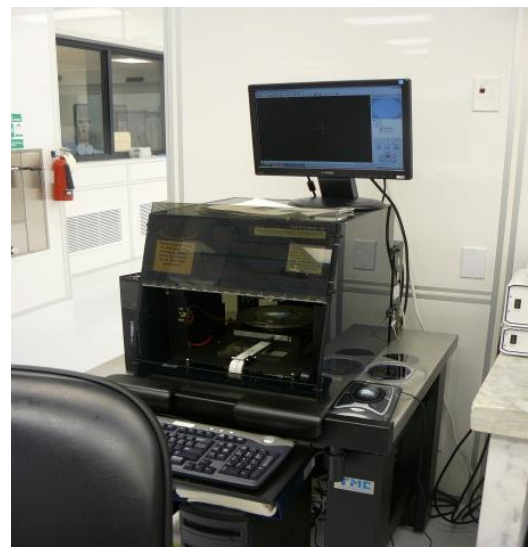

Figure 15: Dektak Profilimeter

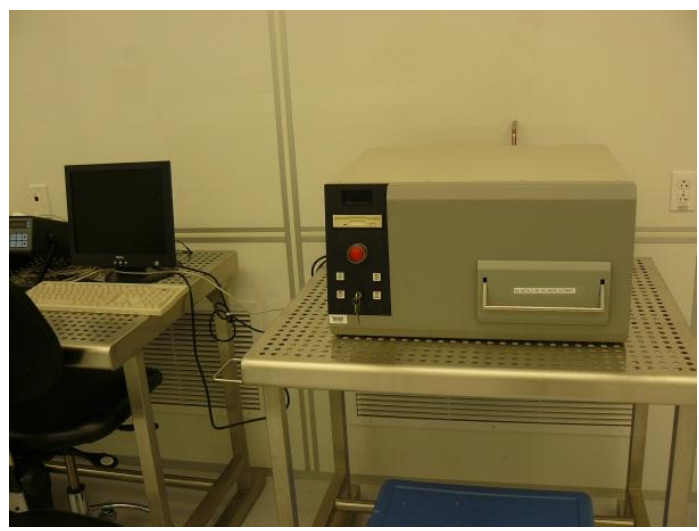

Figure 16: RTP-6003 rapid thermal annealer

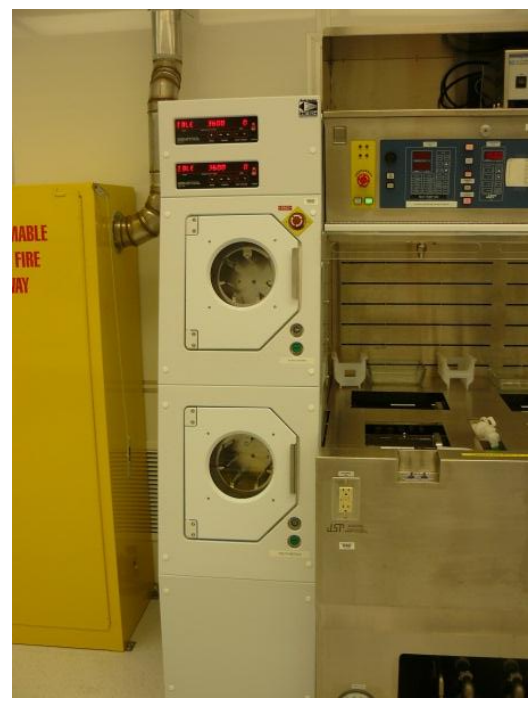

Figure 17: Wafer washer-dryer
Dektak 8 Advanced Development Profiler

\section{Modular Process Technology Corp RTP-600S}

Semtech Gold Series Rhetech Wafer Spin Washer-Dryer 


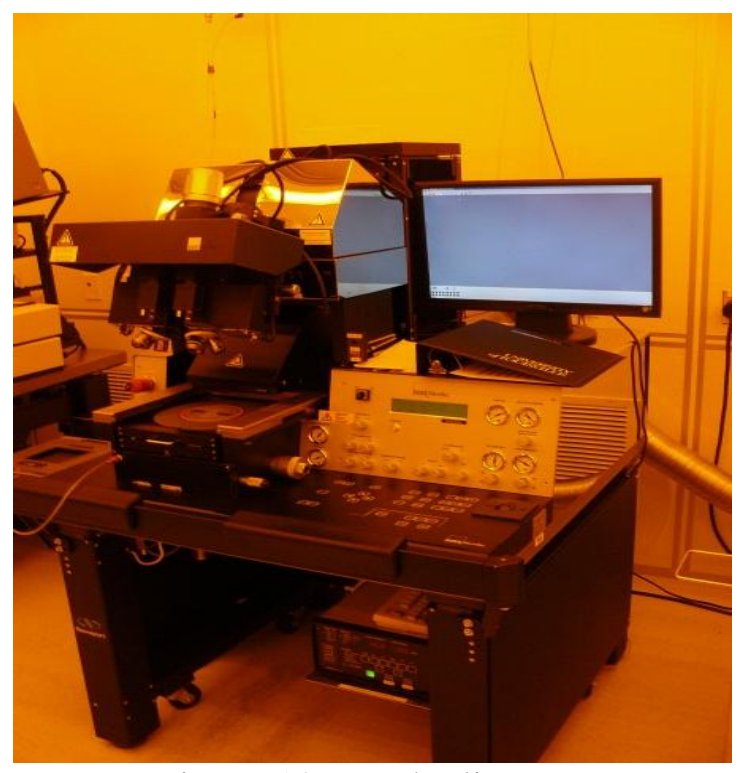

Figure 18: Mask aligner

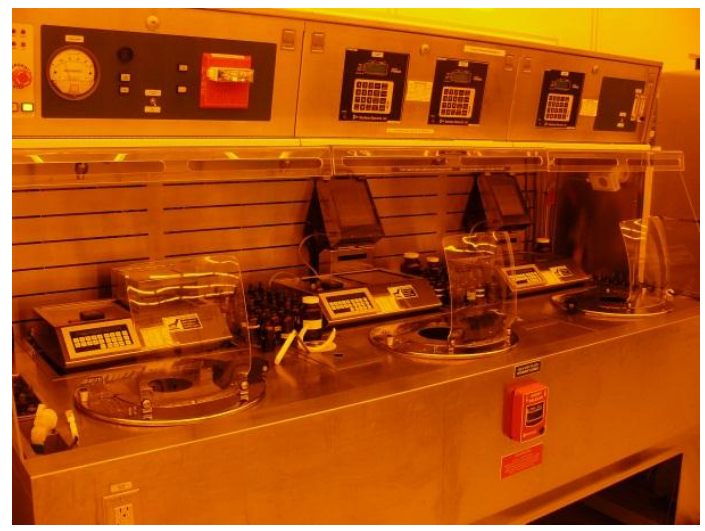

Figure 19: Photolithography bench

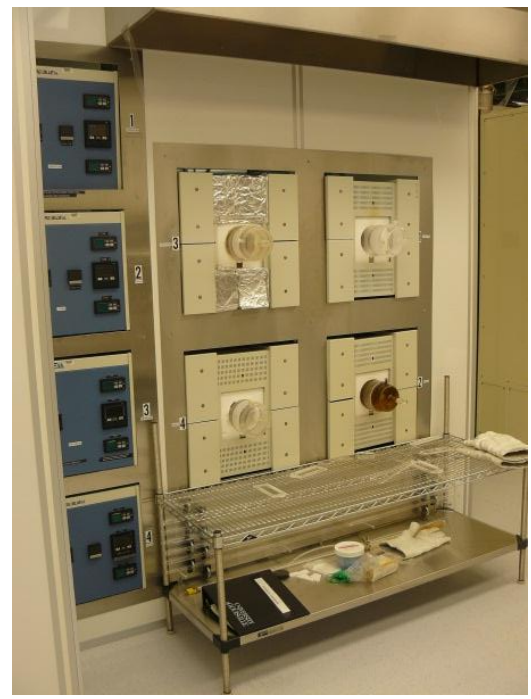

Figure 20: Quartz tube furnaces
SÜSS Microtec Mask Aligner

Headway Research Inc Combo Hood Headway Research Spinner Bowl Headway Research PMW32 Controller
Quartz Tube Furnaces

Lindberg Blue Controllers

Equipped with nitrogen, wet/dry oxygen, and Forming Gas feeds 


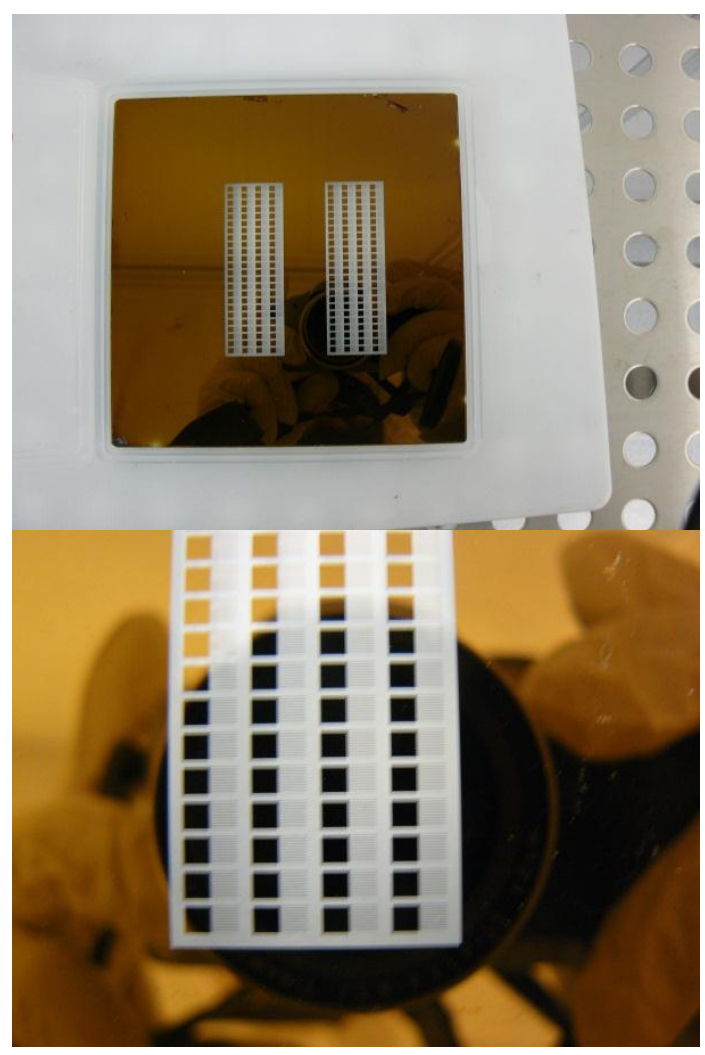

Figure 21: Photomask

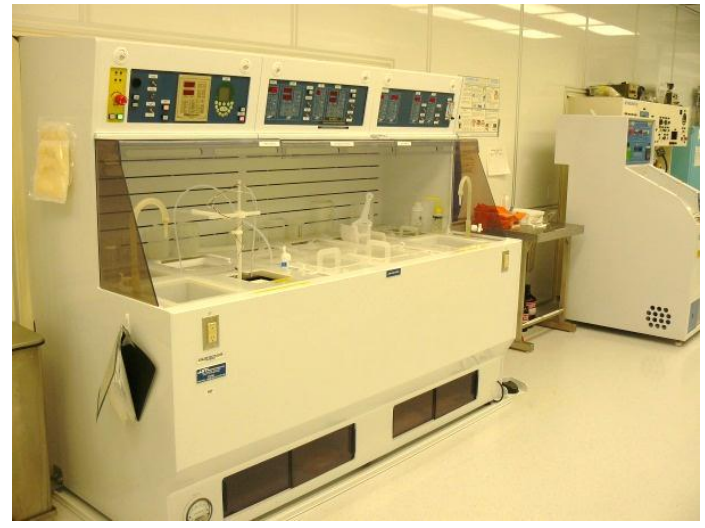

Figure 22: Wet etching bench
Photomasks used to pattern aluminum contact pads and active window collectors
Wet Etching bench equipped with BOE bath, QDR, DI rinse sprayers, Nitrogen gun 


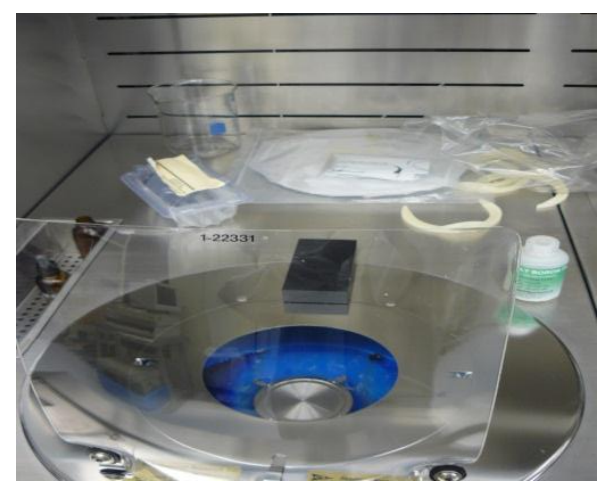

Figure 23: Dopant spin bowl

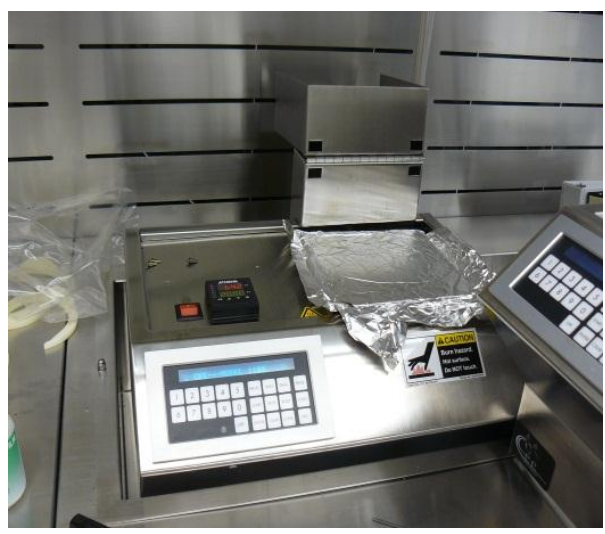

Figure 24: Dopant hotplate

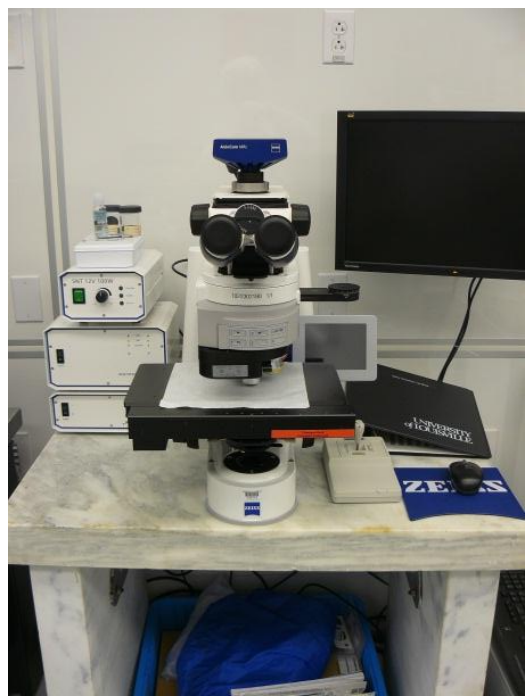

Figure 25: Optical microscope
Spin Bowl dedicated to dopant application

Hot plate dedicated for setting dopant films

Zeiss 5-100X Optical Microscope for inspecting and imaging films 


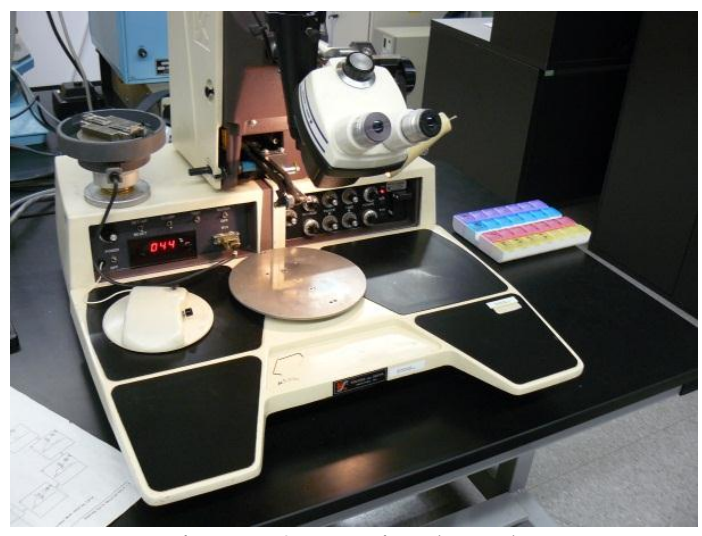

Figure 26: Wire bonder

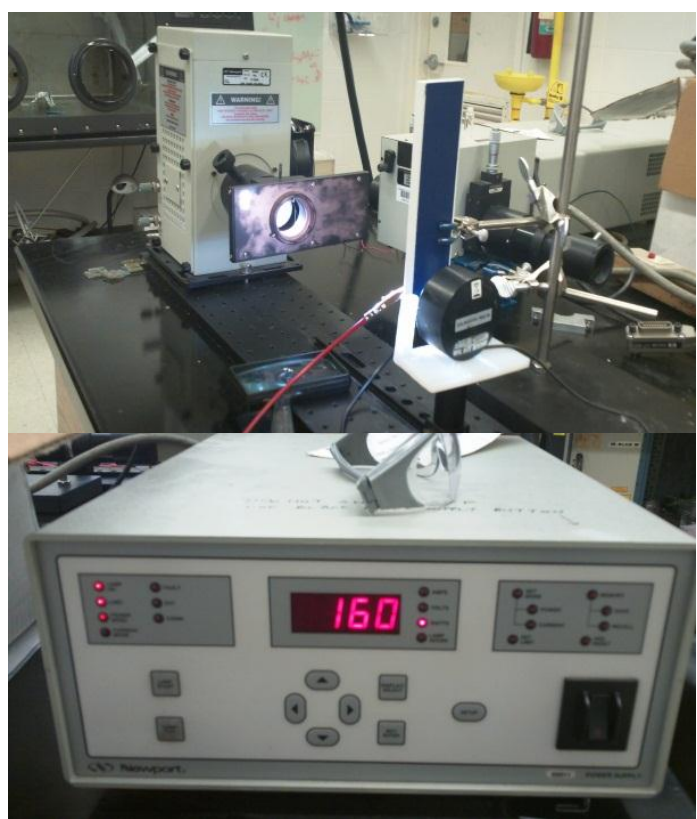

Figure 27: Solar simulator
Kulcke and sofa Model 4123 wedge bonder

Oriel Instruments Model 66902 Solar Simulator/Parameter Analyzer

Power Suite Software Version 2.58 


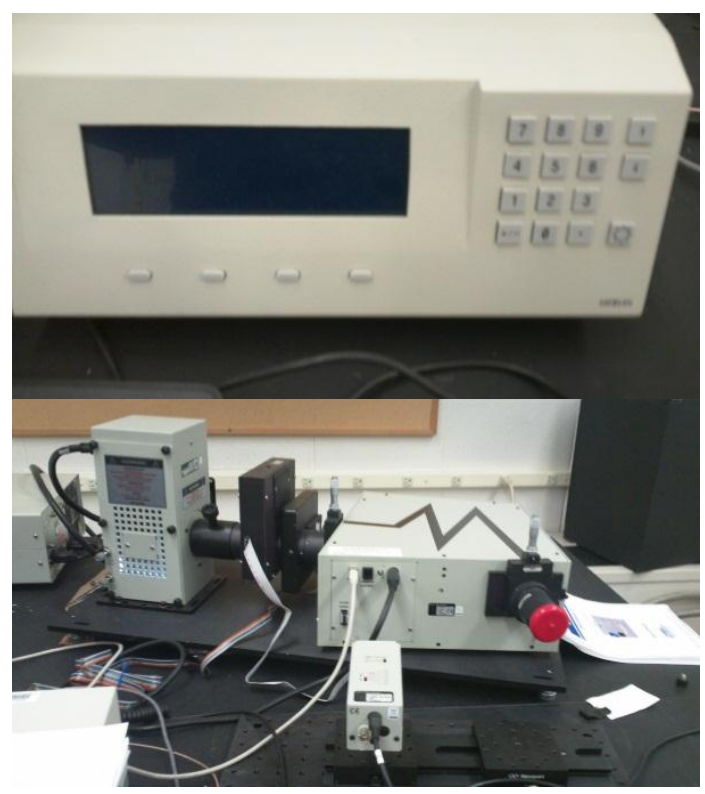

Figure 28: IPCE

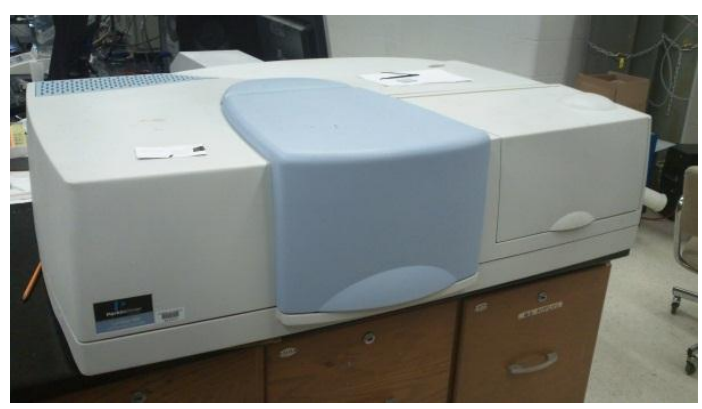

Figure 29: UV/VIS spectrometer
Traqbasic Model 7790 IPCE

Oriel Intruments/Newport Corporation

Newport Merlin Model 70104 lock-in amplifier

Perkin-Elmer Lambda 950

UV/VIS Spectrometer 


\section{RESULTS AND DISCUSSION}

\subsection{Thermal Coefficient of Expansion (TCE) Incompatibility and High Temperature \\ Processing}

In order for devices made of heterogeneous materials to be high temperature processing compatible, the thermal coefficients of expansion (TCE) must match within about $10 \%$. When the thermal coefficients of expansion do not match within $10 \%$, heterogeneous film structures show excessive stress and can delaminate, destroying the films and devices

Table 2: THERMAL COEFFICIENTS OF EXPANSION ${ }^{[15]}$

\begin{tabular}{|l|c|c|c|c|c|c|}
\hline & $\mathbf{G e}$ & $\mathbf{S i}_{.25} \mathbf{G e}_{.75}$ & $\mathbf{S i}_{.5} \mathbf{G e}_{.5}$ & $\mathbf{S i}_{.75} \mathbf{G e} .25$ & Si & Sn \\
\hline $\begin{array}{l}\text { Linear } \\
\begin{array}{l}\text { Coefficient of } \\
\text { thermal } \\
\text { expansion } \\
(\Delta \mathrm{L} / \mathrm{L} \Delta \mathrm{T})\left({ }^{\circ} \mathrm{C}^{-1}\right)\end{array}\end{array}$ & $5.8^{-1} 10^{-6}$ & $5.0^{*} 10^{-6}$ & $4.2^{*} * 10^{-6}$ & $3.4 * 10^{-6}$ & $2.6^{*} 10^{-6}$ & $22^{*} 10^{-6}$ \\
\hline
\end{tabular}

Solar cell and photodetector devices must have at least a P-N structure, and preferably have a P-I-N structure for optimal efficiency. The doping structure is required to create a field for charge carrier separation; this field also establishes diode performance. Wafers all come with either an n-type or p-type background doping; all wafers used in this project were n-type. The top deposited layers were doped p-type using polyboron film and high temperature thermal diffusion. The TCE's in Table 1 show that the TCE for germanium is 2.23 times that of silicon, far above the recommended $10 \%$ allowable variance. This became apparent due to film delamination during diffusion 
processes when film stress and delamination caused the destruction of film layers, rendering many of the deposited films and wafers unusable for further fabrication.

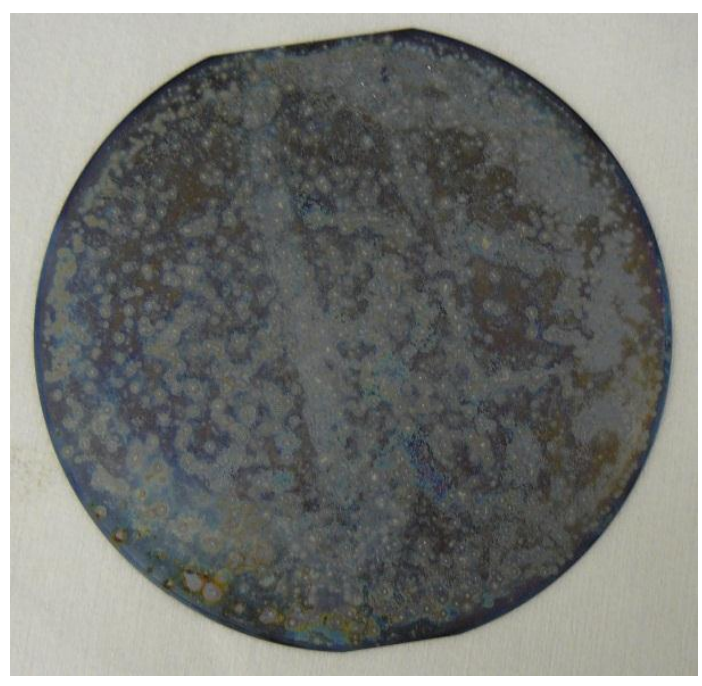

Figure 30: Ge device wafer after polyboron diffusion $850^{\circ} \mathrm{C}$ in quartz furnace followed by oxidation $850^{\circ} \mathrm{C}$ and etching

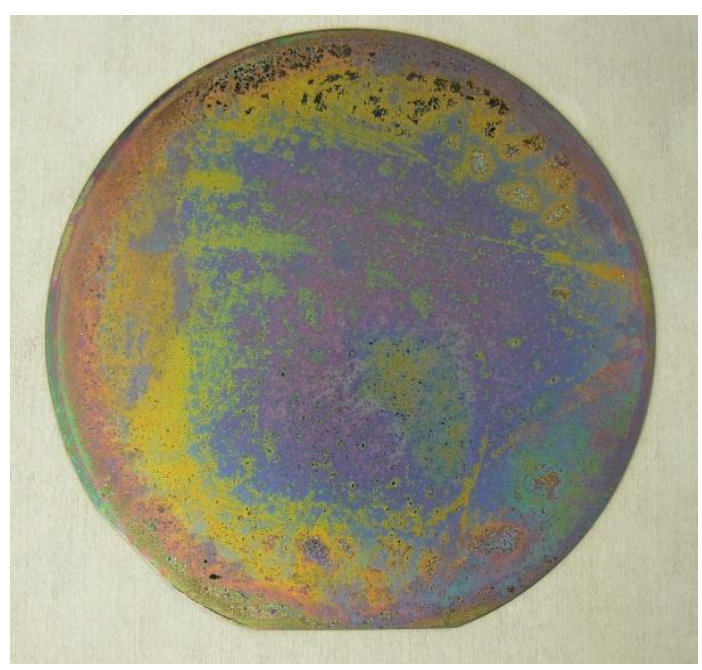

Figure 31: Ge device wafer following polyboron diffusion $850^{\circ} \mathrm{C}$ in RTP 5 minutes followed by oxidation and etching

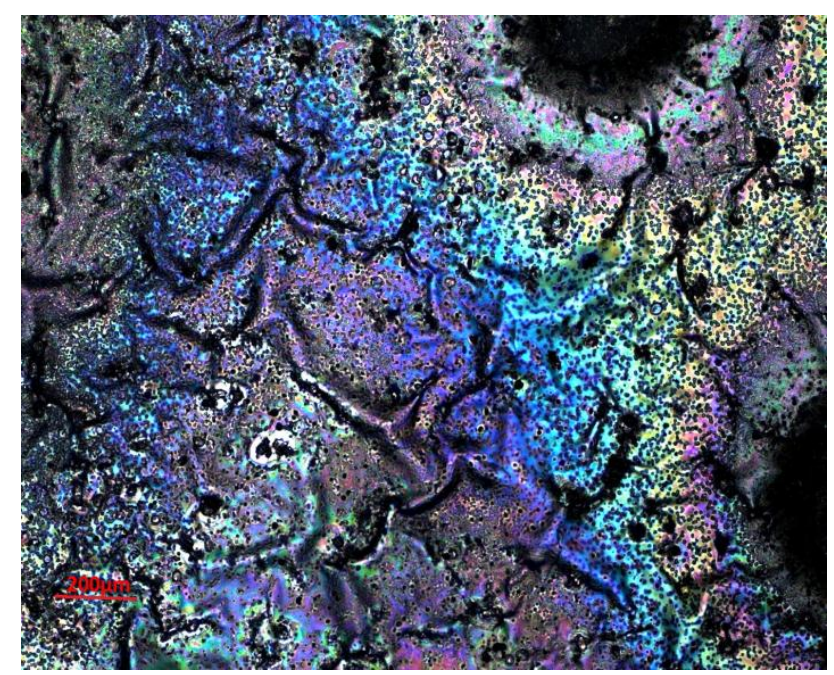

Figure 32: Optical micrograph of Ge on Si after diffusion

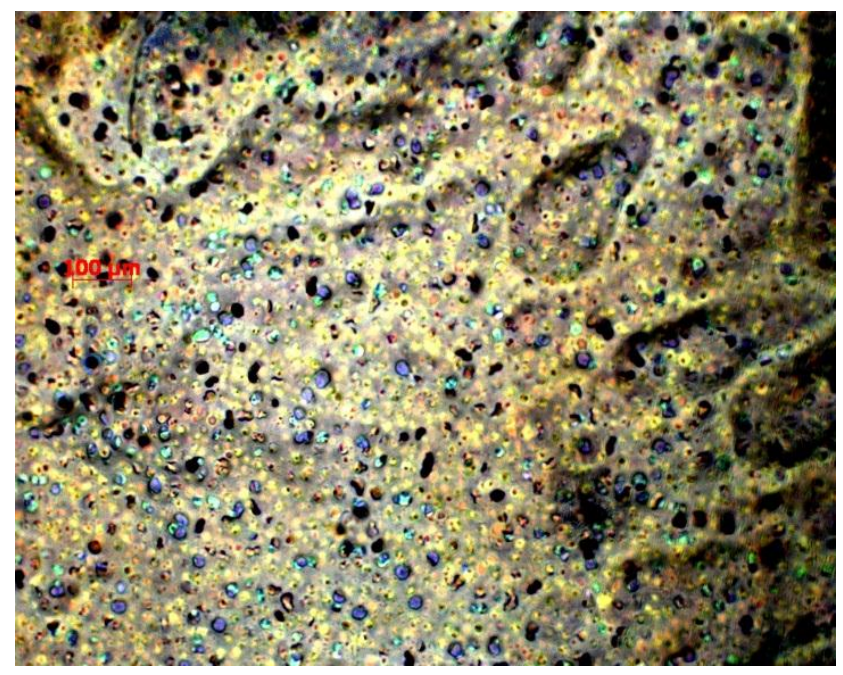

Figure 33: Optical micrograph of Ge device following RTP diffusion 


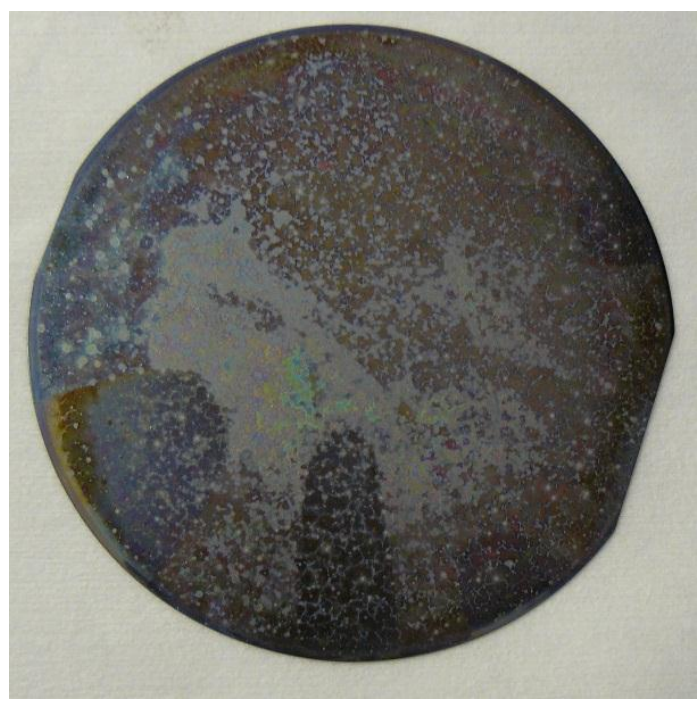

Figure 34: $5 \% \mathrm{SnGe}$ after polyboron diffusion $850^{\circ} \mathrm{C}$, wet oxidation $850^{\circ} \mathrm{C}$, and etching to remove polyboron film

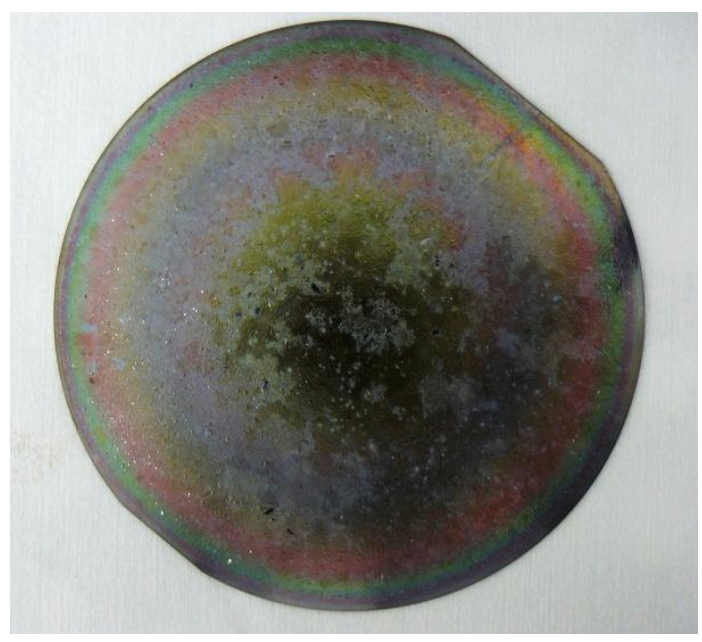

Figure 36: 7\% GeSn after polyboron diffusion $850^{\circ} \mathrm{C}$, wet oxidation $850^{\circ} \mathrm{C}$ and etching

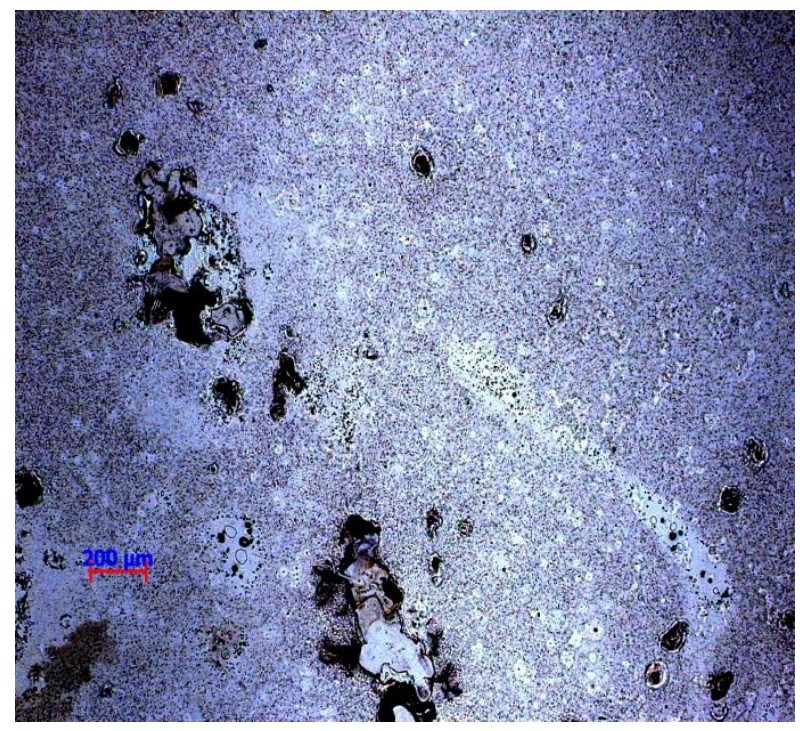

Figure 35: Optical micrograph of $5 \% \mathrm{SnGe}$ after doping processes

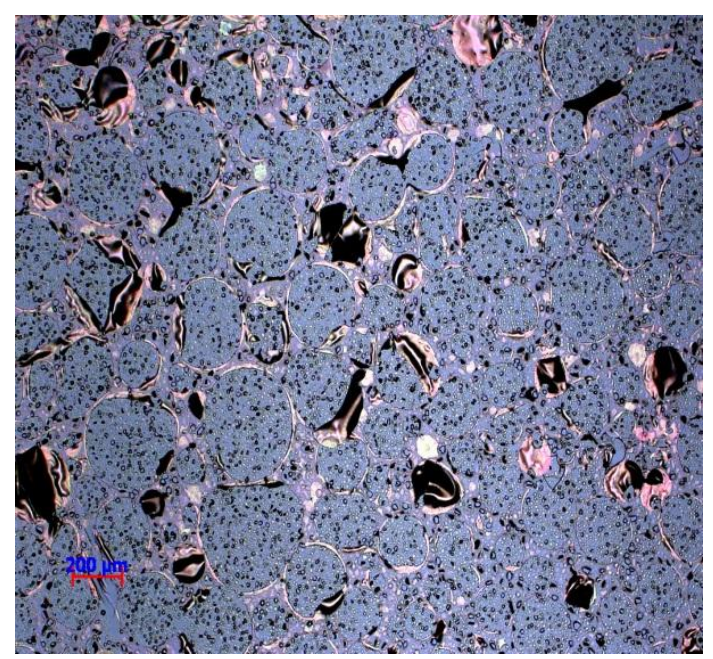

Figure 37: Optical micrograph of film defects in $7 \%$ SnGe after doping processes 


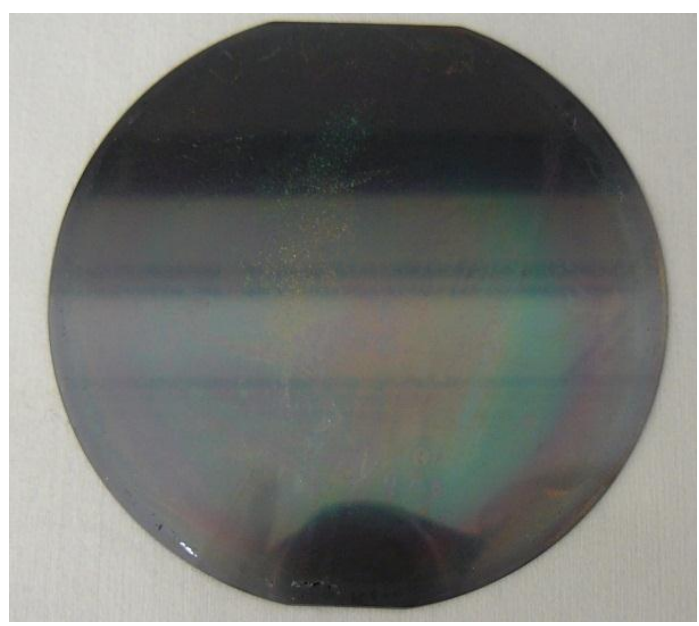

Figure 38:10\% SnGe after polyboron diffusion $850^{\circ} \mathrm{C}$, wet oxidation, and etching to remove polyboron film

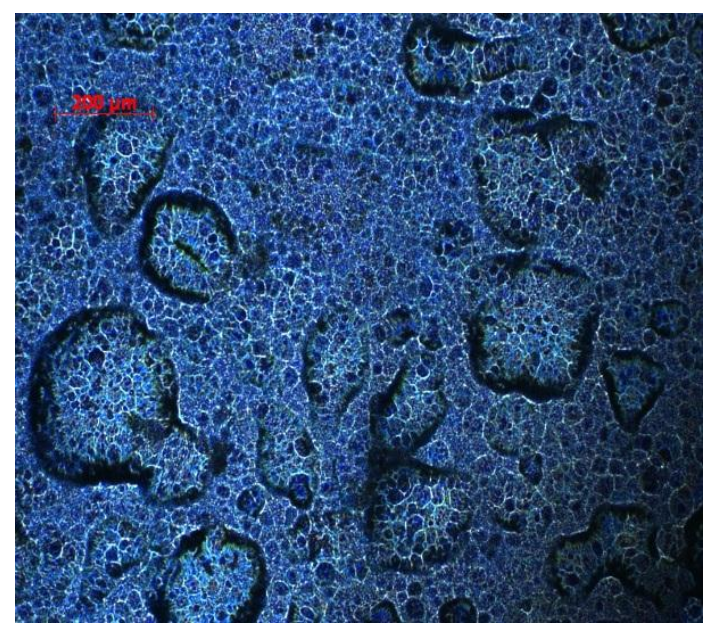

Figure 39: Optical micrograph of $10 \%$ SnGe after doping processes

High temperature processing is not compatible with these materials. Some measure of success in fabrication was achieved through conservative ramping of temperature and by lowering diffusion temperatures. Working devices were fabricated through multiple attempts using thermal diffusion, but successful doping without film delamination was inconsistent. Even with conservative ramp rates, delamination was still observed; even the devices that were successfully fabricated showed regions of delamination after doping processes. The success rate and repeatability of the process is extremely low using high temperature diffusion; delamination most likely contributed to poor dopant incorporation and reduced device efficiencies as will be discussed in later sections.

After observing the TCE incompatibility problems, other doping processes and fabrication regimes were considered. PECVD is a very common process for depositing insulating silicon nitride films according to the reaction described below 


$$
3 \mathrm{SiH}_{4}+4 \mathrm{NH}_{3} \rightarrow \mathrm{Si}_{3} \mathrm{~N}_{4}+12 \mathrm{H}_{2}
$$

Interestingly, nitrogen in trace amounts can act as an n-type dopant as described in NIDOS (nitrogen doped silicon) films. It was proposed that if it were possible to deposit nitrogen doped n-type films, the devices could have been fabricated on p-type wafers. Several attempts were made to deposit nitrogen doped silicon films through PECVD recipe manipulation by increasing silane and hydrogen flow and reducing ammonia flow or by running a.si recipes with nitrogen and hydrogen flow. The intention was to achieve a silicon deposition with silane and hydrogen in extreme stoichiometric excess when compared to the ammonia or nitrogen flows. All attempts to create conductive n-type films were unsuccessful; the films were high quality insulating silicon nitride films or undoped amorphous silicon. The lowest controllable flow rate for either nitrogen or ammonia was $1 \mathrm{SCCM}$; this flow rate is too high with undiluted nitrogen source gasses to deposit NIDOS films.

Ion implantation through an outside vendor was also discussed for a possible solution. Ion implantation requires a high temp thermal anneal to activate the dopants. The annealing requirements would not have solved the TCE/delamination problems.

Using a doped 4" Si wafer as a target, doped either $\mathrm{n}+$ or $\mathrm{p}+$ at the surface to RF sputter doped semiconductor films was also considered. The cleanroom staff strongly advised against this approach due to concerns over potential equipment damage and poor stoichiometric control over deposited films.

The only viable solution to this problem is to eliminate high temperature processing by using a low temperature PECVD process to deposit in-situ doped 
semiconductor films. This is the predominant doping method on amorphous cell manufacture because it is the only really viable route for doping amorphous films. In the absence of the capability to deposit in-situ doped amorphous films, thermal diffusion was used because it was the only technique available.

\subsection{Band Gap Measurements}

For band gap measurement, a 300nm thick amorphous film was deposited onto 25x50x5mm Corning (part \# c137-1105) aluminosilicate high transmittance optical slides. The band gaps of the thin films were measured using a Perkins-Elmer Lambda 950 UV/VIS spectrometer, measuring absorbance as a function of wavelength between $200 \mathrm{~nm}$ and $1000 \mathrm{~nm}$. UV/VIS spectrometer testing sweeps radiation wavelength while measuring absorbance vs. a reference blank slide in order to determine absorbance as a function of wavelength. The UV-VIS spectrometer provided data for the Tauc Plot method of amorphous thin film band gap determination The Tauc plot method for amorphous material band gap determination uses the first linear portion of the absorbance curve in early onset absorption to determine the band gap of the measured material. Sample Tauc Plot analyses are shown in Figure 23 and Figure 24. 

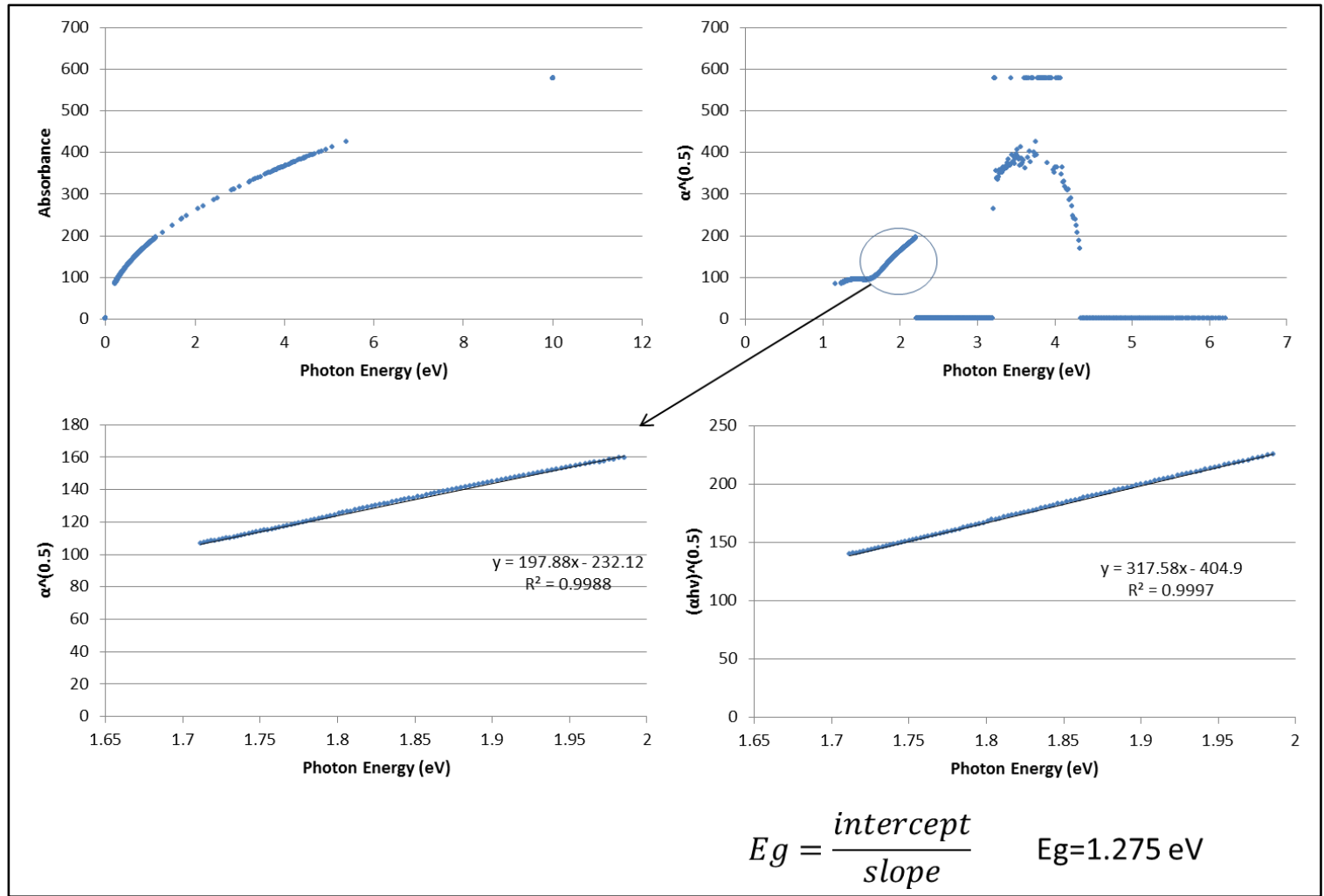

Figure 40: Tauc plot for amorphous germanium

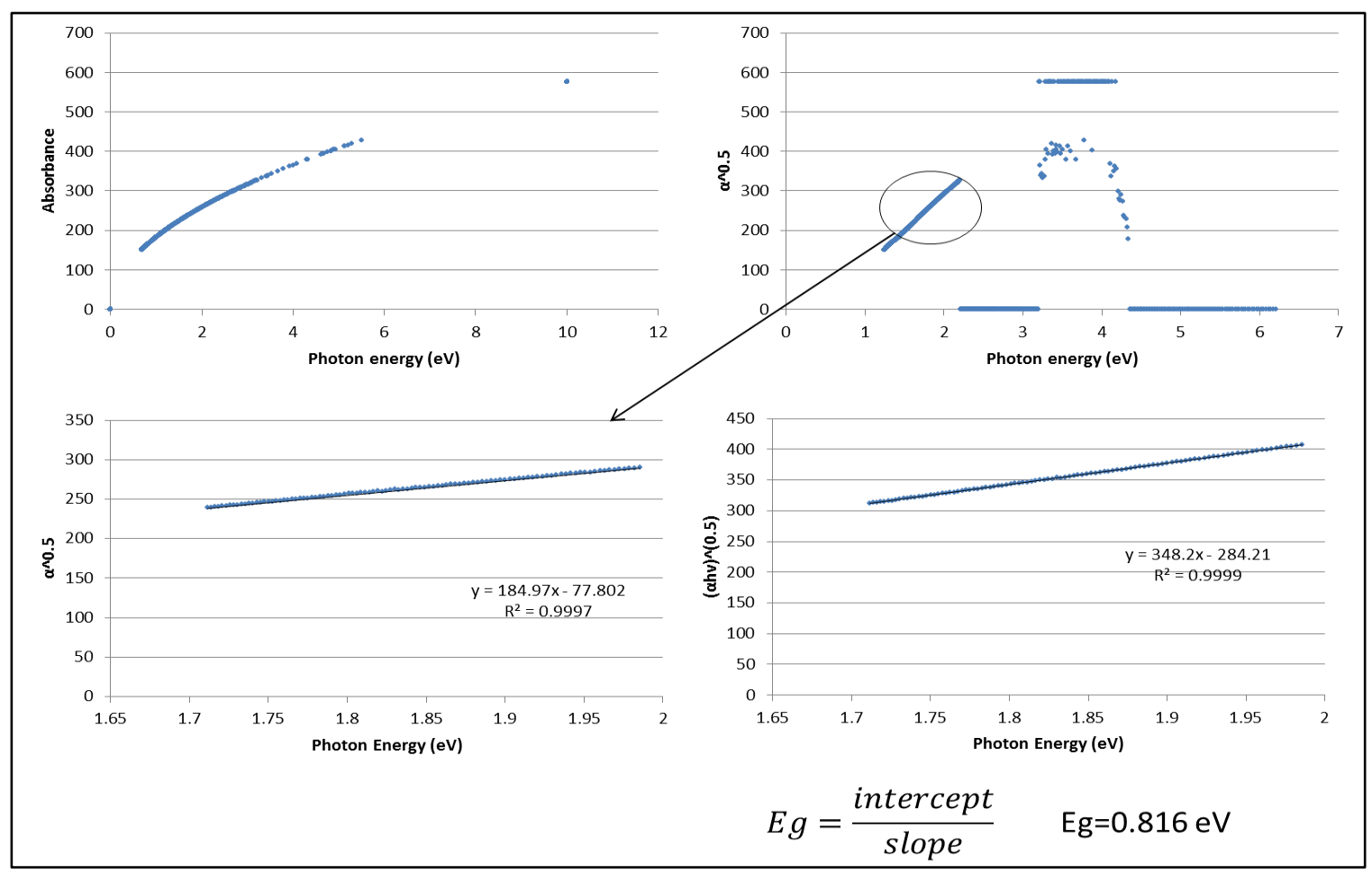

Figure 41: Tauc plot for $10 \% \mathrm{SnGe}$ 
Table 3: BAND GAPS MEASURED FOR AMORPHOUS MATERIALS BY UV/VIS SPECTROSCOPY AND TAUC PLOT METHOD

\begin{tabular}{|c|c|}
\hline Material & Eg (eV) \\
\hline Amorphous Silicon & 1.635 \\
\hline Amorphous SiGe (1:3) & 1.262 \\
\hline Amorphous Ge & 1.275 \\
\hline Amorphous 5\%SnGe & 1.008 \\
\hline Amorphous 10\%SnGe & 0.816 \\
\hline
\end{tabular}

The band gap for crystalline germanium is $0.67 \mathrm{eV}$; the band gap for crystalline silicon is $1.1 \mathrm{eV}$. The band gaps for amorphous films tend to be higher than their crystalline counterparts due to Anderson localization and band edge state differences. The measured band gaps in this work for both amorphous sputtered germanium and PECVD deposited films are consistent with this phenomenon.

In UV/VIS absorption testing, the Germanium-Tin films showed band gap depression as compared to pure germanium similar to what was reported for crystalline alloys by Fang et al. Fang reported an upper limit for band gap suppression in germanium films can be achieved at $\sim 20 \% \operatorname{tin}^{[8]}$. More experiments are needed to determine the upper limits with this amorphous film process and verify band gap depression. More study would be beneficial to confirm this trend of band gap depression in amorphous germanium as a function of tin content. UV/VIS spectroscopy indicates band gap depression, but as will be discussed later IPCE data does not show appreciable increased absorption at longer wavelengths as would be expected with band gap depression. 


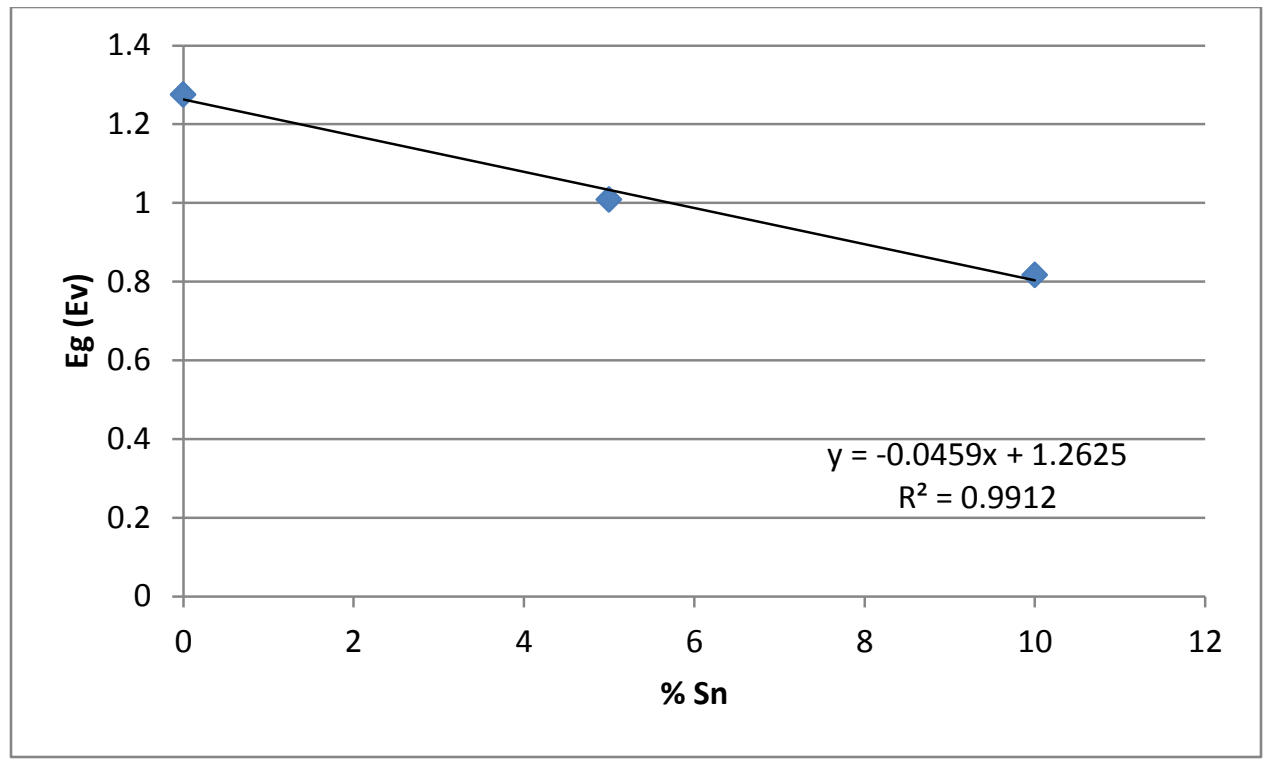

Figure 42: UV/VIS and Tauc plot band gap of GeSn as a function of $\mathrm{Sn} \%$

This band gap depression phenomenon can be used to tune the bad gap of the amorphous germanium material for specific purposes; this property can be useful in making amorphous multijunction cells or for making a material for detecting a specific wavelength as could be used in a laser detector. A very common eye safe laser system is the Nd:YAG laser with a wavelength of $1064 \mathrm{~nm}$; this would correspond to a material with a band gap of $1.16 \mathrm{eV}$ or lower to detect. Based on the measured band gap of $1.27 \mathrm{eV}$, amorphous germanium alone would not be a suitable material for detection with such laser systems, but tin doped germanium would meet the band gap requirements. Current materials used for commercial laser Nd:YAG detectors are typically crystalline germanium materials which can be very expensive; this device could substantially reduce the cost of production of such a detector. 


\subsection{SOLAR CELL AM 1.5 PERFORMANCE}

\subsubsection{Amorphous Silicon Devices}

\section{a. $\quad 5$ Minute Diffusion $900^{\circ} \mathrm{C}$ in RTP, No Annealing Before Doping}

Figure 43 shows the diode and IPCE performance of amorphous silicon cells that were doped using polyboron spin on film and thermal diffusion in the RTP at $900^{\circ} \mathrm{C}$.

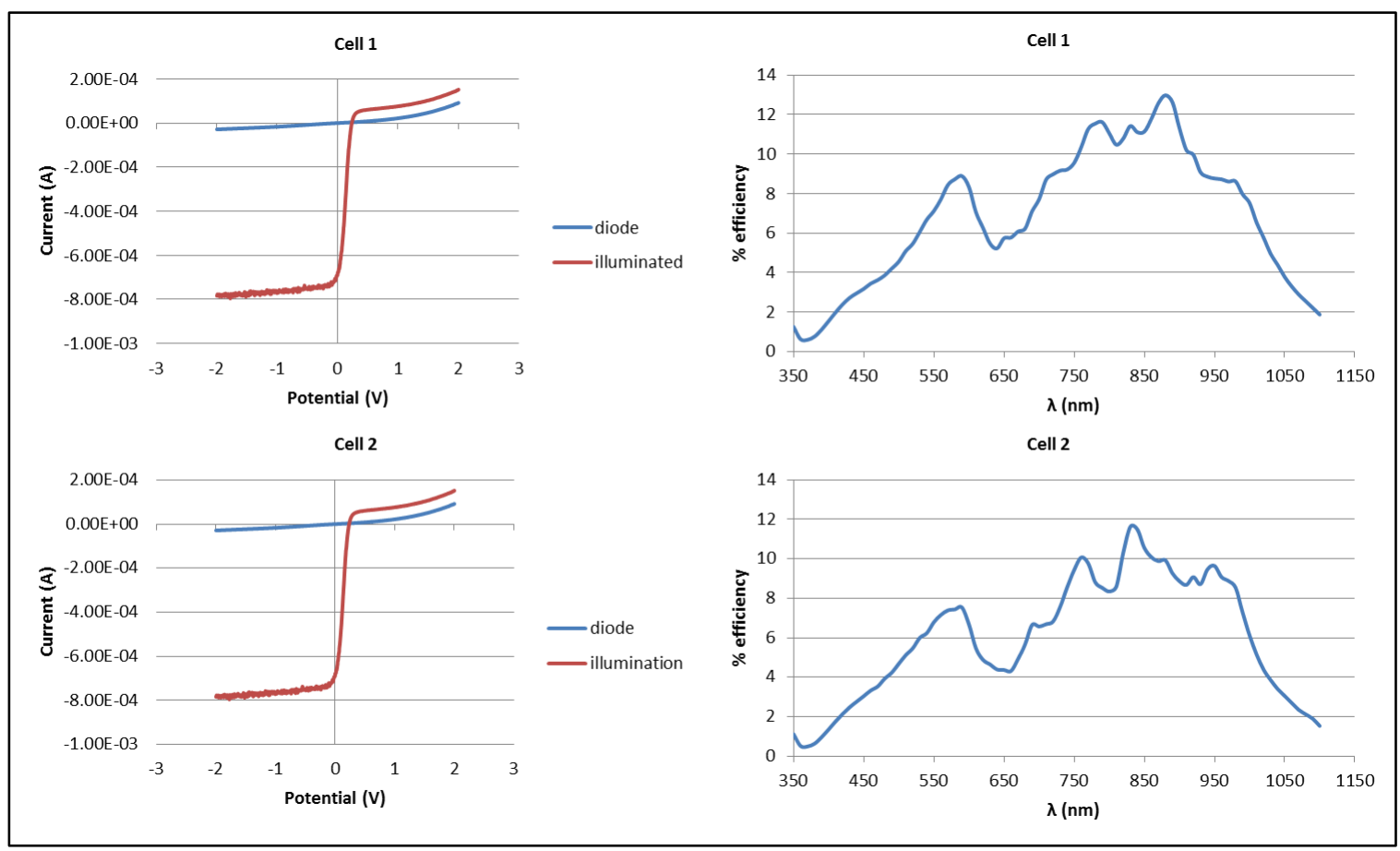

Figure 43: Amorphous silicon no anneal, 5 minute diffusion 900C RTP, IV and IPCE 
Table 4 and figure 44 show solar performance parameters and efficiency data of nonannealed planar amorphous silicon devices doped with polyboron film at $900^{\circ} \mathrm{C}$ in the RTP.

Table 4: SOLAR PERFORMANCE

NON-ANNEALED A.SI, 5 MIN

DIFFUSION

\begin{tabular}{|c|l|l|}
\hline & Cell 1 & Cell 2 \\
\hline Jsc (A/cm $\left.{ }^{2}\right)$ & 0.017 & 0.017 \\
\hline Voc (V) & 0.23448 & 0.23475 \\
\hline FF & 0.30604 & 0.30089 \\
\hline Pmax & $1.21 \mathrm{E}-03$ & $1.21 \mathrm{E}-03$ \\
$\left(\mathbf{W} / \mathbf{c m}^{2}\right)$ & & \\
\hline Pin (W/cm $)$ & 0.1 & 0.1 \\
\hline $\begin{array}{c}\text { Efficiency } \\
(\%)\end{array}$ & 1.215 & 1.215 \\
\hline
\end{tabular}

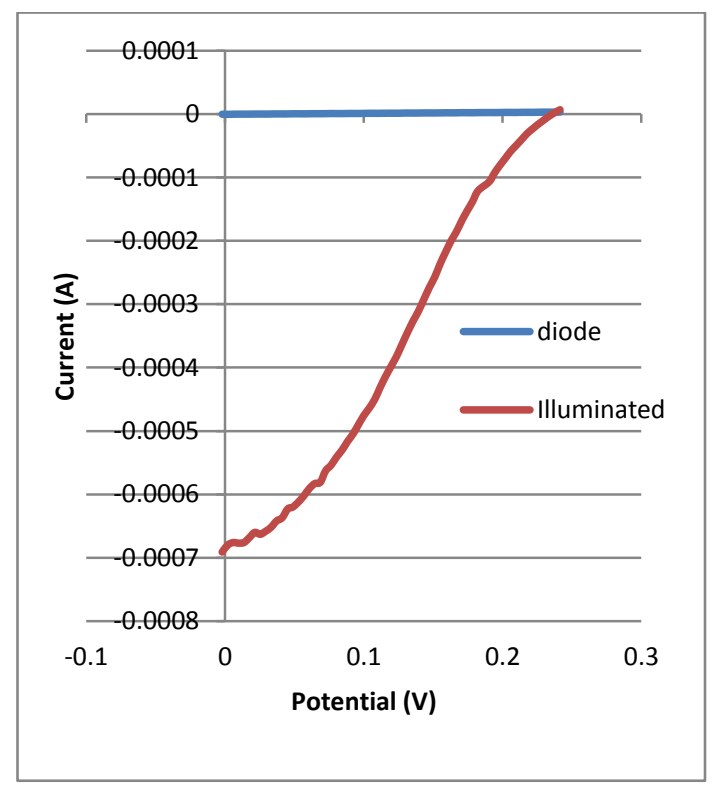

Figure 44: IV Curve displaying Isc and Voc for a.Si Cell 1

The amorphous silicon devices were fabricated on a silicon wafer as a proof of concept in order to prove that amorphous layers could be deposited and doped to form P$\mathrm{N}$ structures with some degree of photo activity. As discussed earlier in the background, doping of amorphous materials via thermal diffusion is extremely unpredictable because 
amorphous film diffusivities can vary greatly depending on deposition conditions and the films tend to anneal to polycrystalline during diffusion. The mobility of dopants through grain boundaries is several orders of magnitude higher than through the grains themselves. This leads to dopant spiking at the grain boundaries and unpredictable, irregular doping profiles. There were several variants of amorphous silicon cells made in order to test diffusion conditions and whether or not annealing before doping has any effect on the performance of the cell.

The 5 minute non-annealed cells showed efficiencies of $1.2 \%$ which is slightly lower than was expected. Early amorphous cells typically showed efficiencies of 4-5\%; it was expected that the cells would approach $3+\%$ efficiencies similar to the early variants developed in the 1970s by RCA. The doping process limitations are the most likely culprit in the low efficiencies of these cells. The open circuit voltage is low and the fill factor of the cells is rather low. Commercially available amorphous cells typically have a fill factor of 0.4-0.7 and an open circuit voltages of 0.33-0.55V. A lower open circuit voltage is indicative of probable lack of an intrinsic layer and poor doping. The lower fill factor is indicative of high defect densities ${ }^{[16]}$. Both conditions can likely be attributed to trying to perform thermal diffusion into an amorphous film followed by an oxidation and etching.

The polyboron film is boron suspended in a polymer material. When running polyboron diffusions, it is necessary to blanket the wafer in nitrogen and a low concentration of oxygen. The oxygen is necessary during the diffusion process in order to prevent the polymer in the polyboron film from forming carbon deposits that diffuse into the semiconductor devices. Diffusion in the presence of oxygen allows the carbon from 
the film to oxidize to carbon dioxide at the high temperatures in the oven and exit as an exhaust gas. The presence of oxygen can partially oxidize the amorphous silicon layer during this diffusion; removal of the boron film later, in fact, requires oxidation of the silicon. After diffusion, the wafer is etched then wet oxidized again in order to oxidize the silicon and form borosilicate glass which can then be easily etched off in BOE. This process sacrifices a bit of the amorphous film in order to remove the polyboron. Some of the doped layer is sacrificed in order to remove the film and expose silicon suitable for aluminum contact deposition.

b. $\quad 20$ Minute Diffusion $900^{\circ} \mathrm{C}$ in RTP, No Annealing Before Doping Figure 45 shows the IV performance and IPCE of non-annealed amorphous silicon cells doped with polyboron film and thermal diffusion for 20 minutes in the RTP; table 5 shows performance parameters for each device tested. 


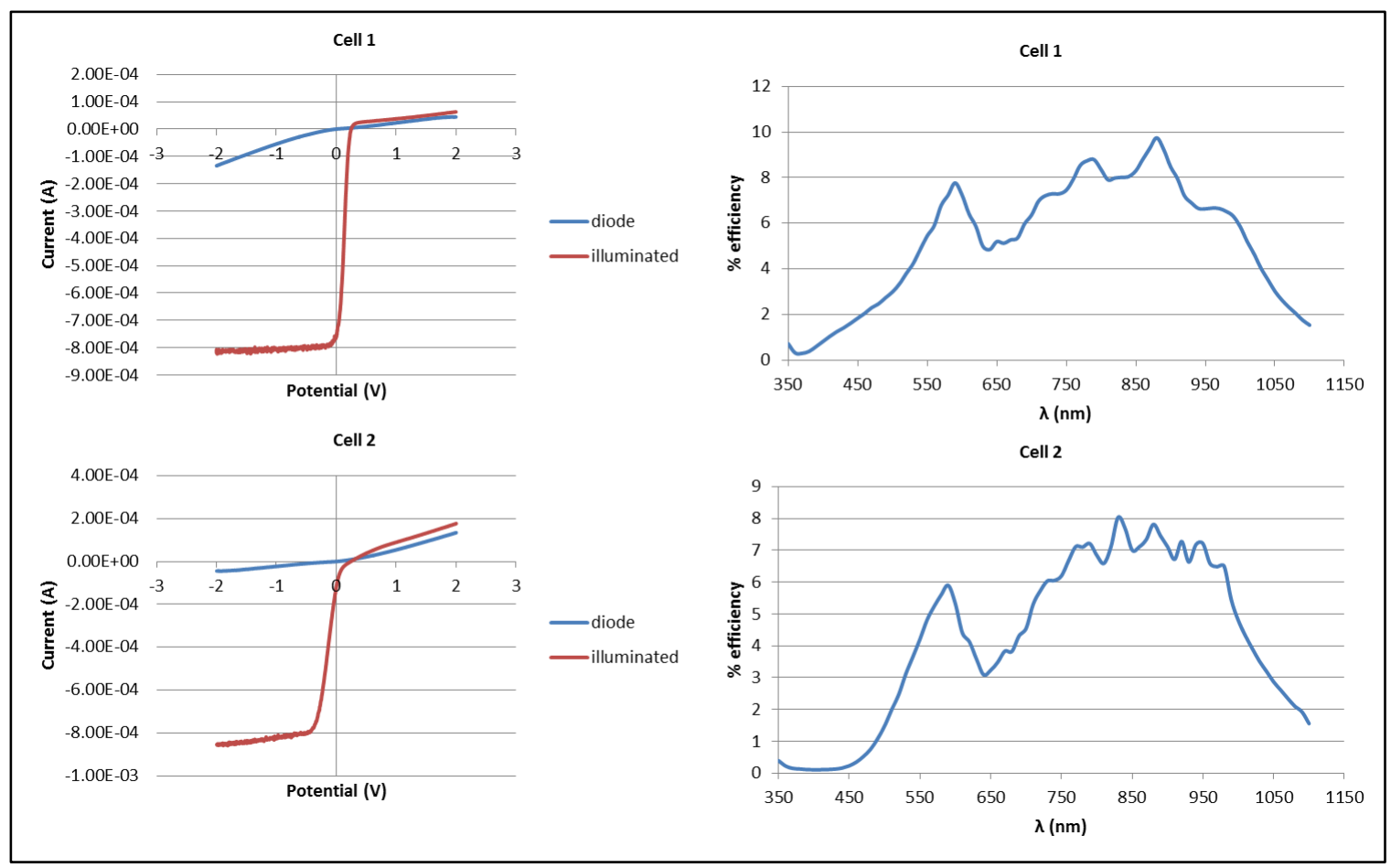

Figure 45: Amorphous silicon, non-annealed 20 minute diffusion in RTP IV and IPCE Table 5: SOLAR PERFORMANCE AMORPHOUS SILICON, NON-ANNEALED, 20 MIN DIFFUSION IN RTP

\begin{tabular}{|c|l|l|}
\hline & Cell 1 & Cell 2 \\
\hline Jsc (A/cm $\left.{ }^{\mathbf{2}}\right)$ & 0.019 & 0.015 \\
\hline Voc (V) & 0.22578 & 0.21773 \\
\hline FF & 0.31789 & 0.16686 \\
\hline Pmax (W/cm $)$ & $1.36 \mathrm{E}-03$ & $5.39 \mathrm{E}-04$ \\
\hline Pin (W/m $\left.\mathbf{~}^{\mathbf{2}}\right)$ & 0.1 & 0.1 \\
\hline Efficiency (\%) & 1.3636 & 0.5394 \\
\hline
\end{tabular}

The amorphous devices with a 20 minute diffusion without annealing before doping also showed some success in making functional solar cells but suffered from some of the same defect and doping problems as described previously. 


\section{c. Annealed 5 Minutes in RTP $900^{\circ} \mathrm{C}$ Before Doping, 5 Minute Diffusion in RTP}

Figures 45 and 46 show the IV and IPCE performance of amorphous silicon cells that were annealed for 5 minutes in the RTP. The cells were then doped using polyboron film and thermal diffusion for 5 minutes at $900^{\circ} \mathrm{C}$ in the RTP.

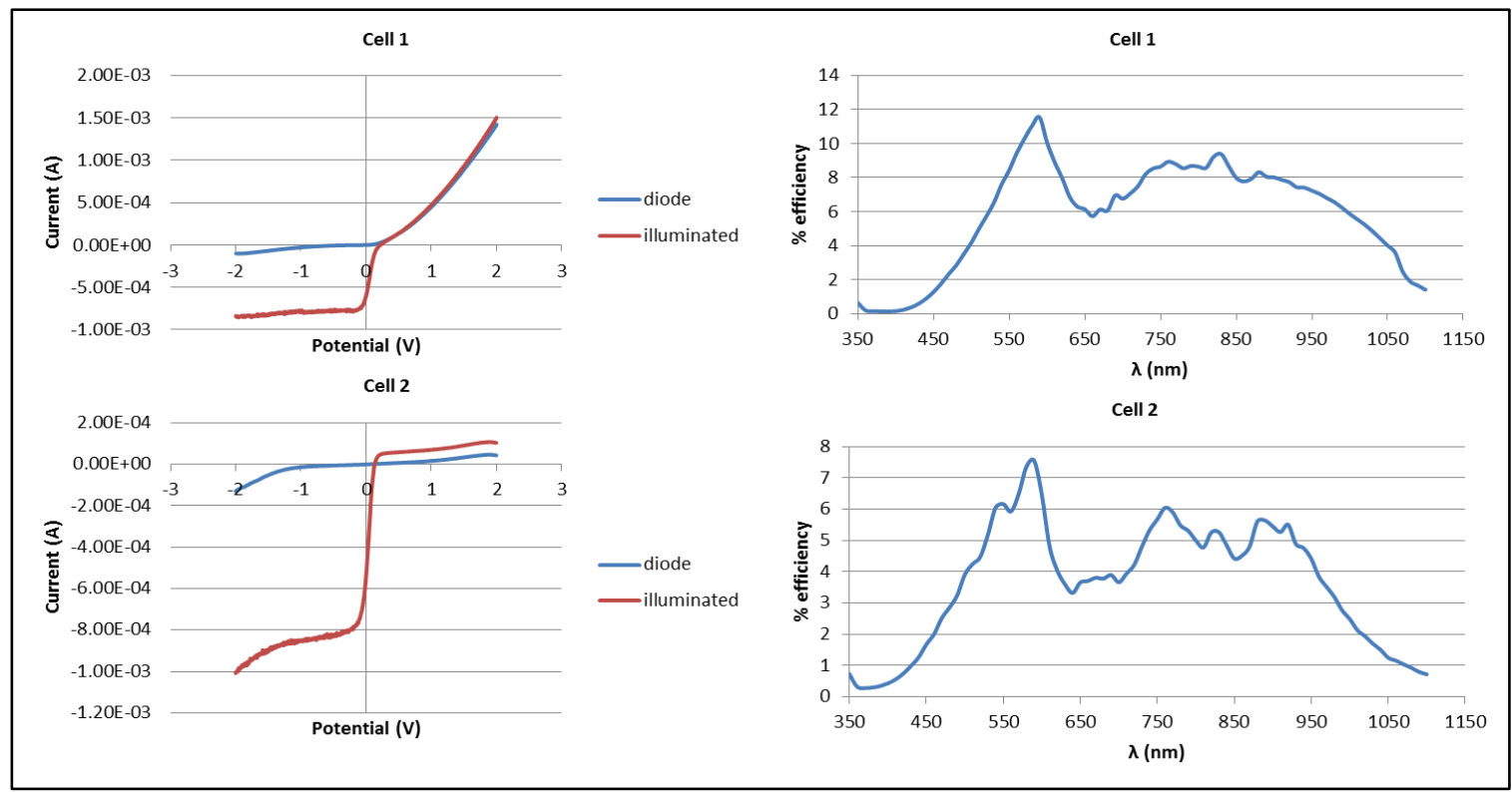

Figure 46: Amorphous silicon annealed 5 minute diffusion IV and IPCE cells 1 and 2

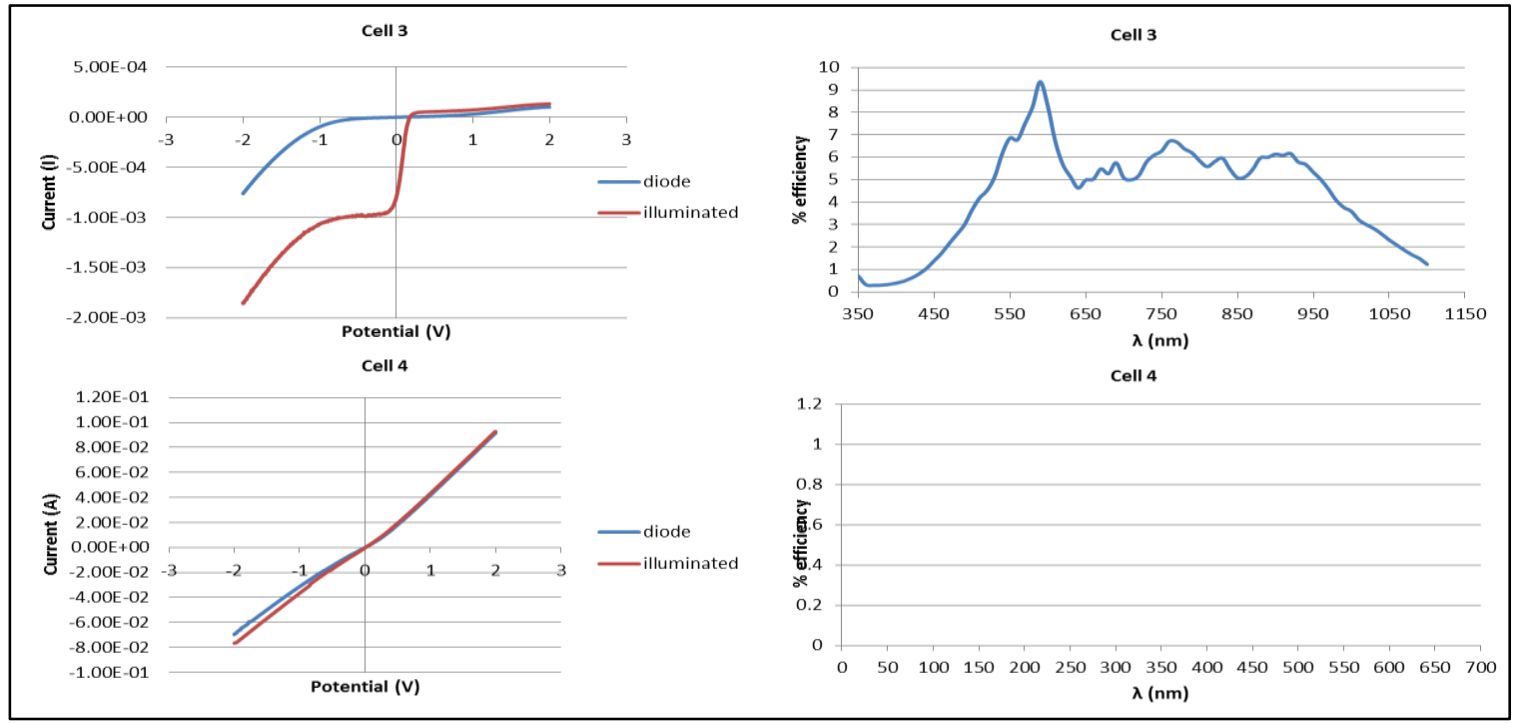

Figure 47: Amorphous silicon, 5min anneal in RTP before doping IV and IPCE, cells 3 and 4 
Table 6 shows the performance parameters for each device tested.

Table 6: SOLAR PERFORMANCE 5 MIN ANNEALED BEFORE DOPING, 5 MIN DIFFUSION IN RTP

\begin{tabular}{|c|l|l|l|l|}
\hline & Cell 1 & Cell 2 & Cell 3 & Avg \\
\hline Jsc (A/cm $)$ & 0.015 & 0.013 & 0.016 & 0.0147 \\
\hline Voc (V) & 0.217726 & 0.127525 & 0.16675 & 0.17067 \\
\hline FF & 0.16857 & 0.22509 & 0.31272 & 0.23546 \\
\hline Pmax (W/cm $\left.{ }^{2}\right)$ & 0.0005349 & .000382 & 0.0008202 & 0.00579 \\
\hline Pin (W/cm $\left.{ }^{2}\right)$ & 0.1 & 0.1 & 0.1 & 0.1 \\
\hline Efficiency (\%) & 0.539 & 0.38 & 0.82 & 0.58 \\
\hline
\end{tabular}

Annealing before doping showed a large decrease in efficiency for a five minute diffusion when compared to the previous five minute diffusion devices. The extremely short diffusion time was selected based on research by others indicating that the diffusivities in amorphous films is a few order of magnitudes faster than in crystalline materials $^{[17]}$. Using typical diffusion modeling equations with these increased diffusivity ranges indicated that the diffusion time needed to be less than 10 minutes to prevent diffusing all the way through the thin amorphous layer into the crystalline layer underneath. Annealing before doping processes leads to the amorphous film annealing to a polycrystalline film. As described earlier, diffusivities at grain boundaries are higher making dopant incorporating into the thin film unlikely. In the previous five minute devices, the starting film was amorphous, and while the diffusivity in the film is unpredictable, it is at least relatively uniform across the entire film. As the film anneals to 
polycrystalline, some of the dopants are likely incorporated into the crystals, leaving behind doped film.

In this device, the film had already crystallized before doping. The dopants likely spiked through the grain boundaries to the substrate below leaving behind a very unevenly doped film. The short diffusion time likely prevented much dopant from diffusing into the silicon crystals. This very unevenly doped film would not have a very high quality uniform P-N or P-I-N structure, and thus would explain the reduced performance as compared to the previous non-annealed devices with a five minute diffusion.

Cell number four is a good example of poor dopant incorporation into the device. The linear curve exhibited by Cell 4 is indicative of resistor behavior. Even if the dopant were to diffuse through the amorphous layer to the substrate below, a P-N structure should have still been established. If a P-N structure were established, the device should show diode behavior and only allow current passage on one direction. This device shows current passage in both directions as a linear function of the potential. The linear relationship is what would be expected from a conductive semiconductor film with only one dopant incorporated. The wafer is background doped n-type, and is conductive. The absence of diode behavior would be caused by the lack or boron doping. The doped amorphous layer may have been removed locally during oxidation and etching or the dopants did not incorporate into the film in that location on the wafer. 
d. Annealed 5 Minutes in RTP $900^{\circ} \mathrm{C}$ Before Doping, 20 Minute Diffusion $900^{\circ} \mathrm{C}$ in RTP

Figures 48 and 49 show IV and IPCE performance of amorphous silicon cells that were annealed five minutes in the RTP at $900^{\circ} \mathrm{C}$ before doping using polyboron film and thermal diffusion in the RTP at $900^{\circ} \mathrm{C}$ for 20 minutes.

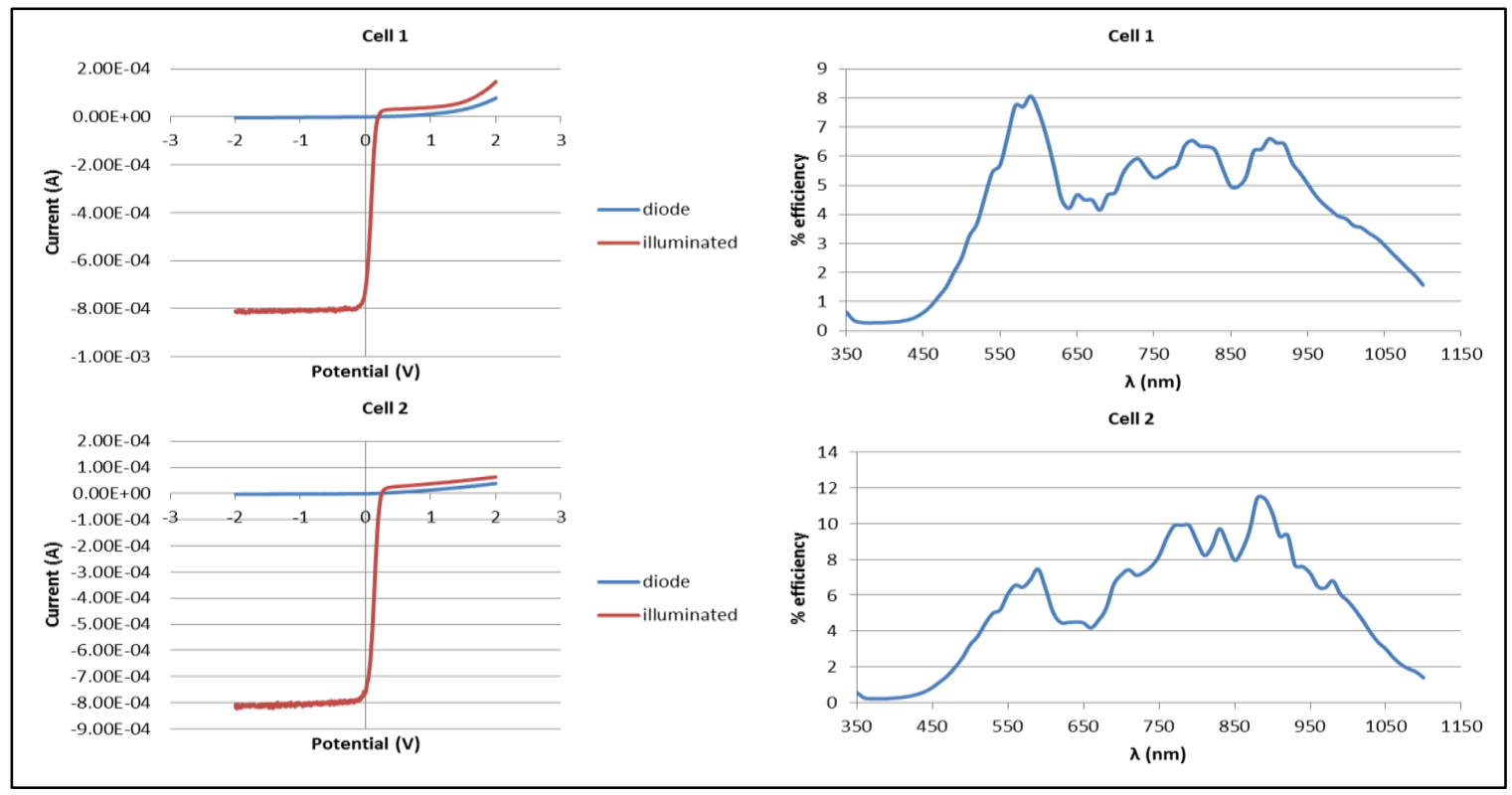

Figure 48: Annealed a.Si 20 minute diffusion 900C Cells 1\&2 IV and IPCE

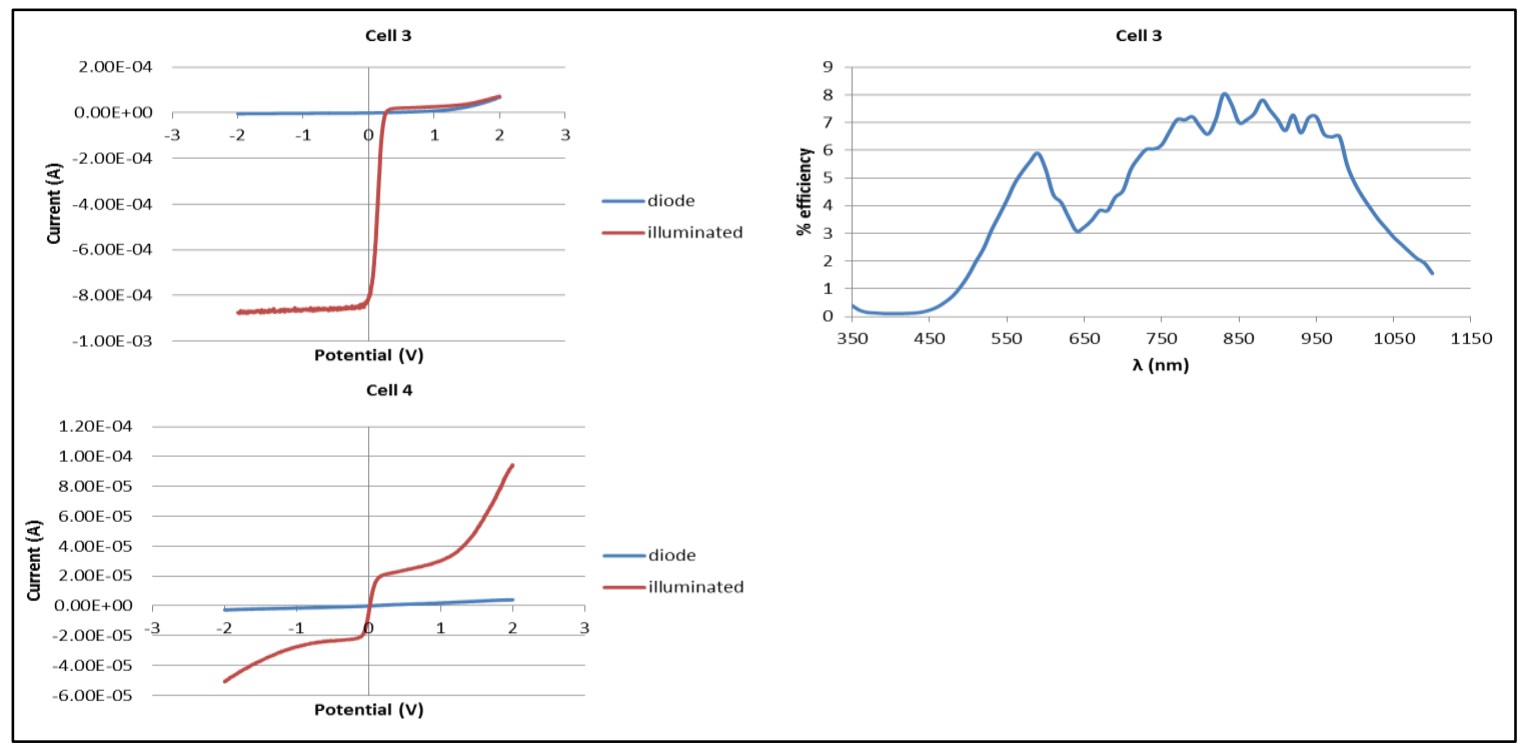

Figure 49: Annealed a.Si 20 minute diffusion 900C Cells 3\&4 IV and IPCE 
Table 7 shows measured performance parameters of all of the tested devices.

Table 7: SOLAR CELL PERFORMANCE ANNEALED A.SI 20 MIN DIFFUSION

\begin{tabular}{|c|l|l|l|l|}
\hline & Cell 1 & Cell 2 & Cell 3 & Avg \\
\hline Jsc (A/cm $\left.{ }^{2}\right)$ & 0.018 & 0.019 & 0.020 & 0.019 \\
\hline Voc (V) & 0.1982 & 0.2453 & 0.2650 & 0.2361 \\
\hline FF & 0.2292 & 0.2926 & 0.2791 & 0.2669 \\
\hline Pmax (W/cm $\left.{ }^{2}\right)$ & $8.09 \mathrm{E}-04$ & $1.36 \mathrm{e}-03$ & $1.49 \mathrm{E}-03$ & $1.21 \mathrm{E}-03$ \\
\hline Pin (W/cm $\left.\mathbf{c m}^{2}\right)$ & 0.1 & 0.1 & 0.1 & 0.1 \\
\hline Efficiency (\%) & 0.8087 & 1.3637 & 1.4907 & 1.2197 \\
\hline
\end{tabular}

These cells showed improvement over the 5 minute diffusion on annealed cells.

The longer diffusion time into these annealed films would allow for the dopant to run through the grain boundaries to substrate and essentially stop vertical diffusion. The diffusivity in amorphous films is much higher; the dopant likely diffused back and laterally into the polycrystalline film on the substrate a little better than the five minute diffusion, explaining the improved performance. Cell performance is still very unpredictable using this fabrication process. 


\subsubsection{Germanium Based Devices}

Figures 50 and 51 show the IV and IPCE characteristics of germanium based devices.

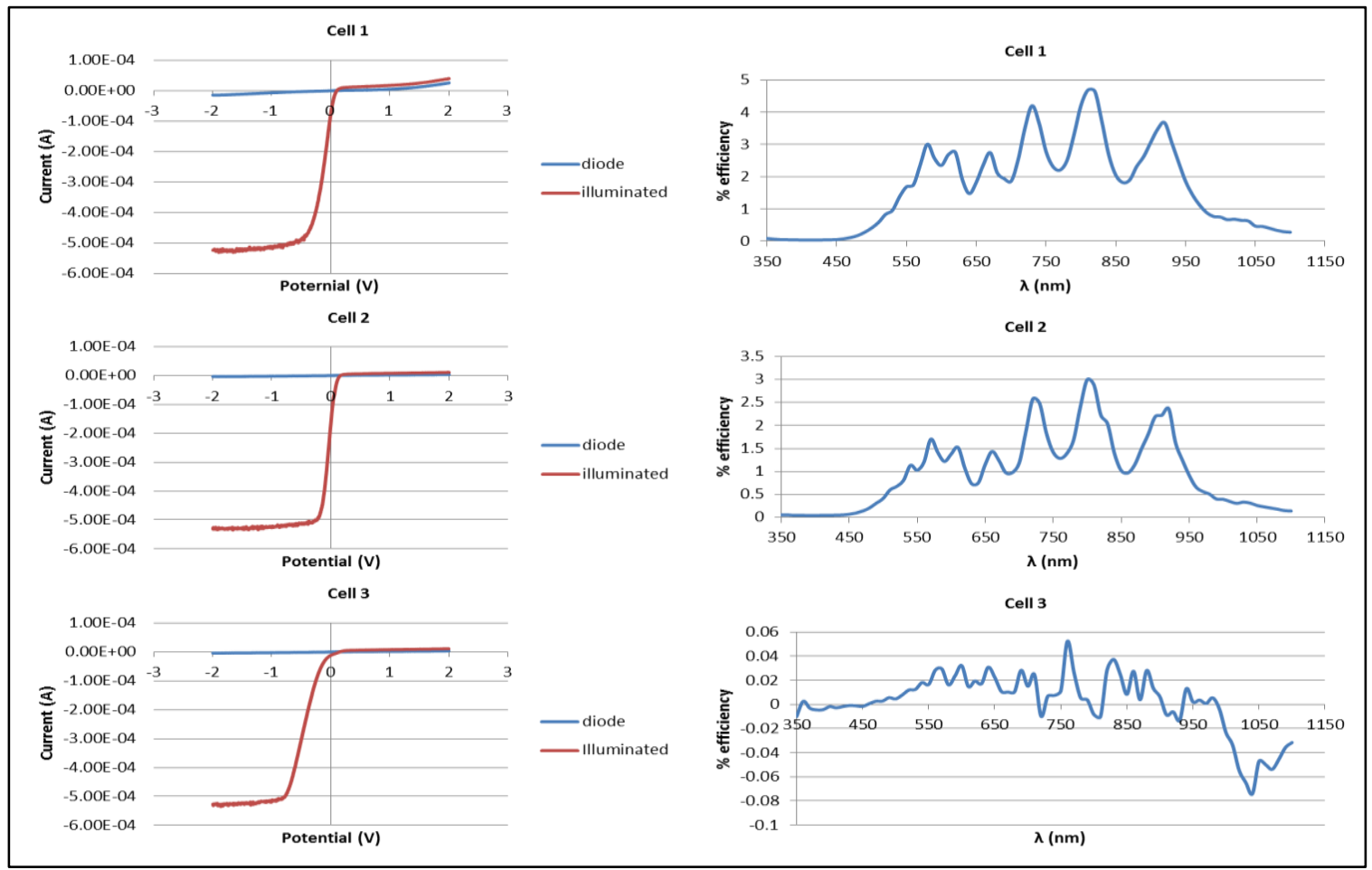

Figure 50: Germanium Cells 1-3 IV and IPCE 


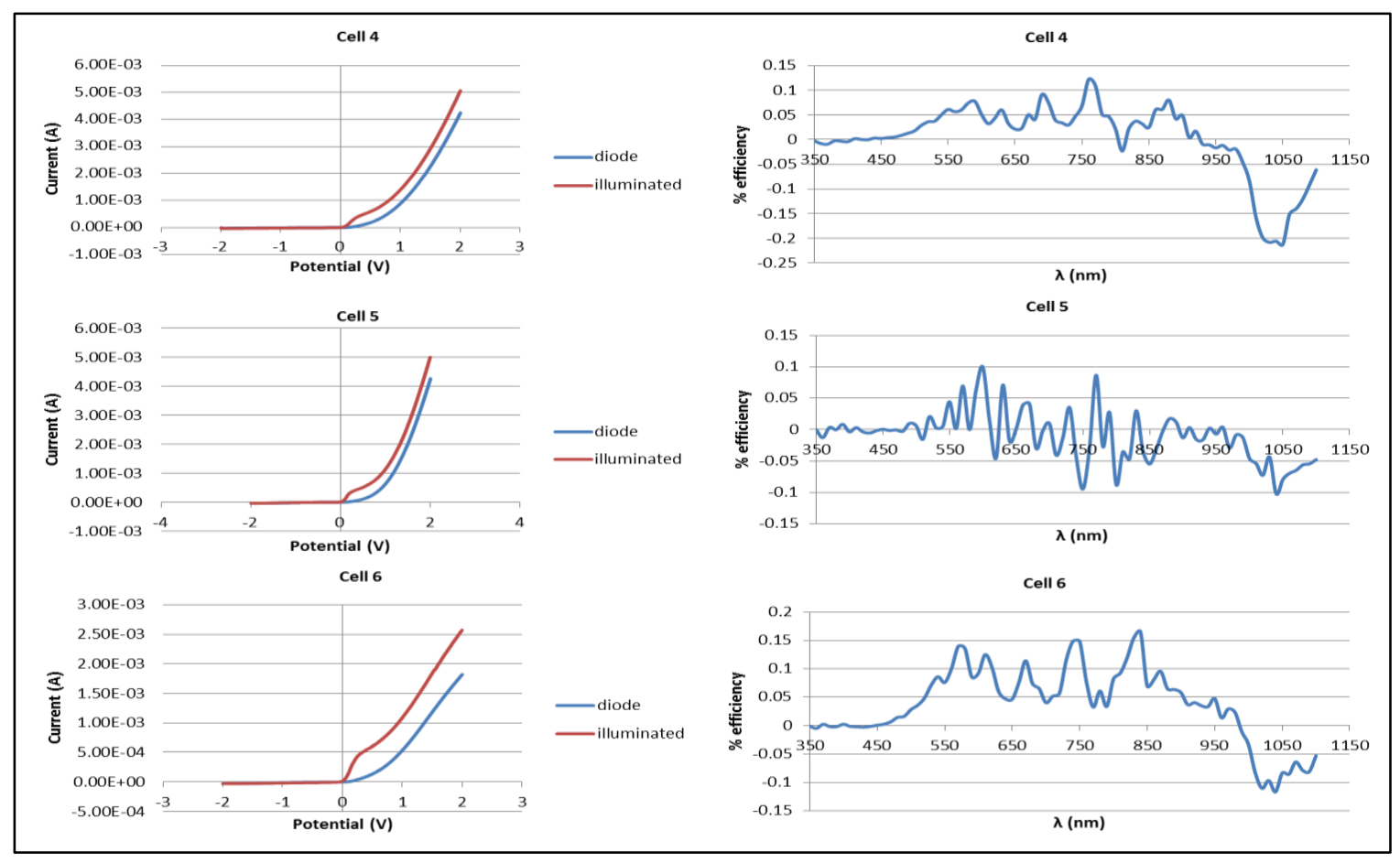

Figure 51: Germanium cells 4-6 IV and IPCE

Table 8 shows the measured performance parameters for all of the tested germanium devices.

Table 8: SOLAR PERFORMANCE GERMANIUM CELLS

\begin{tabular}{|l|l|l|l|l|l|l|}
\hline & Cell 1 & Cell 2 & Cell 3 & Cell 4 & Cell 5 & Cell 6 \\
\hline $\begin{array}{l}\text { Jsc } \\
\left(\mathbf{A} / \mathbf{c m}^{2}\right)\end{array}$ & 0.000298 & 0.001978 & 0 & 0 & 0 & 0 \\
\hline $\begin{array}{l}\text { Voc } \\
(\text { V) }\end{array}$ & 0.15225 & 0.11575 & 0 & 0 & 0 & 0 \\
\hline $\begin{array}{l}\text { Pmax } \\
\left(\mathbf{W} / \mathbf{c m}^{2}\right)\end{array}$ & $1.19 \mathrm{E}-5$ & $3.32 \mathrm{E}-5$ & 0 & 0 & 0 & 0 \\
\hline FF & 0.26474 & 0.15983 & 0 & 0 & 0 & 0 \\
\hline $\begin{array}{l}\text { Pin } \\
\left(\mathbf{W} / \mathbf{c m}^{2}\right)\end{array}$ & 0.1 & 0.1 & 0.1 & 0.1 & 0.1 & 0.1 \\
\hline Eff (\%) & 0.0119 & 0.03248 & 0 & 0 & 0 & 0 \\
\hline
\end{tabular}


Only two out of six germanium only devices showed any degree of photo conversion and the conversion efficiency is small enough to be considered negligible. The devices showed all showed diode behavior which is an indication that doping did take place and P-N structures at the very least were established. The devices showed increases in current under illumination and bias indicating that there was some absorption taking place but the cell is not showing conversion due to recombination losses. The recombination losses are likely due to low conductivity in the film and inability to achieve carrier separation. The current is higher under bias and illumination than under bias alone, indicating that the bias is necessary in order to achieve carrier separation under illumination.

The germanium films were sputtered with argon and were not passivated. The lack of germanium passivation would lead to a decrease in germanium film conductivity; this could explain the lack of solar conversion in the presence of decent diode behavior. Other germanium deposition techniques like CVD use germane gas and the reaction is similar to the silane reaction described previously. As the germane decomposes in the CVD reaction, hydrogen gas is released and desorbed. Additional hydrogen can also be introduced in the CVD process to help passivate the film. All cells discussed thus far fabricated using these techniques have exhibited low efficiency. The lack of passivation and reduction in conductivity in conjunction with the relatively low conversions and power generation by these cells would explain the lack of photo conversion.

Another possible consideration is trace metal contamination from the PVD-75. The PVD is also used to sputter materials like gold that have well documented tendencies to create trap states which degrade semiconductor performance. A high vacuum is used 
during sputtering processes but the shields and shutters near the target and the substrate have deposits of various materials on them that can be potentially dislodged during sputtering processes. Flaking of material from the substrate shutter area above the targets was frequently found before and after runs. All precautions were taken to attempt to remove loose materials and clean the chamber before sputtering.

The TCE differences of germanium and silicon coupled with high temperature processing in thermal diffusion likely played a role in reduced efficiency. The wafer showed stress in the upper amorphous silicon layer after diffusion with portions of the film delaminating. The delamination would lead to a loss of adhesion and conductivity between films.

The measured band gap for amorphous germanium is $1.27 \mathrm{eV}$; this is lower than the measured gap for the amorphous silicon $(1.64 \mathrm{eV})$. The lower band gap should have led to a higher conversion efficiency than silicon devices.by absorbing over more of the incoming spectrum. Due to the smaller band gap higher conversion efficiency in the longer wavelength range was expected to be seen from these devices in the IPCE when compared to the silicon only devices. The TCE differences of germanium and silicon coupled with high temperature processing in thermal diffusion likely played a role in reduced efficiency. The wafer showed stress in the upper amorphous silicon layer after diffusion with portions of the film delaminating. The delamination would lead to a loss of adhesion and conductivity between films. The germanium films were sputtered with argon and were not passivated. The Lesker PVD-75 only has two plasma gas options: argon and oxygen. Argon only was used to deposit the film as an oxygen plasma would have deposited insulating oxide layers. The lack of germanium passivation would lead to 
a decrease in germanium film conductance; this could explain the lack of solar conversion in the presence of descent diode behavior. Other deposition techniques like CVD use germane gas and the reaction is similar to the silane reaction described previously. Additional hydrogen can also be introduced in the CVD process to help passivate the film. The lack of passivation and reduction in conductance in conjunction with the relatively low conversions and power generation by these cells would explain the lack of photo conversion.

The Cells showed higher current under illumination, suggesting that some absorption is taking place, but charge carriers are not being separated and extracted. The lack of conversion seems to stem from the lack of an open circuit voltage.

Attempts were made to anneal germanium films under forming gas $\left(\mathrm{N}_{2}, \mathrm{H}_{2}\right)$ $550^{\circ} \mathrm{C}$ and $600^{\circ} \mathrm{C}$ in a quartz tube furnace dedicated for annealing processes. The aim was to passivate the films, improve film conductivity, and improve overall germanium cell efficiencies. In annealing, the germanium films sublimated, which was highly unexpected. The films were annealed far below the melting point of the solid and under such conditions the vapor pressure of germanium should have been extremely low and the film should not have sublimated. There is a sublimation reaction that takes place between germanium and germanium dioxide forming germanium monoxide at temperatures above $550^{\circ} \mathrm{C}^{[18]}$. This reaction was actually suggested to be used in the IC industry in the 1970's to remove native oxide layers under vacuum conditions rather than wet etching processes. The wafers were briefly etched in HF prior to going into the oven to remove native oxide layers and the ovens were blanketed with forming gas. The films sublimated from the bottom up, meaning that the film closest to the bottom of the oven 
was sublimating first. The tube furnace ends are open and even though the oven was blanketed in forming gas there is some backflow of atmospheric air into the ovens. $\mathrm{N}_{2}$ is still inert at $550^{\circ} \mathrm{C}$ and the reaction would produce germanium nitride, a solid, if reaction with nitrogen were the culprit. The nature of the sublimation suggests backflow of atmospheric air because a cooler gas entering from the open ended oven cap would flow along the oven floor while the hot forming gas flowed over top, forming almost an inversion layer. The presence of oxygen in the furnace led to dry oxidation conditions and provided a constant flux of oxygen for the oxidation of germanium followed by the sublimation reaction. The presence of oxygen during annealing processes in the tube furnaces with silicon has never been a problem in the past because thin oxide layers formed on crystalline silicon would be removed during etching in most fabrication sequences and there is no similar sublimation reaction with silicon. 


\subsubsection{5\% SnGe Based Devices}

Figures 52 and 53 show the IV and IPCE performance of $5 \%$ SnGe based devices.

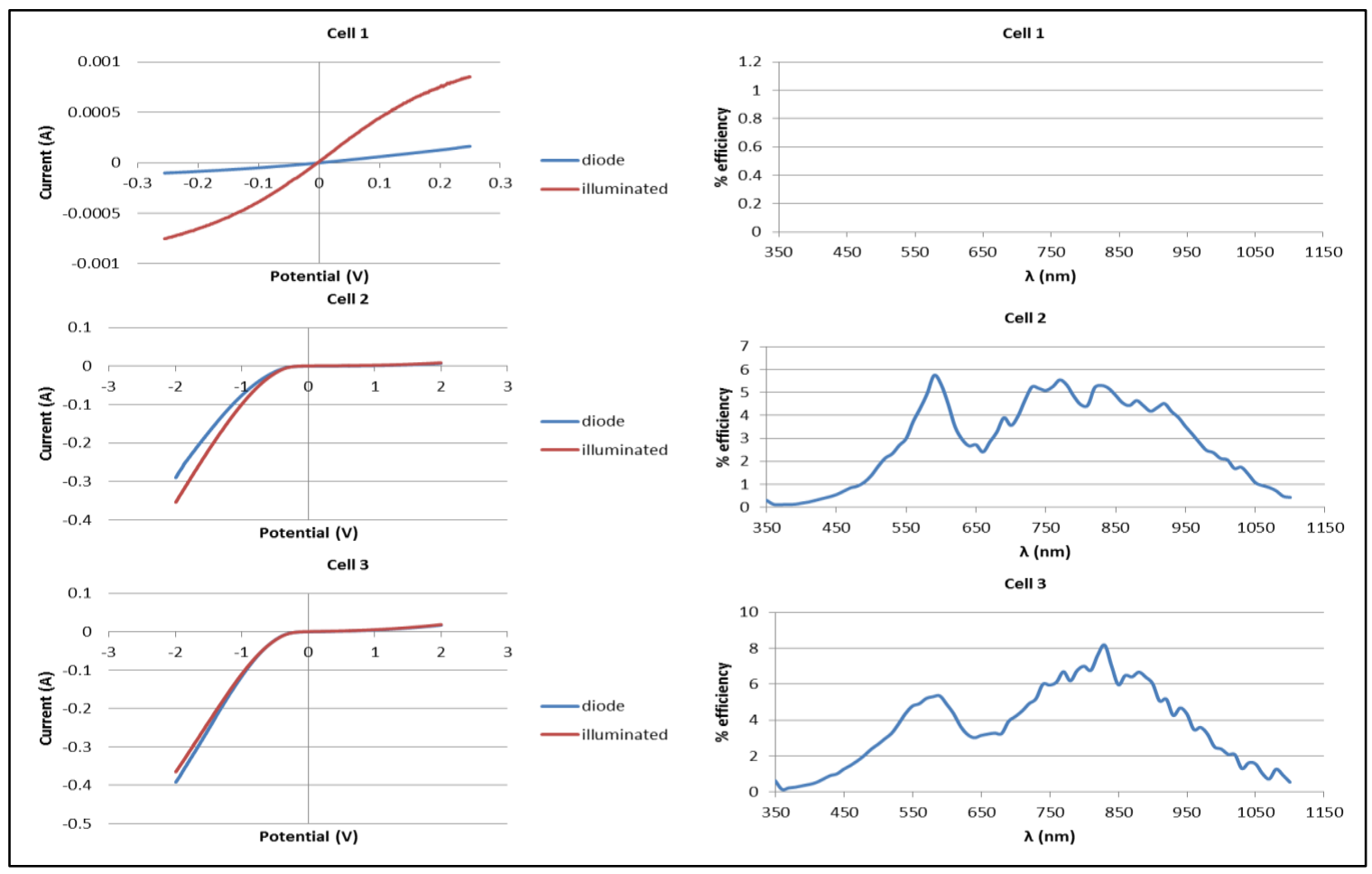

Figure 52: 5\% SnGe Cells 1-3 IV and IPCE

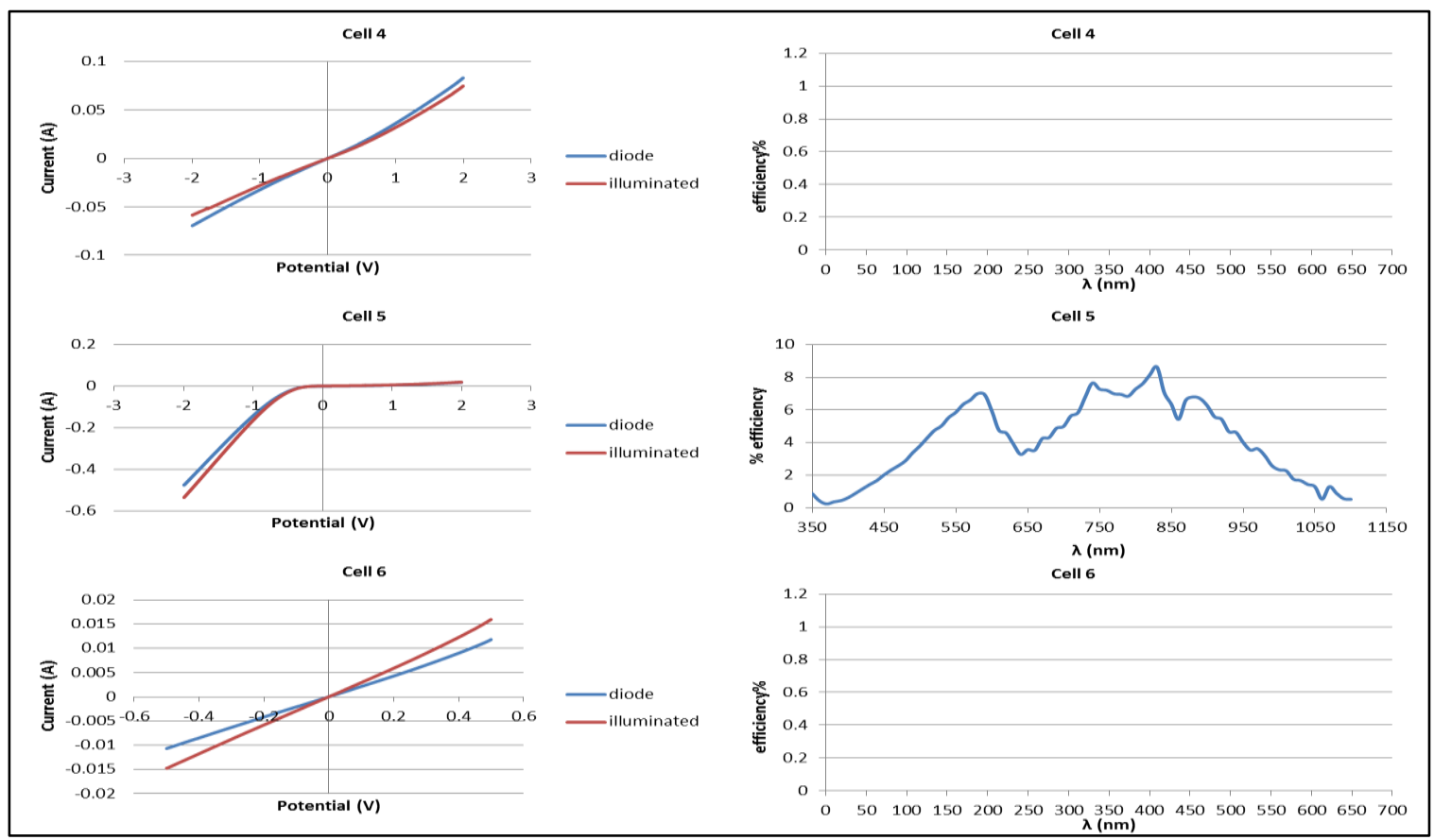

Figure 53: 5\% SnGe Cells 4-6 IV and IPCE 
Table 9 shows the measured performance parameters for all tested 5\% SnGe based devices.

Table 9: SOLAR PERFORMANCE 5\%SNGECELLS

\begin{tabular}{|l|l|l|l|l|l|l|}
\hline & Cell 1 & Cell 2 & Cell 3 & Cell 4 & Cell 5 & Cell 6 \\
\hline $\begin{array}{l}\text { Jsc } \\
\left(\mathbf{A} / \mathbf{c m}^{2}\right)\end{array}$ & 0 & 0.018 & 0.015 & 0 & 0.020 & 0 \\
\hline Voc (V) & 0 & 0.0908 & 0.1105 & 0 & 0.1172 & 0 \\
\hline $\begin{array}{l}\text { Pmax } \\
\left(\mathbf{W} / \mathbf{c m}^{2}\right)\end{array}$ & 0 & $6.07 \mathrm{E}-04$ & $5.23 \mathrm{E}-04$ & 0 & $7.50 \mathrm{E}-04$ & 0 \\
\hline FF & 0 & 0.3701 & 0.2973 & 0 & 0.3213 & 0 \\
\hline $\begin{array}{l}\text { Pin } \\
\left(\mathbf{W} / \mathbf{c m}^{2}\right)\end{array}$ & 0.1 & 0.1 & 0.1 & 0.1 & 0.1 & 0.1 \\
\hline Eff $(\%)$ & 0 & 0.6070 & 0.5234 & 0 & 0.7499 & 0 \\
\hline
\end{tabular}

Only three out of 6 tested devices showed photo conversion. The three devices that did not show conversion exhibited resistor behavior, indicating the lack of a P-N junction. The lack of a P-N junction suggests that doping inclusion in the upper amorphous films is suspect. The three devices that did function showed higher efficiency when compared to germanium only films, suggesting that including tin does have an effect on the overall efficiency. UV/VIS spectroscopy intimated band gap depression with the inclusion of tin in the germanium film. As previously discussed, lower band gap materials can absorb more of the spectrum because more of the spectrum is above the band gap energy. This would also suggest that the cells fabricated with this material should show conversion onset sooner and higher absorption in the longer wavelength region of the IPCE. When compared to germanium only devices, both of these phenomena are observed; the results are consistent with band gap depression. However tin is a conductor as well and incorporation of a conductor into the germanium film may 
be increasing the overall conductivity of the film rather than depressing the band gap.

IPCE .data is not displaying effects to be expected with band gap depression 


\subsection{4 $10 \%$ SnGe Based Devices}

Figures 54 and 55 show the IV and IPCE performance of $10 \%$ SnGe based devices.

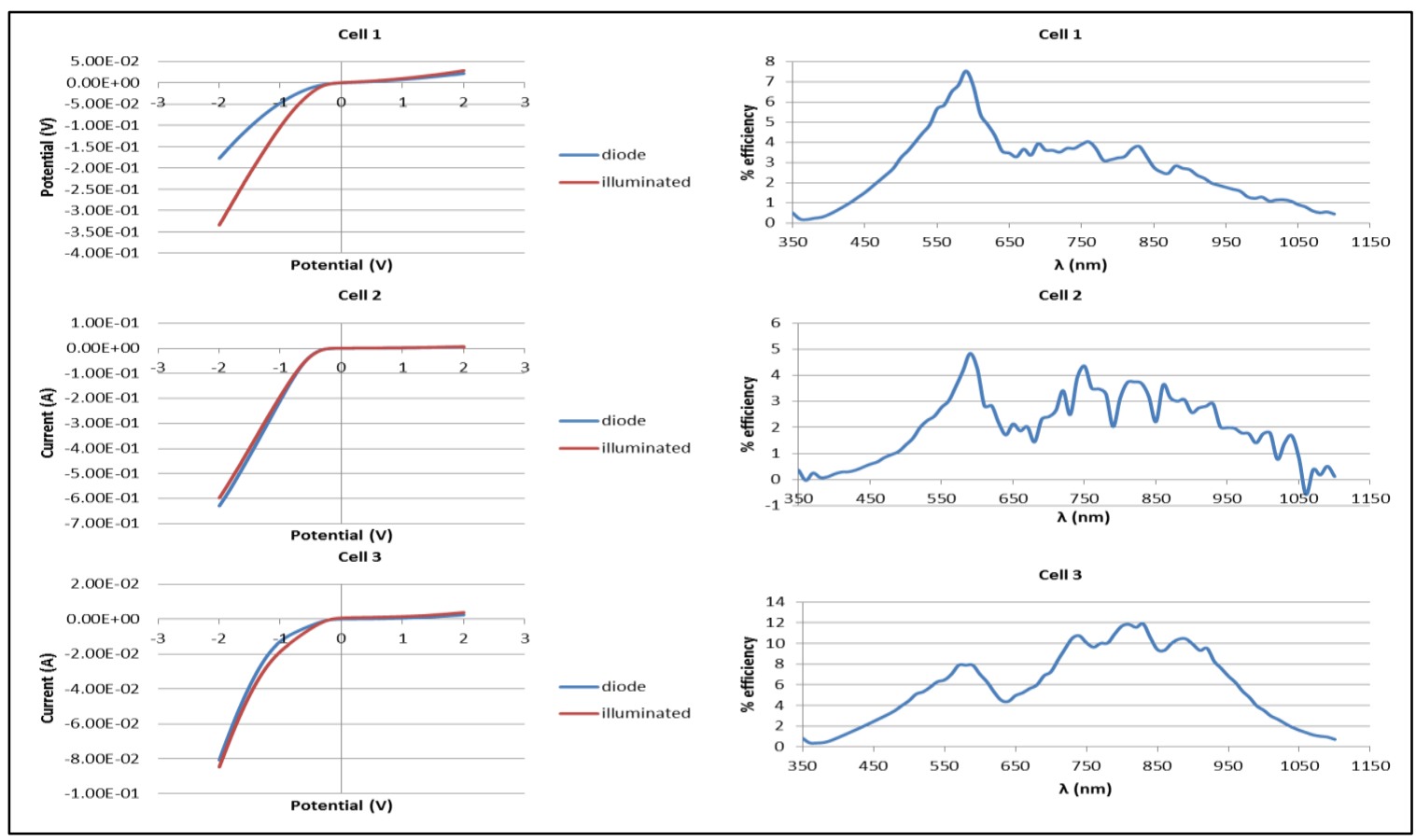

Figure 54: 10\% SnGe cells 1-3 IV and IPCE

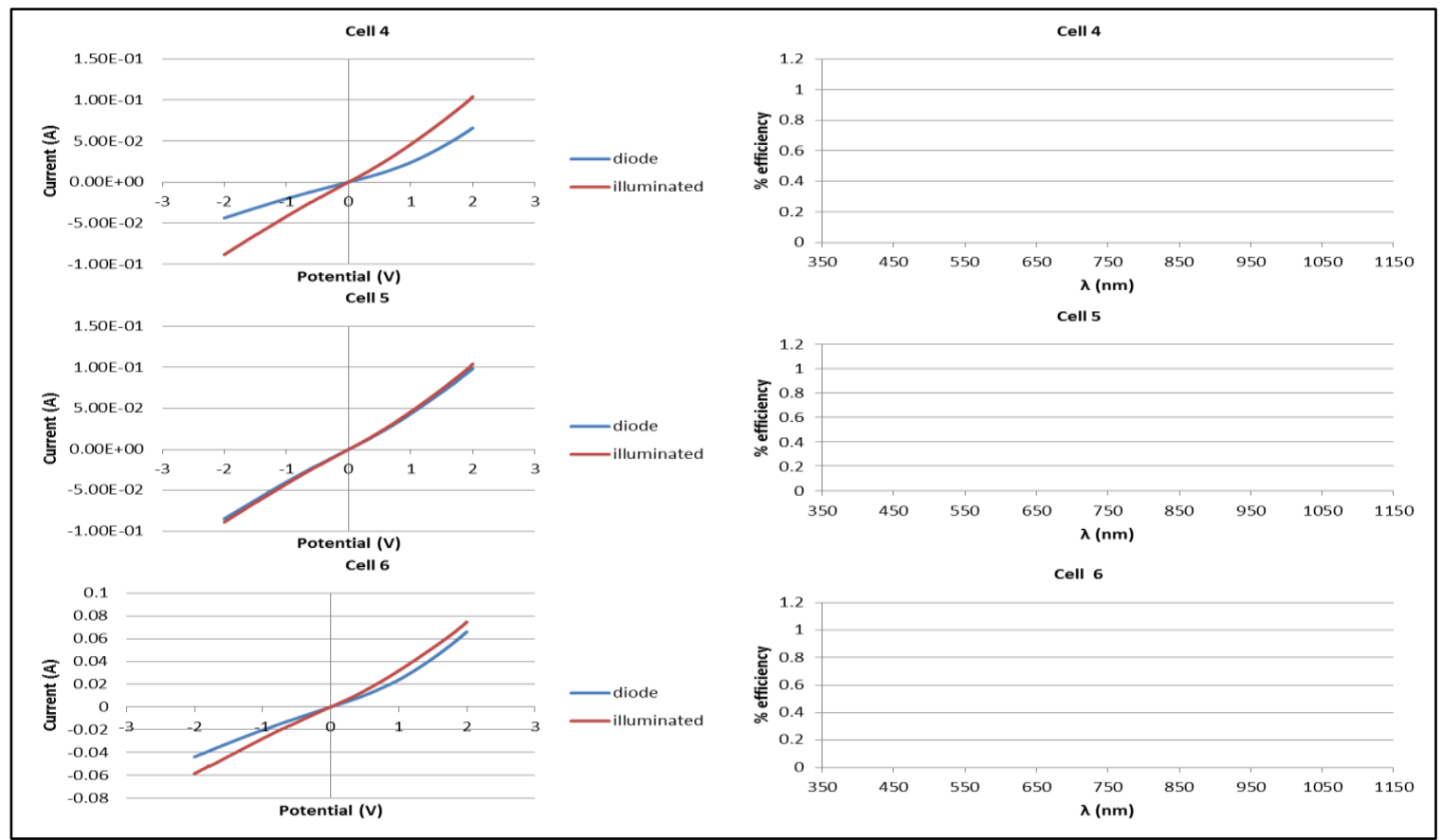

Figure 55: 10\% SnGe cells 4-6 IV and IPCE 
Table 10 shows the measured performance parameters for all $10 \%$ SnGe based devices. Figure 56 shows a typical portion of an IV plot used to determine key performance parameters.

Table 10: 10\% SNGE SOLAR PERFORMANCE

\begin{tabular}{|l|l|l|l|l|l|l|}
\hline & Cell 1 & Cell 2 & Cell 3 & Cell 4 & Cell 5 & Cell 6 \\
\hline $\begin{array}{l}\text { Jsc } \\
\left(\mathbf{A} / \mathbf{c m}^{2}\right)\end{array}$ & 0.016 & 0.016 & 0.016 & 0 & 0 & 0 \\
\hline $\begin{array}{l}\text { Voc } \\
(\mathbf{V})\end{array}$ & 0.0530 & 0.1315 & 0.1513 & 0 & 0 & 0 \\
\hline $\begin{array}{l}\text { Pmax } \\
\left(\mathbf{W} / \mathbf{c m}^{2}\right)\end{array}$ & $2.83 \mathrm{E}-04$ & $7.65 \mathrm{E}-04$ & $8.39 \mathrm{E}-04$ & 0 & 0 & 0 \\
\hline FF & 0.3379 & 0.3580 & 0.3531 & 0 & 0 & 0 \\
\hline $\begin{array}{l}\text { Pin } \\
\left(\mathbf{W} / \mathbf{c m}^{2}\right)\end{array}$ & 0.1 & 0.1 & 0.1 & 0.1 & 0.1 & 0.1 \\
\hline Eff (\%) & 0.2828 & 0.7655 & 0.8386 & 0 & 0 & 0 \\
\hline
\end{tabular}

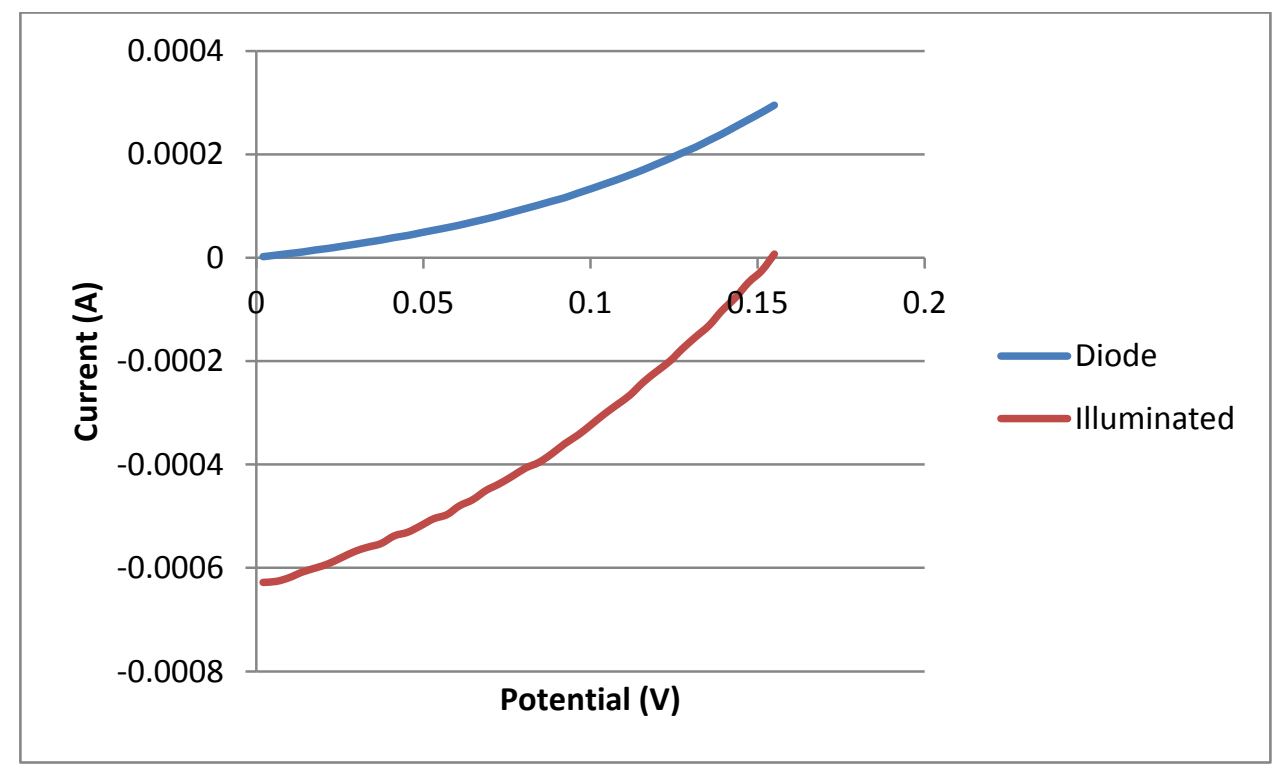

Figure 56: IV Curve for Cell 3 displaying open circuit voltage and short circuit current density

The $10 \%$ tin germanium suffered from the same shortcomings described for the other devices. Cells four, five and six exhibited resistor behavior and showed no diode 
behavior. The working $10 \%$ devices showed slight overall efficiency improvements and improved conversion at longer wavelengths when compared to the $5 \% \mathrm{Sn}$ and Ge only devices. These are both consistent with band gap depression as a function of tin content. The other consideration is that tin, as a conductor may also be improving the overall conductivity of the films with increasing content, improving carrier separation. This would alleviate some of the problems due to lack of passivation.

The IPCE averages of best two devices of each material configuration were plotted in Figure 57.

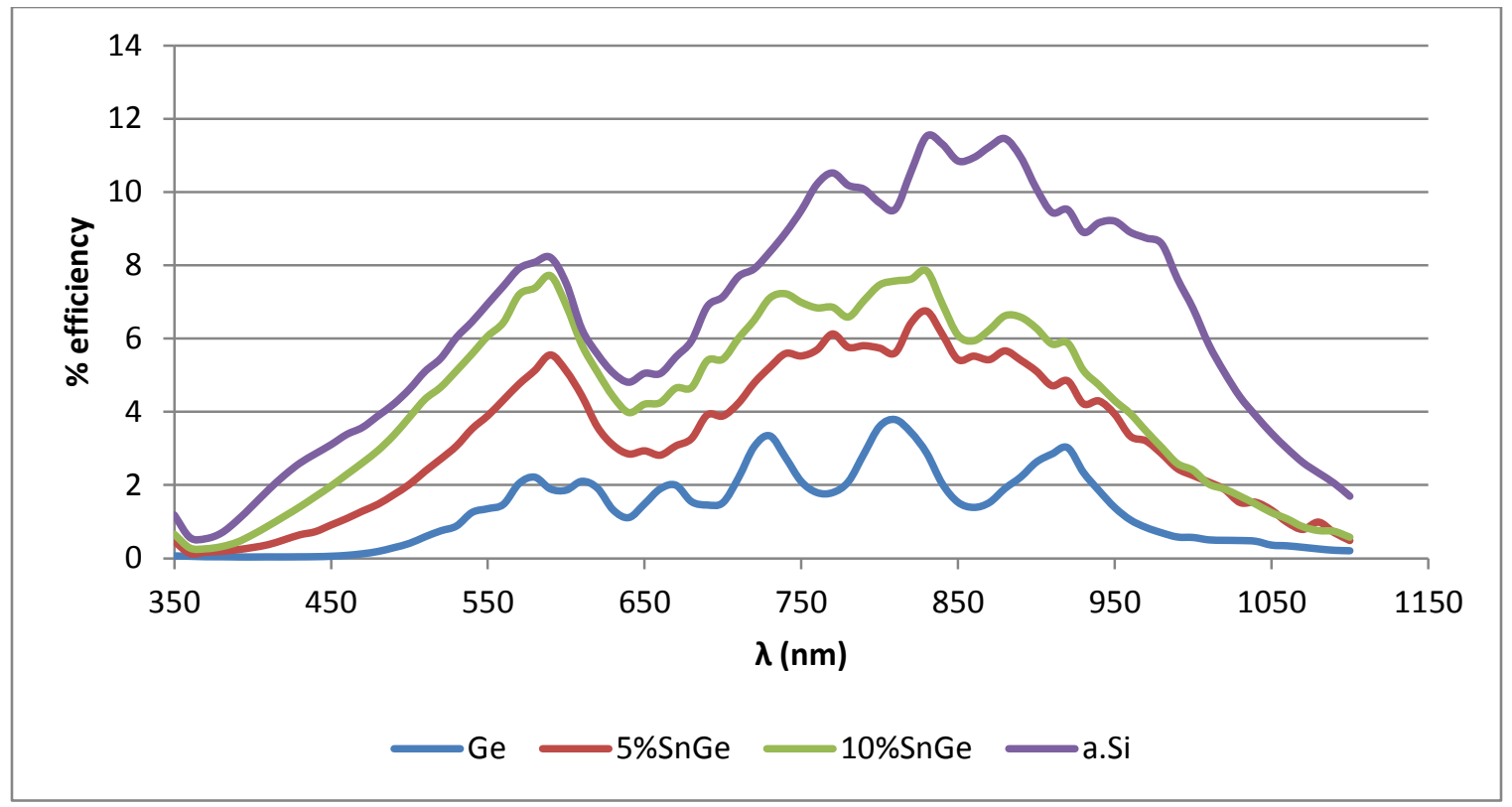

Figure 57: Average IPCE of best 2 function devices made with each material

Figure 57 shows that with increasing tin content, conversion efficiency of the germanium devices increases. The germanium devices do not approach the conversion efficiencies of the amorphous silicon devices and do not show onset of high absorption at longer wavelengths as would be expected with band gap depression. The IPCE of the thin 
films begins to closely resemble that of silicon. From the appearance and general shape of the graph of the IPCE data, the question arises whether the performance of the thin germanium film is giving rise to the solar conversion or if the doped silicon substrate or doped amorphous silicon cap is contributing to the conversion. This would be best investigated through use of a different substrate material like a copper foil. 


\section{CONCLUSIONS}

Several variants of amorphous thin film solar cells were fabricated using several different materials in order to evaluate and compare material performance. Devices fabricated from amorphous silicon showed the highest conversion efficiencies.

UV/VIS spectroscopy showed band gap depression as a function of increasing tin content however this phenomenon was not clearly supported by IPCE data. It would be expected with band gap depression that the onset of high absorption would begin at longer wavelengths. With increasing tin content, germanium cell overall efficiency and incident photon conversion efficiency did show an increase. The low degree of increase in incident photon conversion efficiency at long wavelengths brings into question whether or not this is band gap depression, or if film conductivity is increasing due to the inclusion of tin, if there is a decrease in light scattering with tin addition, or if delamination decreases with tin addition. The germanium films are not passivated and increased absorption over the spectrum as compared to silicon may be being muted by reduced conductivity in germanium films as compared to passivated amorphous silicon.

The doping processes available in the cleanroom are currently limited to thermal diffusion of spin on dopants. This process works well for crystalline materials but is not a good match for doping amorphous materials. The diffusivity of amorphous material can vary greatly depending on the film characteristics and deposition conditions. Amorphous films tend to anneal to polycrystalline materials during high temperature processing. Dopant diffusivity at grain boundaries in amorphous materials is several orders of magnitude higher at grain boundaries than through the grains themselves leading to 
dopant spiking at the grain boundaries and unpredictable diffusion. The removal process for polyboron requires a high temperature wet oxidation. This wet oxidation process followed by a BOE etch to remove borosilicate glass may be removing most of the doped amorphous layers and playing a role in the difficulty in establishing P-N diode performance, difficulty in charge carrier separation, and lower than expected open circuit voltages.

TCE disparities of more than $10 \%$ coupled with high temperature processing leads to film stress. Film stress can become critical leading to delamination, rendering devices unusable. Ion implantation in amorphous films in heterogeneous structures is not a viable process either. Ion implantation requires high temperature annealing to activate the dopants by incorporating them in the lattice. In theory, this could work with the short range lattices in amorphous films, however in heterogeneous structures with significant TCE differences, this would lead to high film stress and possible delamination. Using doped wafers as sputtering targets was not permitted by cleanroom staff due to concerns over potential equipment damage. Amorphous films are generally doped using in-situ processes, which eliminates most of the problems with thermal diffusion. The Oxford PECVD is intended to be capable of in-situ doping; this function will be enabled in the very near future, eliminating many of the doping problems observed in this work. 


\section{RECOMMENDATIONS}

To further this study, it would be beneficial to sputter germanium in the presence of hydrogen as well as argon in order to attempt to passivate the germanium film, improving amorphous film conductivity. CVD processes for comparable depositions deposit passivated films. Another option for passivation is to eliminate oxygen in the annealing furnace with higher forming gas flows and installation of the end cap port caps. Currently there are two ports on the end caps which are open to the atmosphere. The oven end caps are designed to have caps over the end ports as seen in the trash furnace in the cleanroom. There is also a flared side port for connecting to exhaust lines which could be used to eliminate the backflow of atmospheric air into the oven. Annealing is in the RTP under such conditions is possible but should not be performed due to the potential germanium sublimation and potential contamination of the RTP chamber.

In-situ doping should be used to dope the films used in these structures. Using insitu doping would limit some of the film stress problems in the heterogeneous structure observed after high temperature processing.

More absorption data for band gap evaluation would be beneficial in characterizing the observed band gap depression as a function of tin content. More UV/VIS spectroscopy data coupled with better quality germanium films would allow for a more direct comparison between amorphous germanium devices and amorphous silicon when looking for efficiency improvements. Passivating the germanium layers would also allow for more direct performance comparison to PECVD silicon layers. 


\section{APPENDIX 1}

\section{TAUC PLOT SAMPLE CALCULATION FOR AMORPHOUS BAND GAPS BASED ON UV/VIS SPECTROSCOPY}

AMORPHOUS GERMANIUM UV/VIS ABSORPTION DATA AND BAND GAP CALCULATION

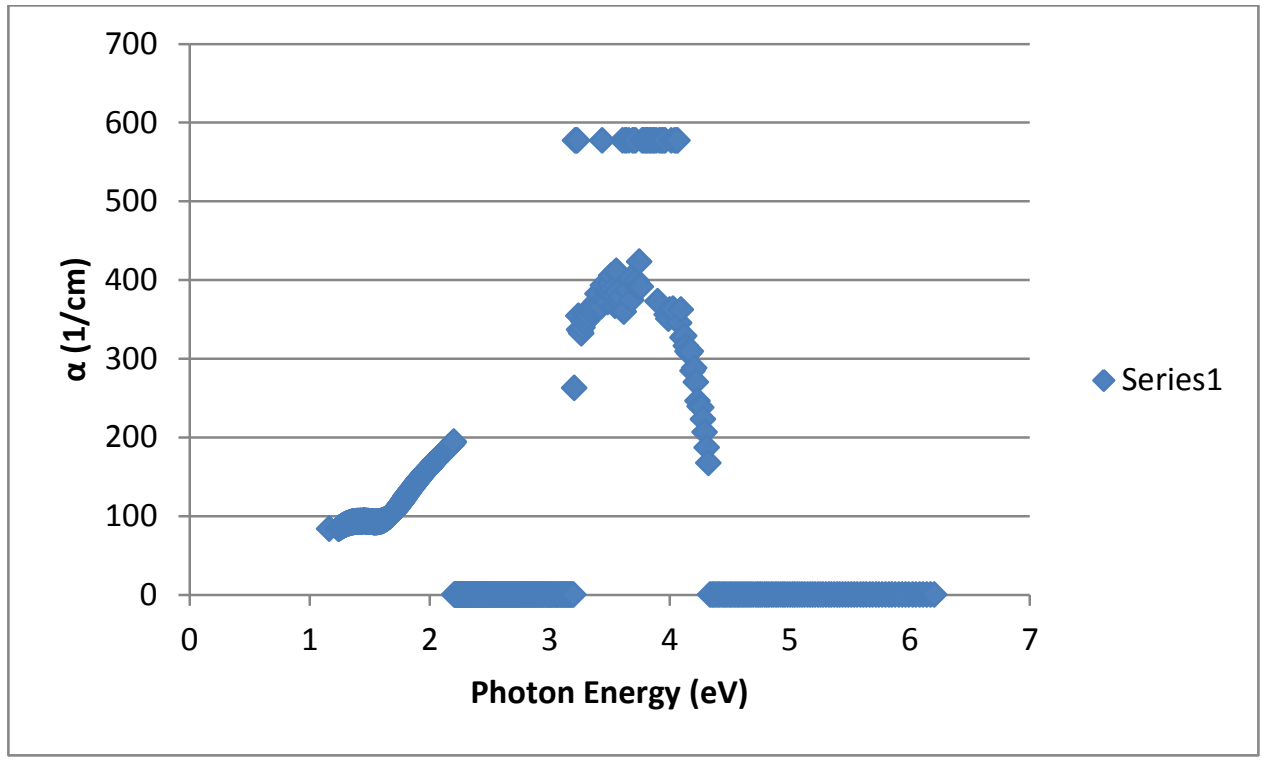

Figure 58: Tauc Plot absorbance coefficient vs photon energy

Linear portion from 1.71-1.98eV pulled out from above curve and fitted to a linear trendline to ensure good fit and $\mathrm{R}^{2}$ 


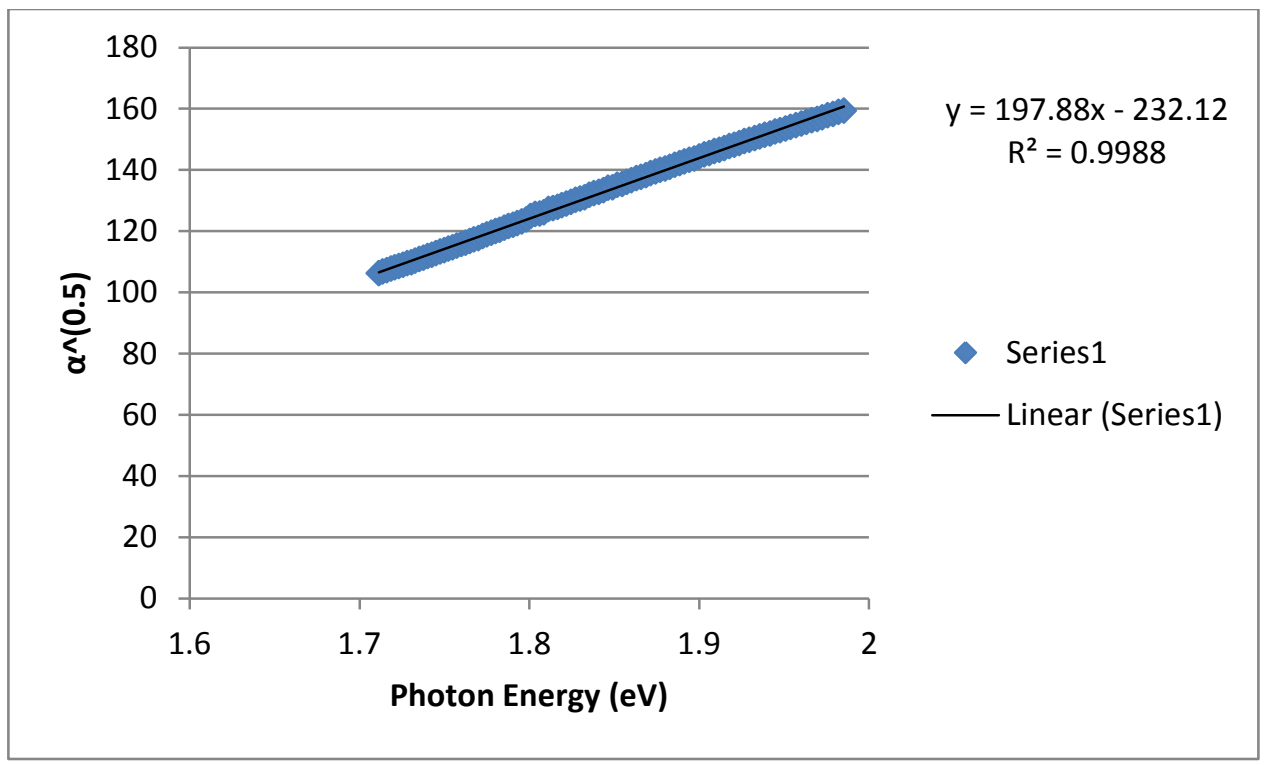

Figure 59: Tauc Plot square root of absorbance coefficient vs photon energy

Corresponding incident photon energy vs alpha times planck's constant raised to the one half

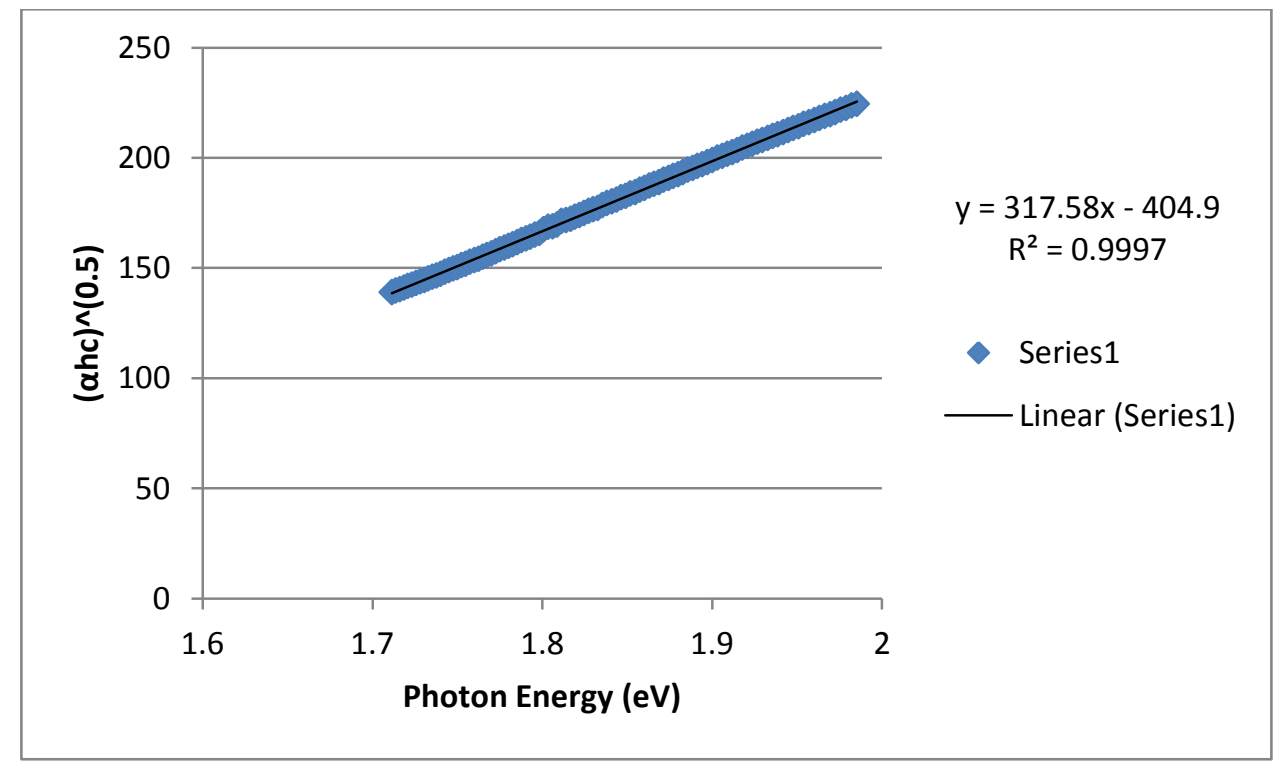

Figure 60: Final Tauc plot graph used for band gap determination

$\mathrm{Eg}=$ intercept/slope

\section{Eg $\quad 1.275 \mathrm{eV}$}




\section{Constants}

\begin{tabular}{|l|r|l|}
\hline $\mathrm{h}$ & $4.14 \mathrm{E}-15$ & $\mathrm{ev} / \mathrm{s}$ \\
\hline $\mathrm{c}$ & $3 \mathrm{E}+17$ & $\mathrm{~nm} / \mathrm{s}$ \\
\hline $\mathrm{h}^{*} \mathrm{c}$ & $1.24 \mathrm{E}+03$ & \\
\hline $\begin{array}{l}\text { Film } \\
\text { thickness }\end{array}$ & 0.00003 & $\mathrm{~cm}$ \\
\hline
\end{tabular}




\section{APPENDIX 2}

\section{SOLAR PERFORMANCE SAMPLE CALCULATIONS}

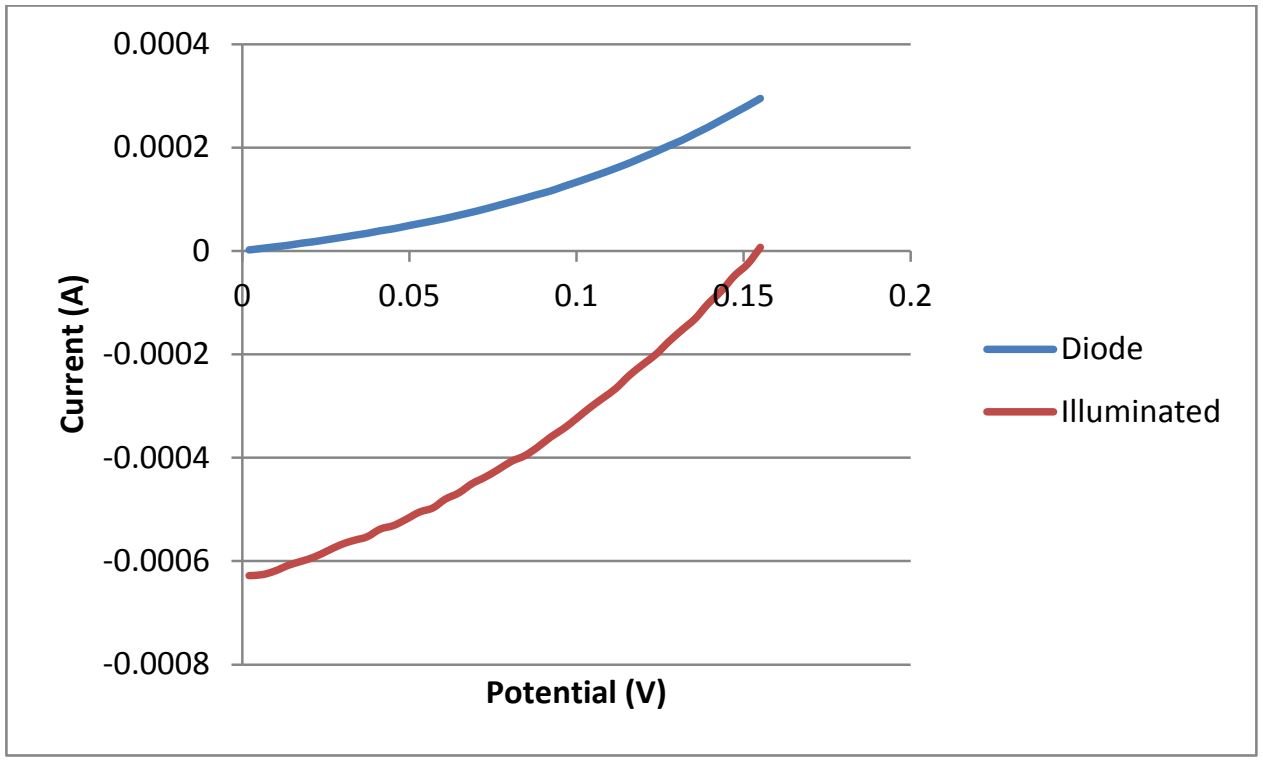

\begin{tabular}{|l|r|l|}
\hline Jsc & 0.016 & $\mathrm{~A} / \mathrm{cm}^{\wedge} 2$ \\
\hline Voc & 0.151274 & \\
\hline Pmax & 0.000839 & $\mathrm{~W} / \mathrm{cm}^{\wedge} 2$ \\
\hline FF & 0.353102 & \\
\hline Pin & 0.1 & $\mathrm{~W} / \mathrm{m}^{\wedge} 2$ \\
\hline Eff. & 0.838617 & $\%$ \\
\hline
\end{tabular}

The short circuit current density is the measured current when the cell is unbiased divided by the area of the cell, in this case $0.04 \mathrm{~cm}^{2}$.

$$
J_{s c}=\frac{I_{s c}}{\text { cell area }}=\frac{0.000628 \mathrm{~A}}{0.04 \mathrm{~cm}^{2}}=0.0157 \frac{\mathrm{A}}{\mathrm{cm}^{2}}
$$

The open circuit voltage is the voltage at which current equals zero, in this case it is $0.15724 \mathrm{~V}$.

Power is calculated by multiplying the short circuit current density by the corresponding voltage.

$$
P=J_{S C} * V
$$


Power max is determined by using the max function in excel to find the maximum from the power column. In this case, the Power max is $0.000839 \mathrm{~W} / \mathrm{cm}^{2}$.

Fill Factor is calculated by dividing $\mathrm{P}_{\max }$ by $\mathrm{V}_{\mathrm{oc}}$ and $\mathrm{J}_{\mathrm{sc}}$

$$
F F=\frac{P_{\text {max }}}{V_{o c} J_{s c}}=\frac{0.000839 \frac{w}{\mathrm{~cm}^{2}}}{(0.15724 V)\left(0.0157 \frac{\mathrm{A}}{\mathrm{cm}^{2}}\right)}=0.353102 \text { (unitless) }
$$

Overall efficiency is determined as the ratio of power in vs the power generated and can be calculated in two ways

$$
E f f \%=\frac{\text { insolative power in }}{\text { max power generated }}=\frac{0.1 \frac{W}{\mathrm{~cm}^{2}}}{0.00839} *(100 \%)=0.839 \%
$$

Or the other method

$$
E f f \%=\frac{F F * V_{o c} * J_{S c}}{\text { insolative power in }}=\frac{(0.35102) *(0.15744 \mathrm{~V}) *\left(0.0157 \frac{\mathrm{A}}{\mathrm{cm}^{2}}\right)}{0.1 \frac{\mathrm{W}}{\mathrm{cm}^{2}}} *(100 \%)
$$


Data used for efficiency calculations:

Note - the sign of current has been current has been changed between the measured value and the short circuit current density in order to make calculated power positive. The sign of current is arbitrary in this voltammetric dataset.

\begin{tabular}{|l|r|r|r|r|}
\multicolumn{1}{|l}{ Diode } & \multicolumn{1}{l}{ Illuminated } & \multicolumn{1}{l}{ sc } \\
\hline 0.155025 & 0.000295 & 0.000007 & -0.00018 & $-2.7129 \mathrm{E}-05$ \\
\hline 0.151274 & 0.000281 & -0.000025 & 0.000625 & $9.45463 \mathrm{E}-05$ \\
\hline 0.147275 & 0.000267 & -0.000048 & 0.0012 & 0.00017673 \\
\hline 0.143275 & 0.000253 & -0.000078 & 0.00195 & 0.000279386 \\
\hline 0.139275 & 0.000239 & -0.000103 & 0.002575 & 0.000358633 \\
\hline 0.135524 & 0.000227 & -0.000131 & 0.003275 & 0.000443841 \\
\hline 0.131525 & 0.000214 & -0.000153 & 0.003825 & 0.000503083 \\
\hline 0.127525 & 0.000203 & -0.000176 & 0.0044 & 0.00056111 \\
\hline 0.123774 & 0.000192 & -0.0002 & 0.005 & 0.00061887 \\
\hline 0.119775 & 0.000181 & -0.00022 & 0.0055 & 0.000658763 \\
\hline 0.115775 & 0.00017 & -0.000241 & 0.006025 & 0.000697544 \\
\hline 0.111775 & 0.00016 & -0.000266 & 0.00665 & 0.000743304 \\
\hline 0.108024 & 0.000151 & -0.000284 & 0.0071 & 0.00076697 \\
\hline 0.104025 & 0.000142 & -0.000303 & 0.007575 & 0.000787989 \\
\hline 0.100025 & 0.000133 & -0.000324 & 0.0081 & 0.000810203 \\
\hline 0.096274 & 0.000125 & -0.000343 & 0.008575 & 0.000825549 \\
\hline 0.092276 & 0.000116 & -0.00036 & 0.009 & 0.00083048 \\
\hline 0.088276 & 0.000109 & -0.00038 & 0.0095 & 0.000838617 \\
\hline 0.084524 & 0.000102 & -0.000396 & 0.0099 & 0.000836787 \\
\hline 0.080526 & 0.000095 & -0.000407 & 0.010175 & 0.000819347 \\
\hline 0.076526 & 0.000088 & -0.000423 & 0.010575 & 0.000809257 \\
\hline 0.072526 & 0.000081 & -0.000438 & 0.01095 & 0.000794154 \\
\hline 0.068774 & 0.000075 & -0.00045 & 0.01125 & 0.000773706 \\
\hline 0.064776 & 0.000069 & -0.000468 & 0.0117 & 0.000757873 \\
\hline 0.060776 & 0.000063 & -0.00048 & 0.012 & 0.000729306 \\
\hline 0.057024 & 0.000058 & -0.000497 & 0.012425 & 0.000708522 \\
\hline 0.053026 & 0.000053 & -0.000505 & 0.012625 & 0.000669447 \\
\hline 0.049026 & 0.000048 & -0.000519 & 0.012975 & 0.000636106 \\
\hline 0.045274 & 0.000043 & -0.000531 & 0.013275 & 0.000601011 \\
\hline 0.041276 & 0.000039 & -0.000538 & 0.01345 & 0.000555155 \\
\hline 0.037276 & 0.000034 & -0.000553 & 0.013825 & 0.000515334 \\
\hline 0.033276 & 0.00003 & -0.00056 & 0.014 & 0.000465857 \\
\hline 0.029524 & 0.000026 & -0.000568 & 0.0142 & 0.000419239 \\
\hline 0.025526 & 0.000022 & -0.00058 & 0.0145 & 0.00037012 \\
\hline 0.021526 & 0.000018 & -0.000592 & 0.0148 & 0.000318577 \\
\hline
\end{tabular}




\begin{tabular}{|r|r|r|r|r|}
0.017774 & 0.000015 & -0.0006 & 0.015 & 0.000266609 \\
\hline 0.013776 & 0.000011 & -0.000608 & 0.0152 & 0.000209388 \\
\hline 0.009775 & 0.000008 & -0.000619 & 0.015475 & 0.000151276 \\
\hline 0.006024 & 0.000005 & -0.000626 & 0.01565 & $9.42739 \mathrm{E}-05$ \\
\hline 0.002025 & 0.000002 & -0.000628 & 0.0157 & $3.18 \mathrm{E}-05$ \\
\hline
\end{tabular}




\section{REFERENCES}

[1] U. Nations in United Nations World Population Report. World Population to 2300, Vol. United Nations Department of Economic and Social Affairs, New York, 2010.

[2] N. Lewis in Powering the Planet. California Institute of Technology, San Francisco, 2007.

[3] R. Ramesh in SunShot Vision Study, Vol. (Ed. U. D. O. Energy), 2012.

[4] E. S. Hamers, Jaap in Roll to roll manufacturing for highly efficient multijunction thin film silicon flexible photovoltaics Vol. SE Powerfoil 6th Framework Programme, Prague, 2010.

[5] H. S. Ullal in Overview and Challenges of Thin Film Solar Electric technologies, Vol. (Ed. U. D. o. E. NREL), NREL, Oak Ridge 2008.

[6] J. Y. Yang, Baojie; Yue, Gouzhen; Guhu, Subhenda, Institute of Electrical and Electronics Engineers 2005.

[7] A. De Vos, Journal of Applied Physics 1980, 13, 839-846.

[8] Y.-Y. X. Fang, Junqi; Tolle, John; Roucka, Radek; D'Costa, Vijay R.; Chizmesha, Andrew V.G.; Kouvetikis, John, Journal of the American Chemical Society 2008, 130, $16095-16102$.

[9] a) M. L. Massimo Feré, Davide Piccinin and Silvia M. Pietralunga, Andrea Zappettini, Paolo M. Ossi and Mario Martinelli, IEEE 2008, 978, 270-272; b) C.-Y. w. Tsao, Jurgen; Campbell, Patrick; Conibeer, Gavin; Song, Dengyuan; Green, Martin A, Solar Energy Materials and Solar Cells 2009, 94, 1501-1505; c) S. M. Pietralunga, M. 
Fere, M. Lanata, D. Piccinin, G. Radnoczi, F. Misjak, A. Lamperti, M. Martinelli and P. M. Ossi, EPL 2009, 88, 28005/p28001-28005/p28006.

[10] W. K. Primak, Robert; Dayal, Yogeshwar, Journal of the Electrochemical Society 1967, 114, 88-91.

[11] S. McNamara in Aluminum Contacts form Schottky Diodes when used with n-type wafers Vol. Louisville, 2011.

[12] J. S. T. Custer, Michael O; Jacobsen, D.C.; Poate, J.M.; Roorda, S.; Sinke, W.C.; Spaepen, F. , Applied Physics Letters 1994, 64, 437-439.

[13] T. K.-S. Mohammed-Brahim, K.; Briand, D.; Sarret, M.; Bonnaud; O.; Kleider, J.P.; Longeaud, C; Lambert, B., Journal of Non-Crystalline Solids 1998, 227-230, 962-966. [14] D. De Salvadora, E. Napolitania, S. Mirabella b, E. Brunob, G. Impellizzeri b, G. Bisognina, and F. P. E.F. Pecorab, A. Carnera, Materials Science and Engineering B 2008, 154-155, 240-256.

[15] V. semiconductor in General Properties of Si, Ge, SiGe, SiO2, and Si3N4, Vol. 2012 Virginia Semiconductor, Fredricksburg Va, 2002, p. Material properties tables and summary.

[16] L. L. Jiang, H.; Rane, S.; Schiff, A.; Wang, Q; Yan, Q, Mat. Res. Soc. Symp. Proc. 2000, 609.

[17] S. M. Abadli, Farida, Thin Film Solids 2007, 517, 1961-1966.

[18] Y. R. Pauleau, Jean-Claud Journal of Less Common Metals 1975, 42, 199-208. 
NAME:

ADDRESS:

DOB:

EDUCATION \& TRAINING:

B.S. Biology

University of Kentucky

1997-2001

B.S., Chemical Engineering University of Louisville 2008-11

M.Eng., Chemical Engineering University of Louisville 2011-12

PROFESSIONAL SOCIETIES: $\quad$ American Institute of Chemical Engineers 